\title{
DIE STUNDE DER ZWERGE
}

Diese erste Veröffentlichung José Antonios erschien am 16. März 1931 in der monarchistischen Tageszeitung "ABC". Sie fiel in den erbitterten Wahlkampf, der am 14. April 1931 zur Ausrufung der Zweiten Republik führte. Als ein Hauptargument gegen die Monarchie führten die republikanischen Parteien im Wahlkampf die vom letzten spanischen König, Alfons XIII. sanktionierte Diktatur des Generals Miguel Primo de Rivera an, der das Land sechs Jahre lang unter Ausschaltung aller demokratischen Freiheiten regiert hatte. Von den führenden Militärs im Stich gelassen, sah sich Miguel Primo de Rivera am 16. Januar 1930 gezwungen, dem König seine Demission einzureichen und das Land zu verlassen. Wenige Wochen später, am 16. März 1930, starb er verbittert in Paris.

Den Jahrestag des Todes nahm der Sohn José Antonio zum Anlaß, seinen Vater gegen die im Wahlkampf erhobenen Vorwürfe der in der Diktaturzeit ausgeschalteten Politiker wie auch gegen die Flut agitatorischer Verleumdungen zu verteidigen. José Antonio, 27 Jahre alt, stand zu dieser Zeit noch im monarchistischen Lager. So weit er sich im ersten Jahr der Zweiten Republik überhaupt politisch betätigte, entsprang dies vornehmlich der Absicht, das Ansehen des Vaters zu schützen.

Gott war barmherzig und hat ihn zu sich in die Gefilde ewigen Friedens genommen. Nach einem kurzen Leiden nun die Ruhe. Zu zahlreich waren seine Verdienste, als daß die göttliche Großmut ihn nicht von diesem Schauspiel erlöst hätte!

Alles brodelt wie in einem Ameisenhaufen. Als wäre gar nichts geschehen. Dieselben Menschen, dieselben leeren Worte, dieselben wichtigtuerischen Gesten. Und alles so zwergenhaft klein! Gegenüber dem gewaltigen Werk von sechs Jahren Ordnung, Friede, Wohlstand, Arbeit, Kultur, menschliche Würde, Freude - nun wieder die alten wurmstichigen Formeln, der alte bombastische Wortschwall, die alten unverständlichen Wortklaubereien der Winkeladvokaten.

Da sind sie wieder, die Politiker, allen schon zur Genüge bekannt. Über sechzig sind sie schon alt. Dutzende von Malen waren sie am Ruder. Kaum einer von ihnen brachte etwas Nennenswertes zustande. Aber sie zogen daraus keine Lehre. Jetzt glauben sie, die Pause, die ihnen auferlegt war und über die sie überall reden, als sei es eine Zeit der Verfolgung gewesen, hätte sie von der nutz- und sinnlosen Vergangenheit erlöst.

Da sind sie wieder, die lächerlichen Intellektuellen, in ihrer aufgeblasenen SpieBigkeit. Sie sind die Nachkommenschaft, die heruntergekommene, jener Intellektuellen, die nicht wahrhaben wollten, daß die Erde sich bewegt, daß sie rund ist und daß es einmal eine Eisenbahn geben wird. All das verstieß ja gegen ihre Formeln! Diese armen Wichte! Wie sollten sie jemals fähig sein, hinter ihren Scheuklappen den Strahl des göttlichen Lichtes wahrzunehmen! Was in ihr spießiges Hirn nicht hineinpaßt, existiert für sie einfach nicht. Und mit überlegenem Lächeln mokieren sie sich noch darüber! 
Da sind sie wieder, die Ohrenbläser, vergiftet von Coffein und Nikotin, diese Snobs, diese Feiglinge, die es so gut verstehen, sich auf die günstigste Seite zu schlagen. (Manche von ihnen - wer sollte das für möglich halten! - Abkömmlinge der Männer, deren Rücken eher brach, als daß sie ihn beugten ...)

$\mathrm{Da}$ sind sie alle wieder. Aufgeplustert wie ein Pfau, armselig; erbärmliche Schreihälse, aufgeplustert in ihrer jämmerlichen Nichtigkeit. Alle reden sie zugleich: Nichts habe man getan. Die Steuergelder seien verschwendet worden. Daß unter dem Regime dieses Diktators militärische Siege errungen wurden, wer konnte schon etwas dazu? Alles Glück, alles Lüge und vor allen Dingen: die Regierung wäre nicht intelligent gewesen (ein geheiligtes Wort, die Dummen zu blenden!). Doch sie regierte für Spanien, auf spanische Art und Weise, nicht nach Lust und Laune der Handvoll Gewählten. Auf scheinheilige Feierlichkeiten wollte sie lieber verzichten als echte zu verfälschen.

Die Zwerge waren stärker als der Riese. Sie banden ihm die Füße und streckten ihn zu Boden. Dann marterten sie ihn mit Nadelstichen. Und er, der Gute, Einfache, Empfindliche, er, der sich gegen solche Niederträchtigkeiten nicht zu wehren wußte, er neigte eines Tages, gerade weil er so sehr Mensch war, sein Haupt, um es nie mehr zu erheben.

Jetzt schlägt die Stunde der Zwerge! Wie sie sich rächen an der Stille, in die er sie versenkte! Wie sie sich aufspielen, wie sie geifern, wie schamlos sie sich drehen in ihrem giftigen, ihrem vergiftenden Sinnestaumel. Und die lächerlichsten aller Zwerge, die Pedanten, sie lächeln ironisch.

Er lächelt ebenfalls. Doch sein Lächeln ist rein, rein wie sein einfacher und starker Geist. Nun aber leiden wir - wie vorher er - alle Qualen der Ungerechtigkeit. Er aber erfreut sich bereits seines Lohnes hoch droben in den Gefilden ewiger Heiterkeit. Thn vermag nichts mehr zu beunruhigen. Denn von dort oben ist der Unterschied zwischen Winzigkeit und wahrer Größe zu erkennen. Die Zeit wird dahingehen, sie ist ein Strom, aus dem sich nur die höchsten Spitzen der Wellenkämme erheben. Sie alle, dieses gemeine Volk, diese Winkeladvokaten und MöchtegernPolitiker, diese Schreiberlinge, Laffen und Gecken, sie alle werden von den Wassern geschluckt werden. Wer erinnert sich in hundert Jahren noch an sie? Sein Bild aber, einfach und kräftig wie sein Geist, wird sich über die Jahrhunderte erheben, groß, heiter, leuchtend durch seinen Ruhm wie durch sein Leiden.

„ABC“ vom 16. März 1931; O. C., a. a. O., S. $781 \mathrm{ff}$.

\section{DIE FUNDAMENTE DES LIBERALEN STAATES}

Am 16. März 1933, also wiederum an einem Gedenktag für den verstorbenen General und Diktator Miguel Primo de Rivera, erscheint in Madrid die erste Nummer einer Zeitschrift, die sich „El Fascio“ nennt und so eindeutig wie mit ihrem Titel auch mit ihrem Inhalt für den Faschismus plädiert. Die Zeitschrift wird sofort verboten; eine weitere Nummer darf nicht mehr erscheinen. 
Das Redaktionskollegium setzt sich aus einigen führenden Mitgliedern der ersten, seit 1931 in Madrid bestehenden kleinen faschistischen Gruppe wie aus parteipolitisch noch ungebundenen Intellektuellen zusammen, die unter Berufung auf das Vorbild des italienischen Faschismus und des deutschen Nationalsozialismus den Gedanken eines „Neuen Staates“ in Spanien propagieren. Sie verwerfen Liberalismus und Marxismus. Unversöhnlich stehen sie der ungefestigten, autoritätslosen Zweiten Republik gegenüber. „El Fascio“ verspottet die parlamentarischen Institutionen des spanischen Staates; die Ablehnung gilt dem demokratischen Regime insgesamt, den monarchistischen wie den republikanischen, den liberalen, den christlichen und den sozialistischen Parteien, den Gewerkschaften wie der in totaler Verneinung zum spanischen Staat stehenden anarchosyndikalistischen Bewegung.

„El Fascio" erscheint zu einem Zeitpunkt, in dem Spanien vom politischen Fieber geschüttelt wird. Es regiert eine linksrepublikanisch-sozialistische Koalition. Sie versagt vor der Aufgabe, die Probleme zu lösen, welche die Monarchie nicht zu lösen verstanden hatte. Sie kann sich weder frei machen von Rachegfühlen gegenüber den alten, die Monarchie einst stützenden Institutionen, noch versteht sie es, die nötige Autorität zu entwickeln, um des anarchistischen Terrors Herr zu werden und separatistischen Tendenzen Einhalt zu gebieten. Ein Statut bestätigt Katalolonien am 9. September 1932 seine Autonomie. Baskische und galizische Parteien fordern die gleichen Rechte; zum erstenmal in seiner Geschichte hört Spanien den Ruf: Hoch lebe ein freies Andalusien. Anarchisten und Sozialisten liefern sich Straßenkämpfe und bestreiken sich gegenseitig. Der linke Flügel der Sozialisten unter Largo Caballero beginnt Anfang 1933 auf eine „proletarische Revolution“ zu drängen. Eine Agrarreform bleibt, nachdem vorher alle Granden und Großgrundbesitzer enteignet worden waren, wegen mangelnder Mittel in der Planung stecken. In Andalusien und Estremadura greift landloses Proletariat zur Selbsthilfe, verteilt nach eigenem Ermessen Grundbesitz oder versucht, Kollektivwirtschaften einzurichten. Mit der politischen Misere geht die wirtschaftliche Hand in Hand. Erschreckt über den Weg, den die Republik genommen hatte, wenden sich Männer wie Unamuno, Ortega oder der Jurist Sánchez Roman enttäuscht von dem Werk ab, das sie selbst mitvorbereitet hatten ${ }^{1}$.

Vor diesem Hintergrund wird die rauhe Sprache wie der radikale Inhalt der Zeitschrift „El Fascio“ verständlich. Als einer der Mitautoren läßt der junge José Antonio zum erstenmal seinen politischen Standort erkennen. Das Erscheinungsdatum der Zeitschrift akzentuiert die persönliche Stellung José Antonios in dem Kreis der Gleichgesinnten. Es weist ebenfalls auf die freundschaftlichen Beziehungen hin, die den gestürzten spanischen Dikator mit dem von den jungen Autoren verehrten Führer des italienischen Staates, Mussolini, verbanden. Dennoch ergibt sich aus dem Inhalt der Zeitschrift, daß José Antonio und seinen Freunden die Diktatur des Generals nur noch als respektables historisches Datum, nicht aber als ein noch geeignetes Vorbild erscheint.

José Antonio vollzieht mit den beiden Artikeln, die er beisteuert, öffentlich die Abkehr von der Vorstellungswelt seines Vaters und der feudalen Gesellschaftsschicht, der er selbst entstammt. Der Sohn sagt sich von der Monarchen-Treue des Vaters los. Er lehnt zudem dessen diktatoriales Regime als eine zeitgerechte und mögliche Alternative zu der ihm überlebt dünkenden, kraftlosen, parlamentarischen Herrschaftsform ab. Die Diktatur konservierte die bestehende Gesellschaft; sie verbot nur politische Meinungen und Strömungen, versagte jedoch in den Augen José Antonios vor der Aufgabe, das Volk durch einen neuen politischen

\footnotetext{
1 Zur politischen Situation: Aunós Pérez, a. a. O., S. 441 ff.; Almagro, a. a. O., S. $50 \mathrm{ff}$.
} 
Geist zu einen und zu beseelen. Die Autoren vom „El Fascio“ wollen der Wirkungslosigkeit vergangener und bestehender Herrschaftsformen mit einer neuen Doktrin und einer neuen Machtkompetenz, eben dem proklamierten „Neuen Staat" begegnen.

Die Ablehnung des liberalen Staates, die in ihrer Argumentation jede über die bloße Adaption der ausländischen Vorbilder hinausgehende spezifisch spanisch Variante vermissen läßt, wird in den folgenden Texten José Antonios ebenso deutlich wie sein Bekenntnis zum faschistischen Staat. In seiner Interpretation von Staat und Vaterland deuten sich nur zaghaft eigenwillige Auffassungen an, die er erst später ausführlicher darlegen wird. José Antonio weist die Richtung, die er einzuschlagen gewillt ist. Aber noch ist er ein Werbender ohne Gefolgschaft. Mit seinem literarischen Trommelschlag ist er der Gründung seiner Falange weit voraus ${ }^{1}$.

Der liberale Staat glaubt an nichts, nicht einmal an sich selbst. Der liberale Staat gestattet es, alles in Zweifel zu ziehen, sogar die Berechtigung seiner eigenen Existenz.

Für den liberalen Herrscher ist die Auffassung, der Staat müsse durch einen anderen ersetzt werden, durchaus berechtigt. Das besagt: Wer an der Spitze eines gegebenen Staates steht, glaubt nicht einmal an die Richtigkeit, an die Gerechtigkeit, an die Berechtigung dieses, seines eigenen Staates. Er gleicht darin dem Kapitän eines Schiffes, der sich nicht darüber im klaren ist, was besser sei : den Nothafen anzulaufen oder Schiffbruch zu erleiden. Der liberale Geist faßt das eigene Schicksal gleichsam als Scherz auf. Danach ist es also erlaubt, nach Regierungsämtern zu streben, selbst wenn man gar nicht an die Existenzberechtigung solcher Ämter glaubt oder der Ansicht ist, mit ihnen seien keinerlei Verpflichtungen verbunden, nicht einmal die, diese Ämter zu verteidigen.

Nur eine Einschränkung gibt es: das Gesetz. Das allerdings. Man darf alles Bestehende zu zerstören trachten, doch ohne dabei die durch die Gesetze vorgezeichneten Grenzen zu überschreiten. Aber was ist „das Gesetz"? Auch kein auf ewige Prinzipien bezogener Begriff. „Das Gesetz“ ist der Ausdruck des souveränen Volkswillens, im Grunde genommen die Entscheidung der Mehrheit bei der Wahl.

Dazu zwei Anmerkungen:

1. Das Gesetz - das Recht - findet für den Liberalismus seine Berechtigung nicht in seinem Zweck, sondern in seinem Ursprung. Die Rechtsschulen, die als ständiges Ziel das Allgemeinwohl vor Augen haben, halten ein Gesetz für gut, wenn es dem Allgemeinwohl dienlich ist, für schlecht dagegen, wenn es das Allgemeinwohl außer acht läßt. Wobei die Frage, wer das Gesetz verkündet, völlig belanglos bleibt. Die demokratische Schule - und die Demokratie ist die Staatsform, in der das liberale Gedankengut seinen deutlichsten Niederschlag gefunden hat - ist der Ansicht, ein Gesetz sei gut und rechtmäßig, wenn es bei der Abstimmung die Mehrheit der Stimmen auf sich zu vereinigen vermochte, selbst wenn seine Bestimmungen schlimmste Grausamkeiten enthalten.

2. Gerechtigkeit ist für den Liberalismus keine Kategorie der Vernunft, sondern

1 „El Fascio“ und die spanische Literatur dazu: Nellessen, a. a. O., S. $67 \mathrm{ff}$. 
ein Produkt des Willens. Es gibt nichts, was an sich und durch sich selbst gerecht sei. Es fehlt eine Bezugsnorm, nach der das Gesetz sich bewerten, seine Gerechtigkeit sich prüfen, jede einzelne verkündete Vorschrift sich messen ließe. Es reicht aus, genügend Stimmen zu finden, die es billigen.

Alles dies kommt in dem einzigen Satz zum Ausdruck: „Das Volk ist souverän.“ Souverän, das heißt, es besitzt die Kraft, seine eigenen Entscheidungen rechtfertigen zu können. Die Entscheidungen des Volkes sind gut, weil das Volk selbst sie getroffen hat. Der Satz der Theoretiker des monarchischen Absolutismus lautete: "Quod principi placuit, legis habet vigorem." Doch es sollte ein Augenblick kommen, da die Theorektiker der Demokratie sagten: „Es bedarf in den Gesellschaften einer gewissen Autorität, die nicht recht zu haben braucht, um ihren Handlungen Rechtsgültigkeit verleihen zu können. Diese Autorität liegt ausschließlich beim Volk." Es sind die Worte Jurieus, eines der Vorläufer Rousseaus.

\section{Freiheit, Gleichheit, Brüderlichkeit}

Der liberale Staat, der Staat ohne Glaube, der Staat des Schulterzuckens schrieb an den Giebel seines Tempels drei schöne Worte: Freiheit, Gleichheit, Brüderlichkeit. Allerdings gedeiht keines der drei unter dem Banner dieses Staates.

Die Freiheit ist lebensunfähig ohne den Schutz eines starken ewigen Prinzips. Wenn die Prinzipien in den Wogen der Volksmeinungen schwanken, besteht Freiheit nur für diejenigen, die mit der Mehrheit einer Meinung sind. Für die Minderheiten bleibt nur eines: leiden und schweigen. Unter den Tyrannen des Mittelalters blieb den Unterdrückten zumindest der Trost, sich tyrannisiert zu wissen. Der Tyrann konnte unterdrücken, die physisch Unterdrückten behielten nichts destoweniger Recht gegenüber dem Tyrannen. Über den Häuptern von Tyrann und Untertan standen ewige Worte geschrieben, die jedem einzelnen sein Recht gaben. Im demokratischen Staat ist dies nicht der Fall; das Gesetz - nicht der Staat, sondern das Gesetz, mutmaßlicher Wille der Mehrheit - hat immer recht. Auf diese Weise wird der Unterdrückte nicht nur unterdrückt, man kann ihn sogar, sollte er es wagen, das Gesetz dreist als ungerecht zu bezeichnen, als gefährlichen Unruhestifter brandmarken. Nicht einmal diese Freiheit bleibt ihm.

Aus diesem Grunde bezeichnete es Duguit als „error nefastus“ anzunehmen, ein Volk gewinne seine Freiheit an dem Tage, an dem es das Dogma der nationalen Souveränität verkünde und das allgemeine Wahlrecht einführe. Vorsicht, so sagt er, mit der absolutistischen Demokratie! Gegen den Despotismus der Volksversammlungen bedarf es vielleicht noch energischerer Schutzmaßnahmen als gegen den Despotismus der Könige. „Eine ungerechte Sache bleibt ungerecht, auch wenn sie vom Volk oder dessen Vertretern verordnet wurde, ebenso ungerecht, als wäre sie von einem Fürsten verordnet. Beim Dogma von der Volkssouveränität wird dies allzugern vergessen."

So gerät die Freiheit unter das Joch der Mehrheiten, ebenso wie die Gleichheit. Zunächst besteht keine Gleichkeit zwischen der herrschenden Partei, die nach 
eigenem Gutdünken Gesetze schafft und abschafft, und den übrigen Staatsbürgern, die sich mit der Herrschaft dieser Partei abfinden müssen. Doch es wird noch schlimmer : der liberale Staat erzeugt eine noch tiefergreifende Ungleichheit, nämlich die auf wirtschaftlichem Gebiet. Der Arbeiter, obwohl dem Kapitalisten im Hinblick auf den Abschluß eines Arbeitsvertrages theoretisch vollkommen gleichgestellt, wird letztlich zum Sklaven der Kapitalisten. Selbstverständlich zwingt ihn dieser in keiner Weise dazu, gewisse Arbeitsbedingungen anzunehmen. Er hungert ihn vielmehr aus, macht ihm Angebote, die der Arbeiter theoretisch ablehnen kann, die er aber, da er sonst nichts zu essen hat, wohl oder übel akzeptieren muß. So brachte der Liberalismus die Akkumulation des Kapitals und die Proletarisierung gewaltiger Massen. Zum Schutze der durch die wirtschaftliche Tyrannei der Machthabenden Unterdrückten mußte sich erst eine so antiliberale Bewegung erheben wie der Sozialismus.

Und schließlich zerschellt die Brüderlichkeit. Da das demokratische Herrschaftssystem nach dem Grundsatz der Mehrheitsherrschaft arbeitet, ist, will man innerhalb dieses Systems erfolgreich bleiben, die Erringung der Mehrheit um jeden Preis erforderlich. Jedes Mittel ist erlaubt. Kann man dem Gegner durch böswillige Verdrehung seiner Worte einige Stimmen entreißen, so zögert keiner, dies zu tun. Das Nebeneinander von Mehrheit und Minderheit bedingt zwangsläufig Teilung. Die Teilung bedingt $\mathrm{Haß}$. Haß und Teilung aber sind unvereinbar mit Brüderlichkeit. Und so erlischt in den Gliedern ein und desselben Volkes das Gefühl, Teil eines höheren Ganzen, einer hohen, allumfassenden, geschichtlichen Einheit zu sein. Der Heimatboden verwandelt sich in ein reines Schlachtfeld, auf dem sich zwei oder mehr streitende Parteien gegenseitig zu verdrängen suchen. Jede einzelne dieser Parteien gehorcht der Losung einer sektiererischen Stimme, während die innige Stimme der gemeinsamen Erde, die alle verbrüdern sollte, verstummt scheint.

\section{Die Ziele des Neuen Staates}

Sämtliche Ziele des Neuen Staates lassen sich in einem Wort zusammenfassen: Einheit. Das Vaterland ist eine allen einzelnen Gruppen übergeordnete geschichtliche Einheit. Dieser Einheit haben sich Klassen und Individuen zu beugen. Ihr Aufbau soll sich auf die folgenden beiden Grundsätze stützen:

1. Was den Zweck des Staates betrifft, so muß er das Instrument im Dienste jener überwirklichen Einheit (unidad transcendente) sein. Nichts kann gut sein, was sich ihr entgegenstellt, gleichgültig, ob es von vielen oder von wenigen unterstützt wird.

2. Die Form des Staates verlangt nationale Solidarität, beherzte und brüderliche Zusammenarbeit. Der Klassenkampf und die todbringende Auseinandersetzung der Parteien sind unvereinbar mit unserer Auffassung von den Aufgaben des Staates.

Eine neue Politik zu finden, in der diese beiden Grundsätze sich vereinigen, das ist die Aufgabe, die der Generation unserer Zeit von der Geschichte zugewiesen ist. „El Fascio“, Nr. 1, 16. 3. 1933; O. C., a. a. O., S. 601. 


\section{NOTWENDIGE KLARSTELLUNGEN}

Wer, auf Italien verweisend, die Auffassung vertritt, der Faschismus sei unlösbar mit dem Leben Mussolinis verbunden, versteht weder den Faschismus, noch hat er sich je bemüht nachzuforschen, was „korporativer Staat" bedeutet. Der faschistische Staat, der dem festen Willen des Duce so viel verdankt, wird seinen geistigen Vater überleben, weil er eine unverrückbare, starke Organisation darstellt.

Die spanische Diktatur begrenzte stets ihre eigene Lebensdauer und verstand sich selbst nur als vorübergehendes, im Augenblick jedoch notwendiges Übel. Man darf nicht glauben, nicht einmal vermuten, wir machten den Versuch, eine neue Diktatur zu errichten, so groß die Vorzüge der alten auch waren. Wir trachten nach der vollkommenen und endgültigen Eroberung des Staates ${ }^{1}$, nicht für einige Jahre, sondern für immer. Die letzten Anhänger der gescheiterten, kurz vor dem Zusammenbruch stehenden Demokratie, suchen böswillig - bei ihnen nicht weiter verwunderlich - in der Bevölkerung Verwirrung zu stiften, um den morschen Rest $\mathrm{zu}$ retten. Wir sind dazu da, die Täuschung all derer zu verhindern, die sich nicht täuschen lassen wollen. Wir verfechten keine Diktatur, die das sinkende Schiff notdürftig zu flicken, die einem Übel nur zeitweilig abzuhelfen vermag und die im Grunde nur dem bestehenden System und den Praktiken des Verderben bringenden Liberalismus Kontinuität sichern. Wir wollen vielmehr eine bleibende nationale Einrichtung; wir wollen einen starken, wahrhaft spanischen Staat mit einer treibenden Macht, die wirklich regiert, und einer korporativen Kammer, welche die wahre Wirklichkeit der Nation verkörpert. Wir kämpfen nicht für eine vergängliche Diktatur, sondern für die Institutionalisierung und das ewige Fortbestehen eines Systems. Diese Klarstellung ist höchst bedeutsam und darf nicht übersehen werden.

„El Fascio“, Nr. 1, 16. 3. 1933; O. C., a. a. O., S. 1057 f.

OFFENE BRIEFE ZUM THEMA FASCHISMUS

Die liberal-monarchistische Zeitung „ABC“ hatte mit ihrem Kommentar zum Verbot der Zeitschrift „El Fascio“ den Unwillen José Antonios erregt. In einem Brief an den seiner Familie gut bekannten Herausgeber, den Marques de Luca de

1 José Antonio spielt damit auf den Titel der ersten spanischen Zeitung faschistischen Typs an: „La Conquista del Estado“, „Die Eroberung des Staates", die von Ramiro Ledesma Ramos im Frühjahr 1931 herausgegeben wurde, aber, von dauernden Verboten bedroht, nur sporadisch erschien und Ende des gleichen Jahres eingestellt wurde. Ledesma Ramos gehörte zu den Autoren der Zeitschrift „El Fascio“. Er stieß 1934 zur Falange José Antonios, erhielt die Mitgliedsnummer 1, sagte sich jedoch ein Jahr später wieder von ihr los. Zu Beginn des Bürgerkrieges wurde er verhaftet, und obwohl er nichts mit der Vorbereitung des Aufstandes zu tun gehabt hatte, auf einem Gefangenentransport erschossen. Siehe dazu: Nellessen, a. a. O., S. $50 \mathrm{ff}$. 
Tena verwahrte er sich gegen die oberflächliche Art, in welcher der Faschismus abgetan worden sei. Er bat um Veröffentlichung einer Stellungnahme. Sie erschien in "ABC" am 22. 3. 33. Luca de Tena antwortete in der gleichen Ausgabe und fragte José Antonio unter anderem, indem er auf die Praktiken der Machteroberung in Italien und Deutschland verwies, mit welchen Mitteln José Antonio und sein faschistischer Freundeskreis Liberalismus und Marxismus in Spanien ausschalten wolle. José Antonio nahm dies zum Anlaß, noch einmal um die Veröffentlichung einer Antwort zu bitten. Sie erschien in "ABC“ am 23. 3. 33.

\section{Erster Brief an Juan Ignacio Luca de Tena [22. 3. 1933]:}

Du weißt genau, daß ich im Gegensatz zu dem, was in diesen Tagen über mich gemunkelt wird, nicht nach einem Platz in der Parteiführung einer jungen faschistischen Bewegung trachte. Meine Berufung als Student läßt sich schwerlich mit der eines Führers vereinbaren. Aber als Student, welcher der Betrachtung des Phänomens einige Stunden gewidmet hat, schmerzt es mich, daß „ABC“, Deine bewundernswerte Zeitung, ihre Besorgnis über den Faschismus mit einigen wenigen mürrischen Sätzen äußert, die ein recht oberflächliches Verständnis des Faschismus erkennen lassen. Ich bitte in den Spalten dieser Zeitung um Gehör, um die darin gemachten Ausführungen ein wenig zu präzisieren. Was in der Bewegung, die augenblicklich in Europa ihren Höhepunkt zu erreichen scheint, zurecht die geringste Rolle spielt, ist die Taktik der Gewalt (die einen rein nebensächlichen, vielleicht zeitbedingten Charakter hat und in manchen Ländern nicht einmal erforderlich ist). Aber das diese Bewegung bestimmende tiefgründige Gedankengut verdient eine viel eingehendere Betrachtung.

Der Faschismus ist keine Taktik (die Gewalt), er ist eine Idee (die Einheit). Gegenüber dem Marxismus, der als Dogma den Kampf der Klassen verkündet, und gegenüber dem Liberalismus, der als mechanisches Prinzip den Kampf der Parteien fordert, behauptet der Faschismus, daß es etwas über den Parteien und über den Klassen gibt, eine dauernde überwirkliche höchste Wesenheit: die historische Einheit, Vaterland genannt. Jenes Vaterland, das nicht nur der Boden ist, auf dem verschiedene rivalisierende, machthungrige Parteien sich gegenseitig, sei es auch nur mit den Waffen der Verleumdung, zerfleischen. Auch nicht das gleichmütig hingenommene Schlachtfeld, auf dem sich der ewige Kampf zwischen der Bourgeoisie, die ein Proletariat auszubeuten sucht, und einem Proletariat, das eine Bourgeoisie zu tyrannisieren sucht, abspielt. Es ist die unzertrennliche Einheit aller, im Dienste einer geschichtlichen Mission und einer höchsten gemeinsamen Bestimmung. Sie weist jedem einzelnen seine Aufgabe, seine Rechte und seine Opfer zu.

In einem faschistischen Staat siegt weder die mächtigste Klasse noch die stärkste Partei; selbst wenn eine Partei die meisten Anhänger besitzt, braucht sie keineswegs immer recht zu haben, mag auch der törichte Glaube an das durch die Quantität der Wahlstimmen sanktionierte Recht anderer Meinung sein. In einem faschistischen Staat siegt die allen gemeinsame Idee. Sie ist die Konstante des nationalen Denkens, das zu verwirklichen Aufgabe des Staates ist. 
Der liberale Staat glaubt an nichts, nicht einmal an sich selbst. Er sieht allen möglichen Experimenten mit verschränkten Armen zu, selbst jenen, die auf die Zerstörung seiner selbst gerichtet sind. Ihm genügt es, wenn alles nach festgelegten Regeln abläuft. Ein Beispiel: nach Ansicht des Liberalismus darf man Unmoral, $\mathrm{Haß}$ gegen das Vaterland und Rebellion predigen. Der Staat mischt sich nicht ein; denn er muß ja zugeben, daß diese Leute möglicherweise recht haben. Eines allerdings darf nicht sein: der liberale Staat duldet nicht, daß eine Versammlung stattfindet, wenn sie nicht so und so viele Stunden vorher angekündigt wurde; er schaltet sich ein, wenn man es unterläßt, drei Exemplare einer Verordnung in irgendein Amt zu schicken, um sie dort stempeln zu lassen. Kann man sich etwas Unsinnigeres vorstellen? Ein Staat, für den es keine Wahrheit gibt, kennt als einzige, absolute, unbedingte Wahrheit nur den Zweifel. Er macht ein Dogma aus dem Antidogma. So kommt es, daß die Liberalen bereit sind, für die Behauptung zu sterben, es gäbe keine Idee, für die zu sterben sich lohne.

Vorbei sind die Zeiten dieser unfruchtbaren Gesinnung. Man muß an etwas glauben. Hat man es mit dem liberalen Credo zu irgend etwas gebracht? Ich kenne, ehrlich gesagt, nur Beispiele einer trächtigen Politik, die dieses oder jenes glaubte.

Läßt sich ein Staat davon überzeugen, daß nichts gut oder schlecht ist, daß seine einzige Aufgabe darin besteht, den Polizisten zu spielen, so geht dieser Staat schon in Gemeindewahlen zugrunde, über denen nur der erste Hauch eines stärkeren Glaubens liegt.

Um einen Glauben zu entzünden, nicht den Glauben der Rechten, der im Grunde danach trachtet, alles, sogar das Ungerechte, zu erhalten, nicht den Glauben der Linken, der im Grunde danach trachtet, alles, auch das Gute, zu vernichten, sondern um einen gemeinsamen vereinenden nationalen Glauben zu entzünden, ist der Faschismus entstanden. Seine Fruchtbarkeit erwächst aus seinem Glauben; daran werden alle Verfolgungen scheitern. Das wissen auch diejenigen, die von der Zwietracht profitieren. Deswegen auch reicht ihr Mut nicht weiter als bis zur Verleumdung. Sie suchen den Arbeitern den Faschismus als eine Bewegung von Junkern hinzustellen, obwohl nichts dem müßigen Junker - Parasit, denn er führt ein Leben ohne Funktionen - ferner steht als der Bürger eines faschistischen Staates. Denn dessen Recht ist abhängig von dem Dienst, den er an dem Platz leistet, der ihm zugewiesen ist. Wenn etwas den Namen Arbeiterstaat verdient, so ist es der faschistische Staat. In ihm bilden, das werden die Arbeiter erfahren, mag man sich auch noch so sehr dagegen sträuben, die Arbeiter-Syndikate direkte, würdige Staatsorgane.

Ich schließe diesen Brief nicht mit einem römischen Gruß, sondern mit einer spanischen Umarmung. Mit ihr verbindet sich mein Wunsch, Dein der edlen Begeisterung so sehr aufgeschlossener und von Natur aus der faden und kalten Atmosphäre des an nichts glaubenden Liberalismus so abgeneigter Geist möge sich an der Flamme dieses neuen Glaubens entzünden, der uns allen ein starkes, opferbereites und großes Spanien schenken kann.

"ABC" vom 22. 3. 1933; O. C., a. a. O., S. $531 \mathrm{ff}$. 
Zweiter Brief an Juan Ignacio Luca de Tena [23. 3. 1933]

Herzlichen Dank für Deine Bereitschaft, meinen Brief zu veröffentlichen, wie auch für Deine anerkennenden Worte. Dennoch bin ich ein wenig entmutigt. Offensichtlich hat mein Brief seinen Zweck, die Dinge klarzustellen, nicht erfüllt. Ich sage dies, da Du in Deiner Meinung über den Faschismus immer noch auf dem gleichen Punkt verharrst. Für Dich ist, wie Du sagst, jede Anwendung von Gewalt schlecht; daher mißbilligst Du es, daß die Sozialisten die Verbreitung der Zeitung „El Fascio" verhindern.

Daraus wird deutlich, daß Dein Denken immer noch im rein Instrumentalen befangen ist und nicht bis zum Wesentlichen vordringt. Ich bin keineswegs über den Versuch empört, die Verbreitung faschistischen Gedankengutes zu verhindern. Empört bin ich darüber, daß dies um eines Klassen- und Gruppenprinzips willen geschieht. Der Sozialismus ist definitionsgemäß keine nationale Partei, er will es auch gar nicht sein. Er ist eine Partei des Kampfes einer Klasse gegen die andere. Es erniedrigt mich, von den in einem Bürgerkrieg siegreich Gebliebenen unterdrückt zu werden. Stolz dagegen macht es mich, wenn meine absolute Handlungsfreiheit wegen der von mir vertretenen nationalen, totalitären Ideen eingeschränkt wird. Menschliche Würde erreicht nur, wer dient. Groß ist nur der, der bereit ist, sich freiwillig unterzuordnen, um an der Erfüllung einer großen Aufgabe mitzuwirken. Diesen wesentlichen Punkt, die Größe des angestrebten Zieles, willst Du nicht sehen. Du reiner Liberaler, der sich nicht $\mathrm{zu}$ entscheiden wagt, der nicht glaubt, daß es eine gute und eine schlechte geschichtliche Bestimmung gibt! Du Liberaler, der Du jegliche Gewalt ablehnst und jeden gemeinen Schlag, den uns nachts ein Räuber hinterrücks versetzt, zweifellos ebenso verurteilst wie den gerechten, strafenden Hieb, mit dem der Vater den Verführer straft, der in sein Haus eindringt! Du Liberaler, der sich dadurch zu erkennen gibt, daß er - ich wiederhole - nur nach dem Instrument urteilt, nicht aber nach dem Impuls, der dahinter steht! Du Liberaler, den zu überzeugen mir vielleicht niemals gelingen wird, dem ich aber mit diesen Zeilen - diesmal bitte ich nicht um deren Veröffentlichung, denn das hieße, Dich ausnutzen - noch einmal meine aufrichtige Zuneigung ausdrücke. „ABC“ vom 23. 3. 1933; O. C., a. a. O., S. 535 f.

\section{5}

\section{DIE GEWALT UND DIE GERECHTIGKEIT}

Zu den Bekannten, die José Antonio nach dem Erscheinen der Zeitschrift „El Fascio" oder nach seinem Disput in "ABC“ auf seine politischen Pläne ansprachen, gehörte auch ein Jugendfreund aus der beiden gemeinsamen andalusischen Heimat, Julián Pemartin. Er wird später Gefolgsmann und einer der Biographen José Antonios ${ }^{1}$.

1 Julián Pemartin: José Antonio. - Madrid 1956. 


\section{Lieber Julián!}

Schon eher wollte ich Dir schreiben, doch ich fand keine Gelegenheit dazu. So schreibe ich heute, am Sonntag, und versuche, mich auf Deine Einwände gegen den Faschismus zu beschränken, die Du mir in Deinem Brief mitgeteilt hast.

1. „Gewalt ist für ihn die einzige Möglichkeit, an die Macht zu gelangen.“ Dies ist schon rein geschichtlich gesehen falsch. Betrachte zum Beispiel Deutschland, wo der Nationalsozialismus durch Wahlen gesiegt hat. Doch was würde es schon ausmachen, wenn es kein anderes Mittel gäbe als das der Gewalt? Jedes Herrschaftssystem ist gewaltsam errichtet worden, sogar der sanfte Liberalismus (die Guillotine von 1793 hat weitaus mehr Tote auf dem Gewissen als Mussolini und Hitler zusammen).

Die Gewalt ist nicht unbedingt abzulehnen. Abzulehnen ist sie, wenn sie gegen die Gerechtigkeit gerichtet ist. Doch selbst Thomas von Aquin gestattete in extremen Fällen die Auflehnung gegen die Tyrannen. Warum also sollte die Anwendung von Gewalt gegen eine triumphierende Sekte von Abtrünnigen, die nur Zwietracht sät, den Fortbestand der Nation mutwillig gefährdet und überstaatlichen Parolen, wie zum Beispiel der Amsterdamer Internationalen, dem Freimaurertum usw., gehorcht, das durch diese Gewaltanwendung errichtete Herrschaftssystem diskreditieren?

2. „Zur Entstehung des Faschismus bedarf es einer Idee und eines Führers, die beide aus dem Volke stammen. "Der erste Teil ist falsch, die Idee kann nicht mehr aus dem Volk hervorgehen. Sie ist „fertig“, und die Männer, die sie kennen, sind meist nicht aus dem Volk. Die Verwirklichung dieser Idee aber bleibt wahrscheinlich einem Mann aus dem Volke vorbehalten. Ein Führer hat etwas von einem Propheten; er braucht ein gewisses $\mathrm{Ma} ß$ an Glauben, gesunder Kraft, Enthusiasmus, Fanatismus, was mit einer geistigen Bildung unvereinbar ist. Ich für meine Person wäre alles andere als ein guter faschistischer Führer. Die Skepsis und die Ironie, von der wir, die wir in geringerem oder größerem Ausmaß eine intellektuelle Neugierde verspüren, uns niemals freizumachen vermögen, machen es uns unmöglich, vorbehaltlos solche Behauptungen aufzustellen, ohne die ein Führer von Massen nicht auskommt. Wenn es also in Jerez de la Frontera wie auch in Madrid Freunde der Bewegung gibt, die bei dem Gedanken, ich könnte Lust verspüren, mich zum Führer des „Fascio“ zu küren, ein leiser Schauer überläuft, so kann ich diese voll und ganz beruhigen.

3. „In den Ländern, in denen der Faschismus siegreich scheint, hat ein berechtigter Anlaß für sein Erscheinen bestanden. " In Spanien vielleicht nicht? Es fehlt vielleicht der Anlaß zum Kriege. Aus diesem Grunde behauptete ich in meinem Brief an Luca de Tena ${ }^{1}$, der Faschismus werde hier wahrscheinlich nicht den Charakter des Gewaltsamen tragen. Aber ist der Verlust der (territorialen, geistigen und geschichtlichen) Einheit in Spanien etwa weniger offensichtlich als anderswo? Auf jeden Fall, so könnte man sagen, müsse man warten, bis die Lage sich ver-

1 Siehe S. 34 . 
schlimmert habe. Doch was hätte man davon, den Augenblick der Verzweiflung abzuwarten? Vor allem dann, wenn eine sozialistische, nur vom Machthunger bestimmte Diktatur am Ruder ist, die Spanien in eine Lage hineinmanövriert, aus der sich das Land, wenn überhaupt, nur mit größter Kraftanstrengung wieder befreien kann.

4. „Der Faschismus ist antikatholisch.“ Dieser Einwand ist charakteristisch für unser Land, in dem jeder päpstlicher als der Papst ist. Während in Rom der Lateranvertrag unterzeichnet wird, gilt hier der Faschismus als antikatholisch, gerade der Faschismus, der in Italien nach 90 Jahren Freimaurertum das Kruzifix und den Religionsunterricht wieder in die Schulen zurückgebracht hat. Ich verstehe das Gefühl der Unruhe in den protestantischen Ländern, in denen die nationale religiöse Tradition mit dem Glaubenseifer einer katholischen Minderheit in Widerstreit geraten könnte. Aber wohin kann in Spanien die Profilierung des wahrhaft Nationalen führen, wenn nicht zur Auffindung der katholischen Konstanten unserer Mission in der Welt? ${ }^{1}$

$\mathrm{Du}$ siehst, nahezu keiner der gegen den Faschismus erhobenen Einwände ist aufrichtig gemeint. Es schwelt in ihnen der geheime Wunsch, eine ideologische Entschuldigung für die Trägheit oder die Feigheit, wenn nicht sogar für das nationale Laster par excellence, für den Neid, zu finden. Er ist imstande, das Beste zunichte zu machen, damit nur ja kein anderer die Gelegenheit erhält, sich hervorzutun. Ich werde dafür Sorge tragen, daß Du einige Exemplare von „EI Fascio“ erhältst, in denen Du einen hinreichenden Ansporn füt Deinen Enthusiasmus und eine Vielzahl polemischer Argumente finden wirst. Solltest Du noch weitere Ausführungen wünschen und ich sie Dir geben können, so bin ich dazu gern bereit.

José Antonio

O. C., a. a. O., S. $534 \mathrm{ff}$.

REDE ZUR GRÜNDUNG DER „FALANGE ESPAÑOLA“ (29. Oktober 1933)

Als José Antonio am 29. Oktober 1933 die Falange gründet, tobt in Spanien der Wahlkampf. Das Ergebnis der dann am 19. November und 3. Dezember stattfindenden Wahlen bringt eine bürgerliche-republikanische Mehrheit an die Macht, die, angewiesen auf die Unterstützung des starken konservativen Flügels, ihre Aufgabe vor allem darin sieht, möglichst viele der von der ersten sozialistischen Regierung getroffenen politischen und sozialen Maßnahmen wieder rückgängig zu machen. Auch die zweite Periode der Republik bleibt gekennzeichnet durch ihre Ordnungs- und Autoritätslosigkeit; es gelingt weder, durch Verwaltungs- und Finanzreform Staatsapparat und Staatshaushalt zu sanieren, noch den ungezügelten

1 Julián Pemartin's Frage nach der Vereinbarkeit von Faschismus und Katholizismus erklärt sich auch daraus, daß der faschistische Freundeskreis José Antonios von militanten Katholiken, wie etwa Ernesto Giménez Caballero bis zum atheistischen, der spanischen Kirche feindlich gesinnten Ramiro Ledesma Ramos reichte. Beide gehörten zum Autorenkreis von „El Fascio“. 
Protest der Arbeiterschaft durch ernsthafte Versuche zu einer sozialen Befriedung zumindest einzudämmen. „Waren die zwei Jahre der Linksregierung eine Periode großer Erwartungen und niederschmetternder Enttäuschungen, so wurden die zwei Jahre der Rechtsregierung eine Zeit eines einzigen kraftlosen, eintönigen Trotts ${ }^{1}$."

Das politische Klima wird revolutionärer, der Regierungswechsel wird für die Anarchosyndikalisten zum Auftakt neuer, nun nicht mehr abreißender Streiks und Attentate. In den sozialistischen Parteien brechen nach der Wahlniederlage die Gegensätzlichkeiten zwischen evolutionärem und revolutionärem Flügel offen aus. Largo Caballero befürwortet vor der sozialistischen Parteiführung „den bewaffneten Aufstand zur Eroberung der Macht", der dann im Oktober 1934, dem „Roten Oktober", blutige Wirklichkeit werden wird².

In diese Atmosphäre totaler Verneinung, in der sich die Parteien gegenüberstehen und sich abzeichnender explosiver, auf die Gewalt setzender Radikalität, fällt die Gründung der Falange. Das Gründungsdatum wurde von José Antonio bewußt gewählt: am 28. Oktober 1922 fand der Marsch auf Rom statt. Die erste Versammlung der Falange wurde im Saal des Teatro de la Comedia abgehalten, der José Antonio von einem Freund seines Vaters kostenlos zur Verfügung gestellt worden war. Neben José Antonio sprachen Ruiz de Alda, ein ehemaliger Fliegeroffizier, der sich durch einen „Plus Ultra“-Flug von Spanien nach Argentinien 1926 einen Namen gemacht hatte und zum Bekanntenkreis José Antonios gehörte, sowie Alfonso Garcia Valdecasas, ebenfalls ein Freund José Antonios, junger Wissenschaftler an der Philosophischen Fakultät Madrids. Die Zuhörer waren durchweg Freunde und Bekannte der Redner, allesamt junge Menschen, zu denen sich die ebenfalls meist jugendlichen Madrider Mitglieder der kleinen bestehenden faschistischen Gruppe gesellten ${ }^{3}$.

Mit seiner ersten großen Rede profiliert José Antonio seine Vorstellungen. Er interpretiert das Vaterland "als eine geschichtliche Mission" und den Staat als „Werkzeug zur Erfüllung dieser Mission“. Er verwirft Klassen und Parteien, bekennt sich nun eindeutig zur Anwendung der Gewalt im politischen Kampf und entwickelt, indem er von der Würde des Dienens und Opferns, der asketischen und soldatischen Lebensauffassung der Falange spricht, die elitäre Stellung, die ihr zukommen soll. Diese Rede offenbart zudem seinen Stil: einerseits der knappe, draufgängerische Ton, andererseits eine ebenso mystisch-verheißungsvolle wie poetisch-schwärmerische Wortmalerei. In der Mischung dieser beiden Elemente, die umso wirksamer ist, als der dreißigjährige José Antonio sich an die Jugend wendet, manifestiert sich mehr als die spanischer Mentalität eigene Beredsamkeit. Sie ist ein Ausdruck jener „etapa de fé“, der Etappe des Glaubens, mit der die junge Generation das zweifelnde, um sich selbst kreisende Denken der Väter, das „tragische Lebensgefühl“ (Unamuno) politisch zu überwinden trachtet. In der Eröffnungsrede wird der Zukunftsstaat zwar beschworen, doch auf die Frage nach der sozialen Beschaffenheit des Neuen Staates antwortet José Antonio wie seine Mitredner nicht mit einem sozial- und wirtschaftspolitischen Programm, sondern mit allgemeinen Hinweisen, die eher erkennen lassen, was die Falange ablehnt als was sie selbst zu propagieren gedenkt.

1 E. Allison Peers: The Spanish Tragedy, London 1936, S. 144.

2 Zur politischen Situation Spaniens: Almagro, a. a. O., S. 87 bis 150; Aunós Pérez, a. a. O., S. 447-467; Madariaga, a. a. O., S. 275-290.

3 Zur soziologischen Gruppierung wie zur Gründung der Falange: Nellessen, a. a. O., S. $73 \mathrm{ff}$. 
Keine langen Danksagungen! Danke, kurz und schlicht gesagt, wie es zu unserem knappen, soldatischen Ton paßt.

Als im März des Jahres 1762 ein unheilvoller Mensch namens Jean Jacques Rousseau den „contrat social“ veröffentlichte, hörte die politische Wahrheit auf, eine zeitlose Idee ${ }^{\mathbf{1}} \mathrm{zu}$ sein. Vorher, in den Zeiten größerer geistiger Tiefe stand den Staaten als den Vollstreckern einer geschichtlichen Sendung Gerechtigkeit und Wahrheit auf der Stirn, ja sogar in den Sternen geschrieben. Da kam Jean Jacques Rousseau und behauptete, Gerechtigkeit und Wahrheit seien keine ewig geltenden Begriffe der Vernunft, sondern nur Willensentscheidungen, stets abhängig vom Augenblick.

Jean Jacques Rousseau ging von der Überzeugung aus, daß die als ein Vollk zusammenlebende Gemeinschaft eine eigene übergeordnete Seele besitze, anders und höher zu bewerten als jede unserer Seelen. Diesem höheren übergeordneten Ich eigne ein unfehlbarer Wille, der in jedem Augenblick das Gerechte und das Ungerechte, das Gute und das Böse zu bestimmen vermöge. Dieser kollektive, dieser souveräne Wille werde einzig und allein durch die Abstimmung zum Ausdruck gebracht - im Sieg der Mehrheit über die Minderheit, wenn es also gilt, den übergeordneten Willen zu erraten. Daraus ergab sich, daß die Abstimmung, jene Komödie, in der man Zettelchen in eine gläserne Urne steckt, uns in jedem Augenblick sagen konnte, ob es einen Gott gibt oder nicht, ob die Wahrheit Wahrheit ist oder nicht, ob das Vaterland weiter bestehen soll oder ob es besser ist, daß es sich zu einem bestimmten Zeitpunkt selbst den Tod gibt.

Der liberale Staat wurde zum Diener dieser Lehre. Er hörte auf, der entschlossene Vollstrecker der Geschicke des Vaterlandes zu sein; er war zufrieden mit der Rolle des Zuschauers bei den Wahlkämpfen. Für den liberalen Staat war es einzig und allein von Bedeutung, daß an den Wahltischen eine bestimmte Anzahl von Männern saß, daß die Wahl um acht begann und um vier Uhr aufhörte, daß die Wahlurnen nicht zerbrochen wurden. Wo doch die edelste Bestimmung jeder Urne darin besteht, in Scherben geschlagen zu werden! Ferner galt es, in aller Ruhe zu respektieren, was aus den Urnen zum Vorschein kam, als ob es den Staat weiter nichts anginge! Diese liberalen Staatsmänner glaubten nicht einmal an ihre eigene Sendung. Sie glaubten nicht, daß sie selbst auf ihrem Posten eine ehrbare Pflicht erfüllten. Jeder, so meinten sie vielmehr, dürfe gegenteiliger Ansicht sein, und wenn er sich des Staates im Guten oder auch im Bösen bemächtigen wolle, so habe er dazu das gleiche Recht wie die Hüter des Staates, den Staat zu verteidigen.

So entstand die demokratische Staatsform. Sie ist in erster Linie das System schlimmster Energieverschwendung. Ein Mann, geschaffen für die hohe Aufgabe des Regierens - vielleicht die edelste aller menschlichen Aufgaben -, mußte 80, 90 oder sogar 95 Prozent seiner Energie darauf verwenden, monoton Beschwerden zu erledigen, Wahlpropaganda zu führen, in den Abgeordnetenbänken ein Nickerchen zu machen, den Wählern zu schmeicheln, ihre Unverschämtheiten zu ertragen (denn von den Wählern würde er ja die Macht erhalten), Kränkungen und Scherereien gerade von denen hinzunehmen, die aus Achtung vor der nahezu gött-

\footnotetext{
1 Entidad permanente; wörtlich: dauernde Wesenheit.
} 
lichen Aufgabe des Regierens doch eigentlich dazu verpflichtet waren, ihm zu gehorchen. Und wenn ihm nach alledem noch einige Stunden in der Frühe oder ein paar Minuten übrigblieben, die er von einer unruhigen Pause abzog, dann erst, in dieser so kurzen Zeitspanne, konnte der zum Regieren befähigte Mann ernsthaft an die eigentlichen Regierungsaufgaben denken.

So verloren die Völker ihre geistige Einheit; denn weil diese Staatsform auf dem Sieg der Mehrheit beruhte, mußte jeder, der an die Macht gelangen wollte, sich die Mehrheit der Stimmen sichern. Notfalls mußte er diese Stimmen den anderen Parteien entreißen, und er durfte sich dabei nicht scheuen, die anderen zu verleumden, sie mit den schlimmsten Schmähungen zu überschütten, ganz bewußt die Wahrheit zu verdrehen und keine Möglichkeit auszulassen, den Gegner zu erniedrigen oder zu lügen. So kam es, daß der Liberalismus zwar die Brüderlichkeit als eines seiner Postulate auf seine Fahne schrieb, es aber noch nie eine Form des menschlichen Zusammenlebens gab, in der sich die Menschen, sich gegenseitig schmähend und alle miteinander verfeindet, weniger als Brüder fühlten als im turbulenten, unangenehmen Leben des liberalen Staates.

Und schließlich bescherte uns der liberale Staat die wirtschaftliche Versklavung; er sagte den Arbeitern mit tragischem Sarkasmus: „Es steht Euch frei zu arbeiten, so viel und so wenig wie Ihr wollt; niemand kann Euch zwingen, diese oder jene Bedingungen anzunehmen. Aber da wir reich sind, bieten wir Euch die Bedingungen, die uns passen. Wenn Ihr nicht wollt, seid Ihr als freie Staatsbürger in keiner Weise gezwungen, sie anzunehmen. Akzeptiert Ihr als arme Staatsbürger aber unsere Bedingungen nicht, so werdet Thr Hungers sterben - umgeben von der größten liberalen Würde." - Ihr braucht Euch in den Ländern, welche die vortrefflichsten demokratischen Einrichtungen besitzen, nur einige hundert Meter von den Prachtvierteln zu entfernen, um auf die Elendsquartiere, die Brutstätten ansteckender Krankheiten zu stoßen. Dort hausen die Arbeiter, zusammengepfercht, nahezu aller menschlichen Würde beraubt. Und anderswo würdet Ihr Landarbeiter finden, die sich vom Morgengrauen bis in die späte Nacht über den Acker beugen, ausgemergelt und ausgedörrt und im ganzen Jahr dank dem Kräftespiel der liberalen Wirtschaft 70- oder $80 \mathrm{mal}$ den Tagelohn von drei Peseten verdienen.

Es mußte zwangsläufig der Sozialismus entstehen, und er entstand zurecht - wir verschweigen keine Wahrheit! Die Arbeiter mußten sich gegen dieses System verteidigen, das ihnen Rechte nur versprach, sich aber nicht darum kümmerte, ihnen ein lebenswürdiges Dasein zu ermöglichen. - Der Sozialismus war die legitime Reaktion gegen die liberale Sklaverei, aber er verfehlte sein Ziel, weil er sich erstens der materialistischen Lebens- und Geschichtsauffassung verschrieb, zweitens sich vom Wunsch nach Vergeltung leiten ließ und drittens die Lehrevom Klassenkampf predigte.

Die sozialistischen Apostel, an welche die armen Arbeiter glauben, haben in ihren eiskalten Stuben leidenschaftslos den Sozialismus ausgeklügelt. Alfonso Garcia Valdecasas ${ }^{\mathbb{1}}$ hat uns ihr wahres Wesen vortrefflich dargestellt. Der Sozialis-

${ }^{1}$ Alfonso Garćia Valdecasas war von der von José Ortega y Gasset gegründeten, aber wir- 
mus dieser Apostel sieht in der Geschichte lediglich ein Spiel wirtschaftlicher Spannung. Das Geistige wird unterschlagen, Religion ist Opium fürs Volk, das Vaterland ist ein Märchen, um die unglücklichen Armen auszubeuten. Es gibt nur Produktion und Organisation. Daher muß der Arbeiter seine Seele sozusagen ausquetschen, damit auch nicht der geringste Tropfen Geistigkeit darin zurückbleibt.

Der Sozialismus trachtet nicht danach, die durch das Chaos der liberalen Staaten zerstörte soziale Gerechtigkeit wieder herzustellen; er will Vergeltung, er will die liberalen Staaten in der Ungerechtigkeit womöglich noch übertreffen.

Schließlich verkündet der Sozialismus das ungeheuerliche Dogma vom Klassenkampf. Er lehrt, Kämpfe zwischen den Klassen seien unabwendbar, sie brächen im Leben zwangsläufig aus, weil nichts auf der Welt die Gegensätze überbrücken könne. Der Sozialismus, der als berechtigte Kritik am wirtschaftlichen Liberalismus entstand, brachte uns das gleiche wie dieser, nur auf einem anderen Wege: er brachte die Zersetzung, den $\mathrm{Haß}$, die Zersplitterung, das Zerreißen aller Bande der Brüderlichkeit und der Solidarität unter den Menschen.

Als wir, die Männer unserer Generation, die Augen öffneten, erblickten wir eine Welt in sittlichem Verfall, eine Welt, die in alle möglichen verschiedenen Gruppen aufgespalten war. Und was uns noch mehr betrübte: Spanien war verkommen, zerrissen durch $\mathrm{Haß}$ und Zwietracht. Und so mußten wir aus tiefster Seele weinen, als wir durch die Dörfer Spaniens zogen, durch diese Dörfer, in denen man noch immer unter dem Mantel äußerster Bescheidenheit Menschen von einer rustikalen Herzensbildung findet, die keine überschwengliche Geste, kein überflüssiges Wort kennen. Menschen, die auf einer trockenen - trocken aber nur dem Anschein nach! - Ackerkrume leben, auf einem Boden, dessen Fruchtbarkeit für Wein und Weizen uns staunen läßt. Als wir durch diese Lande zogen und diese Menschen sahen, von Ortstyrannen gepeinigt, von allen politischen Gruppen vergessen, unter sich uneinig und verwirrt durch verworren-giftige Reden, da mußten wir von diesem Volk denken, was es selbst einmal vom Cid ${ }^{\mathbf{1}}$ gesungen hatte, als es ihn aus seiner Verbannung aus Burgos durch die weiten Felder Kastiliens irren sah:

Mein Gott, welch guter Lehnsmann, wenn er einen guten Herren hätte!

Genau dies wollen wir in der Bewegung finden, die heute ins Leben gerufen wird, den rechtmäßigen Herrn Spaniens, aber einen Herrn wie den heiligen Franz ${ }^{2}$, einen Herrn, den uns der Tod nicht rauben kann. Und damit er uns nicht dahin-

lkungslos gebliebenen „Argupación al Servicio del estado" zur Falange gestoßen. Er verließ sie jedoch 1934 wieder, da sie ihm einen zu sozial-revolutionären Kurs steuerte. In das erste Kabinett der Franco-Regierung vom 1. 2. 1938 wurde er dann als Vertreter eines autoritären Monarchismus berufen.

1 Der Cid, von Legenden umwobener Held der spanischen Geschichte um 1100, der vor allem gegen die Eindringlinge aus Afrika kämpfte. Seine Heldentaten werden im „Poema del Zid" besungen, dem ersten großen Denkmal der spanischen Literatur.

2 Francisco de Borja, am Hofe Karls V. José Antonio spielt auf den Schwur Francisco de Borja's an, den dieser angesichts des verwesten Leichnams Isabellas geleistet haben soll: ex wolle nie wieder einem Herrn dienen, der sterben müsse. 
stirbt, muß er ein Herr sein, der weder Sklave der Interessen einer Gruppe noch einer Klasse ist. ${ }^{1}$

Die jetzt gegründete Bewegung ist keine Partei, sondern eine Bewegung schlechthin, fast möchte ich sagen: eine Antipartei. Sie gehört, das sei heute ein für allemal gesagt, weder zur Rechten noch zur Linken. In der Rechten offenbart sich die Absicht, eine Wirtschaftsordnung aufrechtzuerhalten, die ungerecht ist. In der Linken offenbart sich der Wunsch, eine Wirtschaftsordnung zu stürzen, auch wenn mit diesem Sturz viel Gutes verlorengehen würde. Beide Seiten begründen mit einer Reihe von geistigen Erwägungen ihre Absichten. Jedem aufrichtigen Zuhörer sei gesagt, daß wir für alle diese geistigen Erwägungen und Vorstellungen Verständnis haben, aber um nichts in der Welt werden wir das Schicksal unserer Bewegung an die Interessen einer Gruppe oder Klasse binden, an jene Interessen, die der eigentliche Beweggrund für die vordergründige Teilung in rechts und links sind.

Das Vaterland ist eine totale Einheit, in ihr sind alle Individuen und alle Klassen vereint. Das Vaterland darf weder von der stärksten Klasse noch von der am besten organisierten Partei beherrscht werden. Das Vaterland ist eine transzendente Synthese, eine unteilbare Synthese ${ }^{2}$ mit eigenen Zielen und Aufgaben. Unser Wunsch ist es, daß die heute geborene Bewegung und der von ihr zu schaffende Staat das wirksame, autoritäre Instrument im Dienste jener unumstrittenen, unanfechtbaren Einheit seien, die wir Vaterland nennen.

Damit ist die treibende Kraft für unser zukünftiges Handeln und unser gegenwärtiges Verhalten bestimmt. Wir wären ja nur eine Partei mehr, wollten wir jetzt schon ein Programm mit konkreten Lösungen verkünden. Solche Programme haben nur den Vorteil, niemals verwirklicht zu werden. Hat man dagegen ein klares, konstantes Bewußtsein gegenüber der Geschichte und dem Leben, so gibt uns dieses Bewußtsein, wenn es not tut, auch die Lösungen ein, so wie die Liebe, und sagt, wann wir schelten und wann wir uns vertragen müssen, ohne daß wahrhafte Liebe auch nur im geringsten ein Programm dafür entworfen hätte.

Damit sind die Forderungen umrissen, die unsere totale Auffassung vom Vater-

1 Der "gute Herr" wird von José Antonio bereits konkret als Führer des Neuen Staates verstanden. Das ergibt sich aus seiner Verehrung für Mussolini, von dem er kurz vor der Gründungsversammlung der Falange in Rom, am 19. Oktober zu einer halbstündigen Audienz empfangen worden war. Der Audienz ist kein sachlich bedeutsamer Wert beizumessen. José Antonio, ein junger, in der Politik unbekannter Mann, kam sich vor, „wie ein Schüler, der zu seinem Meister geht". (Manlio Barilli: José Antonio Primo de Rivera, Roma, o. J. [1937] S. 23). José Antonios eigener Bericht über die Audienz ist eine einzige Huldigung an den "jefe". „Jene Unterredung lie $ß$ mich den italienischen Faschismus besser verstehen als die Lektüre vieler Bücher." O.C., a. a. O., S. 522. In dem in der Gründungsrede genannten "guten Herrn" müssen wir einen Hinweis auf Beispiel und Vorbild Mussolinis sehen.

2 Dieser terminologisch der neukantischen Philosophie entlehnte Ausdruck, dessen Adaption durch José Antonio hier nicht untersucht werden kann, wird, wie sich aus dem ganzen Werk José Antonios ergibt, auf das Vaterland bezogen. Es wird ebenso als "Auftrag aller" wie als „unteilbares Ganzes" verstanden. Das Vaterland wird somit zugleich als räumliche Einheit wie als spirituell-politische Forderung, als verpflichtende Mission interpretiert, die es zu erfüllen gilt. 
land und vom Staat, der diesem Vaterland zu dienen hat, stellt: Alle Völker Spaniens, mag ihre Verschiedenartigkeit auch noch so groß sein, müssen sich in einer unwiderruflichen Schicksalsgemeinschaft verbunden fühlen.

Die politischen Parteien müssen verschwinden. Niemand wird als Mitglied einer politischen Partei geboren. Wir alle dagegen kommen als Mitglied einer Familie zur Welt, wir alle sind Bürger einer Gemeinde, wir alle üben eine bestimmte Arbeit aus. Wenn dies - Familie, Gemeinde, Berufsstand - also unsere natürlichen Lebensgemeinschaften sind, wozu bedürfen wir dann noch des zwischengeschalteten, verderbenbringenden Instruments der politischen Parteien? Sie reißen uns aus unseren natürlichen Lebenskreisen heraus, um uns dann in künstlichen Gruppen zusammenzufassen!

Wir wollen weniger liberales Geschwätz und mehr Achtung vor der wahren Freiheit des Menschen; denn die Freiheit des Menschen wird nur dann geachtet, wenn man ihn, wie wir es tun, als Träger ewiger Werte betrachtet, wenn man ihn ehrt als körperliche Hülle einer Seele, die sich selbst zu verdammen oder zu erlösen imstande ist. Nur wenn man den Menschen so sieht, kann man sagen, man achte seine Freiheit wirklich. Erst recht dann, wenn sich diese Freiheit, wie wir es wollen, in ein System der Autorität, der Hierarchie und der Ordnung einfügt.

Alle sollen sich als Mitglied einer vom Ernst getragenen, geschlossenen Gemeinschaft fühlen. Die Aufgaben, die es zu erfüllen gilt, sind vielseitig. Die einen tun ihre Arbeit mit der Hand, die anderen mit dem Kopf, manche sind als Erzieher des Volkes tätig. Aber jeder soll von nun an wissen, daß es in der Gemeinschaft, die wir anstreben, keinen Platz mehr für Schmarotzer und Drohnen geben wird.

Wir wollen, daß nicht so viel Aufhebens gemacht wird von den persönlichen Rechten. Sie gelten im Hause der Hungrigen ja doch nicht. Aber jedem Menschen, jedem Mitglied der politischen Gemeinschaft soll es allein aufgrund dieser Zugehörigkeit möglich sein, sich durch seine Arbeit ein menschenwürdiges, ein gerechtes Leben zu verdienen.

Wir wollen, daß der fromme Sinn, Ausgangspunkt für die Ersteigung der höchsten Gipfel unserer Geschichte, gebührend geehrt und geschützt wird, ohne daß sich deshalb der Staat in Aufgaben einmischt, die ihm nicht zustehen. Der Staat darf aber auch nicht, wie er dies früher manchmal aus anderen Gründen als denen der wahren Religion getan hat, einen Teil jener Aufgaben auf andere Institutionen übertragen, die zu erledigen er selbst verpflichtet ist.

Wir wollen, daß Spanien sich entschlossen wieder zu der weltumspannenden Bedeutung seiner Kultur und seiner Geschichte bekennt.

Wir wollen schließlich auch nicht vor der Anwendung der Gewalt zurückschrecken, wenn sie zur Erreichung unserer Ziele erforderlich sein sollte. Denn wie kann man alles, außer der Gewalt, gestatten und behaupten, der höchste aller moralischen Werte sei die Liebenswürdigkeit! Wer hat etwas davon gesagt, daß wir, wenn unsere Gefühle beleidigt werden, nicht wie Männer reagieren dürfen, sondern liebenswürdig bleiben müssen! Die Kunst, zu überreden, ist auch uns als erstes Verständigungsmittel willkommen. Doch wenn die Gerechtigkeit mit Füßen 
getreten oder das Vaterland beschimpft wird, ist keine andere Sprache mehr zulässig als die der Fäuste und Pistolen.

Dies sind unsere Vorstellungen vom kommenden Staat. Ihn zu errichten ist das Ziel all unseres Strebens!

Doch würde unsere Bewegung mißverstanden, hielte man sie lediglich für eine Denkart. Sie ist keine Art des Denkens, sondern eine Art des Wollens. Es genügt nicht, sich auf die Konstruktion, die politische Struktur zu beschränken. Dem gesamten Leben gegenüber müssen wir in jeder unserer Handlungen eine menschliche, in der Tiefe verankerte ganzheitliche Haltung einnehmen. Diese Haltung wird bestimmt durch den Geist des Dienens und des Opferns, durch eine asketische und soldatische Lebensauffassung. Niemand soll sich einbilden, wir würben hier Anhänger, um fette Pfründen zu verteilen. Auch soll sich keiner einbilden, wir versammelten uns hier, um irgendwelche Privilegien zu verteidigen. Ich wünschte, dieses Mikrofon hier vor mir trüge meine Stimme bis in die letzten Arbeiterwohnungen, um zu verkünden: „Jawohl, wir tragen Krawatten! Jawohl, von uns könnt Ihr behaupten, wir seien feine junge Herren! ${ }^{1}$ Aber wir wollen gerade für das kämpfen, was uns als feine Herren eigentlich gar nichts angeht. Wir wollen den Kampf, damit vielen unseres Standes harte und gerechte Opfer auferlegt werden. Wir wollen dafür kämpfen, daß der totalitäre Staat seine Güter in gleicher Weise an die Kleinen wie an die Großen verteilt. " Dies entspricht unserer Art, aus diesem Holz waren die Herren Spaniens stets geschnitzt. Sie konnten sich den Ehrentitel „Herr" wirklich verdienen, weil sie in fremden Ländern und auch im Vaterland selbst dem Tod ins Angesicht zu schauen wußten, weil sie die größten Bürden auf sich nahmen, und zwar gerade um solcher Dinge willen, die sie als feine Herren gar nichts angingen.

Ich glaube, die Fahne ist gehißt. Jetzt laßt sie uns verteidigen, freudigen Herzens, mit dichterischem Schwung. Angesichts der fortschreitenden Revolutionierung glauben einige, man müßte, um möglichst viele Anhänger aus vielen Lagern zu gewinnen, die lauesten Lösungen anbieten. Sie meinen, in der Propaganda müsse alles verheimlicht werden, was das Gemüt bewegen oder auf eine energische radikale Haltung hindeuten könnte. Welch ein Irrtum! Nur Dichter haben je die Welt zu Taten angefeuert, und wehe demjenigen, der unfähig ist, gegenüber der Poesie der Zerstörung die Flagge dichterischer Verheißung zu hissen!

Mit dichterischer Begeisterung, glühend und inbrünstig, werden wir uns Spanien weihen. Wir werden uns aufopfern, wir werden verzichten, und der Sieg wird unser sein. Den Sieg werden wir - wozu Euch das noch sagen? - in den nächsten Wahlen noch nicht erringen. Stimmt bei den nächsten Wahlen für das, was Euch am wenigsten schlecht zu sein scheint! Doch dort wird unser Spanien nicht geboren, dort ist nicht unser Platz. Da herrscht eine so schlechte und verbrauchte Luft wie in einer Kneipe nach durchzechter Nacht. Dort sind wir am falschen Ort. Ich glaube, ich bin ja auf der Kandidatenliste, aber ich bin ein Kandidat ohne Glaube und

1 "Senoritos"; die Söhne des politisch meist monarchistischen oder rechtsrepublikanischen Adels und des gehobenen Bürgertums, unter denen José Antonio vornehmlich seine Freunde hatte. 
Achtung1. Und das sage ich jetzt offen, obwohl es mich alle Stimmen kosten kann. Das läßt mich kalt. Wir wollen den Stammgästen nicht die schäbigen Reste eines schmutzigen Gelages streitig machen. Unser Platz ist draußen, auch wenn wir vielleicht gelegentlich einmal an einem anderen Ort weilen müssen. Unser Platz ist unter freiem Himmel, in der sternklaren Nacht, das Gewehr in der Hand, und über uns funkeln die Sterne. Sollen doch die anderen weiterzechen! Wir stehen draußen, auf gespannter Wacht, begeisterungsglühend und fest, und in unseren Herzen ahnen wir schon das Morgenrot der Zukunft.

$$
\text { O. C., a. a. O., S. } 17 \mathrm{ff} \text {. }
$$

\section{ÜBER DEN TOTALITÄREN STAAT}

Nach der Gründung der Falange Española bieten sich José Antonio drei Instrumente an, deren er sich zur Propagierung seiner politischen Ziele bedienen kann: die Partei selbst, deren Kurs er, wenn auch noch nicht als gewählter oder bestätigter Führer, so doch als beherrschender Kopf allein bestimmt; sodann die spanischen Cortes, das Parlament, dem er nun angehört, und vor dem er unter Berufung vornehmlich auf das Beispiel Mussolinis die Vorzüge eines Neuen Staates werbend darzustellen versucht; schließlich eine neue Wochenschrift „Falange Española“, kurz „FE“ genannt, mit der er publizistisch Wirkung zu erzielen hofft. Doch die Bedeutung der drei Plattformen seiner politischen Aktivität bleibt gering. Die Falange ist vorläufig nur eine lockere Verbindung jugendlicher Enthusiasten, deren Aktionsradius bei einer das erste Hundert nicht übersteigenden Zahl von Mitgliedern äußerst begrenzt ist. Im Parlament tritt José Antonio als Unabhängiger auf, ohne durch eine Fraktion oder politisch Gleichgesinnte gestützt zu sein. Der neuen Zeitschrift „FE“ fehlt es an finanziellen Mitteln, vom Format, vom Inhalt her, wie durch eine beachtenswerte Auflage publikumswirksam zu werden. Als eine Wochenzeitung unter vielen kargen Blättchen treibt sie dahin, zudem ist sie ständig von staatlichen Zensurmaßnahmen bedroht. Einzelne Nummern dürfen nicht ausgeliefert werden, oder es fehlt an Geld, die Druckkosten zu bezahlen. Vom Dezember 1933 bis Juli 1934 erscheinen nur 15 Ausgaben mit meist nur sechs kleinformatigen Seiten. Dann wird „FE“ endgültig verboten. Bitter beklagt sich José Antonio über den Mangel an Resonanz, wenn er als Redner im Parlament den totalitären Staat zu rechtfertigen versucht oder als politischer Feuilletonist Einheit und Mission Spaniens besingt².

1 José Antonio versucht mit dieser wie nebensächlich eingefügten Bemerkung seine politische Schizophrenie zu verharmlosen. Denn zur gleichen Zeit, in der er mit der Gründung der Falange die Verwerfung der parlamentarischen Demokratie propagiert, kandidiert er selbst zwar als Unabhängiger, aber doch innerhalb einer von Rechtsparteien zusammengestellten Wahlgemeinschaft in der heimatlichen Provinz Cádiz. In den Wahlreden, die er dort im November 1933 hält, erwähnt er nicht seine soeben gegründete Falange. Als Abgeordneter dieser Wahlgemeinschaft, nicht als Falangist, rückt José Antonio in die Cortes ein und erhält erst damit die Möglichkeit, auch das Parlament als Plattform zu benutzen. Sein zweiter Versuch, auch 1936 wieder als Abgeordneter einer Wahlgemeinschaft zu kandidieren, wird abgelehnt. Bis zum Ausbruch des Bürgerkrieges gelingt es der Falange nicht, einen Cortes-Sitz zu erobern. Nellessen, a. a. O., S. 74.

2 Bravo, a. a. O., S. 23, 43. Nellessen, a. a. O., S. 81. 
Herr Gil Robles ${ }^{1}$ ist der Ansicht, nach einem in sich geschlossenen totalitären und autoritären Staat streben heiße den Staat vergöttlichen. Ich aber sage Herrn Robles, daß die Vergöttlichung des Staates genau das Gegenteil dessen ist, was wir wollen.

Wir glauben, daß ein Staat, ebenso wie ein Individuum oder eine Klasse, sein Handeln nur dadurch zu rechtfertigen vermag, da $\beta$ er sich in jedem Augenblick seines Handelns einer ewig gültigen Norm unterwirft. Vergöttlichung des Staates dagegen ist die Vorstellung Rousseaus, der Staat oder die für den Staat verbindlichen Willensäußerungen hätten immer recht. Der Staat wird vergöttlicht durch den Glauben, daß der Wille des Staates, den früher die absoluten Könige äußerten und der heute in der allgemeinen Wahl zutage tritt, immer richtig sei. Die absoluten Könige konnten sich irren, das Volk kann sich irren, denn eine Willensäußerung kann niemals das Wahre oder das Gute sein. Das Gute und das Wahre sind zeitlose Kategorien der Vernunft, und um zu erfahren, ob man recht hat, reicht es nicht aus, den König zu befragen, dessen Wille für die Anhänger der absoluten Souveränität immer gerecht war, noch genügt es, das Volls zu befragen, dessen Wille nach Ansicht der Anhänger Rousseaus stets und immer richtig ist. Es ist vielmehr in jedem Augenblick zu prüfen, ob unser Handeln und Denken einem immer gültigen, einem zeitlosen Streben entspricht.

Die Vergöttlichung des Staates ist daher das genaue Gegenteil dessen, was wir wollen. Wir wollen einen Staat, der stets Instrument im Dienste einer geschichtlichen Bestimmung, im Dienste der geschichtlichen Mission der Einheit ist. Wir meinen, der Staat sei gut, wenn er an das totale geschichtliche Schicksal glaubt, wenn er das Volk als Summe allen Trachtens versteht. Aus diesem Grunde sind wir sowohl gegen eine Diktatur der Linken als auch gegen eine Diktatur der Rechten, ja sogar gegen eine Diktatur beider zusammen. Denn unserer Meinung nach ist ein Volk dies: eine Schicksalsgemeinschaft, eine Gemeinschaft des Bemühens, der Aufopferung und des Kampfes. Man muß sie als Ganzes sehen, als Ganzes geht sie durch die Geschichte, dem Ganzen hat sie zu dienen.

Aus einer Rede José Antonios vor den Cortes, 19. Dezember 1933; O. C., a. a. O., S. $272 \mathrm{ff}$.

8

EUZKADI - FREIES LAND?

Nach Ausrufung der Zweiten Republik verstärkten sich im Baskenland wie in Katalonien starke partikularistische bis separatistische Tendenzen. Im Baskenland Euzkadi ist ein der baskischen Sprache entstammender Regionalbegriff - stimmte im Juni 1932 eine starke Mehrheit für ein die Autonomie sicherndes Regionalstatut, das von José Antonio, als es in den Cortes behandelt wurde, leidenschaftlich abgelehnt wurde, weil es die Einheit Spaniens zerstöre.

1 José María Gil Robles y Quiñones, Führer der katholischen Partei "Acción Popular" und einer dex einflußreichsten Parlamentarier während der Republik. Im Mai 1935 übernahm er das Kriegsministerium. 
Vielleicht fischten Basken schon Jahrhunderte vor der Entdeckung Amerikas durch Columbus auf den Bänken von Neufundland. Doch die Namen jener möglichen Vorläufer verflüchtigten sich im Nebel der Zeit. Die vielen „L“ und „Z" der baskischen Namen ertönen überall in der Welt erst in dem Augenblick, in dem die Träger solcher Namen die Schiffe des spanischen Reiches besteigen. Nur über Spanien finden die Basken sich selbst. Dieses prächtige Volk ungesteuerter Kraft und ruhmloser früherer Entdeckungen findet sein wahres Schicksal darin, die von ihm entdeckten Länder auf kastilische Namen zu taufen und Schiffe über Gebirgskämme von Meer zu Meer zu schleppen.

Man ist jemand, wenn es auch andere gibt. Nicht die andere Art unseres eigenen Körpers macht uns zur Person, sondern ausschließlich die Existenz anderer, von denen wir uns durch das Personsein unterscheiden. Das gilt auch für die Völker, für die Nationen. Die Nation ist keine geographische, ethnische oder sprachliche Realität, sie ist vor allem eine geschichtliche Einheit. Eine Gruppe von Menschen auf einem Stück Erde ist nur Nation, wenn sie als Gesamtheit wirksam ist, wenn sie eine eigene Bestimmung in der Geschichte erfüllt, einen Auftrag, der nicht der Auftrag der anderen ist. Immer sind es die anderen, die uns sagen, daß wir jemand sind.

Im menschlichen Zusammenleben bin ich das, was keiner der anderen ist. Im universalen Zusammenleben ist die Nation das, was die anderen nicht sind. Daher werden die Nationen von außen her bestimmt. Man erkennt sie an der nur ihnen eigenen Form, in der sie einen eigenen, anderen umfassenden Auftrag erfüllen.

Auf diese Weise ist Spanien Nation. Man sollte sagen, sein universales Schicksal, das Schicksal, das Spanien auf magische Weise in den Rang einer Nation erhob, habe des Augenblicks geharrt, in dem das Land geeint wurde. Die letzten 30 Jahre des XV. Jahrhundert erleben gebannt das Zustandekommen der beiden Ereignisse, jedes von einer solch weittragenden Bedeutung, daß es ein ganzes Jahrhundert hätte ausfüllen können: kaum ist die Uneinigkeit der Völker Spaniens überwunden, da öffnen sich Spanien alle Wege. Von diesem Augenblick an ziehen baskische Admirale auf kastilischen Schiffen dahin.

Heute scheint sich das Rad der Geschichte rückwärts drehen zu wollen; Euzkadi hat über sein Statut abgestimmt. Vielleicht tritt das Statut bald in Kraft. Euzkadi geht den Weg seiner Freiheit. Seiner Freiheit? Die Basken sollen bedenken, daß der Staat der universalen Prädestination ihre Stirn erst berührte, als sie mit den anderen Völkern Spaniens eins wurden. Weder vorher noch nachher, obwohl sie seit Hunderten von Jahren eine eigene Sprache redeten und ihr Stirnwinkel so und so viel Grad betrug! Nation, das heißt eine von den anderen differenzierte geschichtliche Einheit, waren sie, als Spanien Nation war. Nunmehr wollen sie die Einheit Spaniens zerbrechen. Sie werden erleben, wie der Gott der Seefahrten und Schlachten, den - wie der Selbstmord - die Zerstörung starker und schöner Einheiten kränkt, sie züchtigen wird. Er wird sie, da sie planlos eine falsche Freiheit anstreben, mit Knechtschaft schlagen. Sie werden keine Nation - Nation im universalen Sinn - mehr sein, sondern nur noch ein Volk ohne geschichtlichen Auftrag, dazu ver- 
urteilt, seine um den Horizont gebrachte Scholle $z u$ bestellen, vielleicht auch in anderen neuen Ländern die Netze zu knüpfen, ohne sich dabei jedoch bewußt zu werden, daß es Welten entdeckt.

Falanga Española (FE), Nr. 1, 7.12.1933; O. C., a. a. O., S. 645 ff.

\section{9}

\section{DER DUDELSACK UND DIE LEIER}

Wie begeistert sind wir! Keine Luft scheint uns so klar wie die unseres Landes, kein Rasen zarter als seiner, keine Musik vergleichbar mit der Musik seiner Bäche. Aber - liegt nicht in diesem völligen Einssein mit dem Boden eine giftige Sinnlichkeit? Es ist, als ob uns an den Boden unsichtbare Wurzeln fesselten. Es ist wie eine Liebe, die zu Selbstvergessen verführt. Zur Sentimentalität. Zum Weinen. Die Liebe, die in Schwermut zerfließt, wenn des Dudelsacks Klage ertönt; die Liebe, die sich auf einen immer engeren Raum zurückzieht: von der weiteren heimatlichen Umgebung zum Tal, in dem man geboren wurde; vom Tal zur Bucht, in der das vaterländische Haus sich spiegelt; vom Haus zum Winkel der Erinnerung. Alles das ist sehr süß, gleichsam süßer Wein. Doch wie beim Wein birgt die Süße die Gefahr des Rausches wie die der Apathie.

Kann man eine solche Art zu lieben Vaterlandsliebe nennen? Wäre Vaterlandsliebe nur innige Zuneigung, dann wäre sie nicht die höchste menschliche Liebe. Die Menschen wären in ihrer Vaterlandsliebe den Pflanzen unterlegen, denn deren Bindung an den Boden ist weit stärker. Es geht nicht an, das erste Beste, was unser Geist uns eingibt, Vaterlandsliebe zu nennen: jene elementare Verwurzelung im Boden. Die Liebe zum Vaterland muß, will sie ihren höchsten Wert erreichen, gerade das Gegenteil, das andere Extrem sein; sie ist das Schwierigste, das von allen Fesseln des Bodens Befreite, das Klarumrissene und Saubere, das Unveränderliche. Vaterlandsliebe muß nicht auf dem Gefühl, sondern auf dem Verstand gründen.

Wir dürfen den süßen Wein des Dudelsacks trinken, ohne ihm jedoch unser Innerstes anzuvertrauen. Alles Sinnliche währt kurz. Tausende und Abertausende von Lenzen sind dahingewelkt, doch wie seit Anbeginn der Schöpfung ist zwei mal zwei immer noch vier. Laßt uns unsere tiefen Liebesgefühle nicht auf den Rasen pflanzen, den so viele Lenze haben welken sehen! Leiten wir sie, schwere- und körperlosen Strahlen gleich - in den ewigen Raum hinein, in dem die Melodie nüchterner Klarheit schwingt. Das Lied der Leier fordert Taten, nüchtern und klar, wie es die Zahlen sind.

Laßt uns also im Vaterland nicht den Bach sehen und den Rasen, nicht das Lied und nicht den Dudelsack, sondern ein Schicksal, eine Aufgabe. Vaterland ist das, was in der Welt als gemeinschaftliches Unternehmen gestaltet wurde. Ohne Aufgabe gibt es kein Vaterland, ohne Glauben an eine gemeinsame Bestimmung löst alles sich in heimatliche Gebiete, ortsgebundene Geschmacksrichtungen und Schattierungen auf. Da verstummt die Leier, der Dudelsack ertönt. Und nichts 
spricht mehr dafür, daß ein Tal, abgesehen vielleicht von irgendwelchen unwesentlichen wirtschaftlichen Bedingungen, mit dem anderen vereint bleibt. Es verschwinden die klaren Konturen der großen Reiche, geplant und gestaltet; sie weichen dem flüsternden Lied zersetzender Geister, die unter den Schwämmen der Fäulnis in jedem Dorf verborgen sind.

FE Nr. 2, 11. 1. 1934; O. C., a. a. O., S. $641 \mathrm{ff}$.

10

REDE ZUR VERKÜNDIGUNG DER „FALANGE ESPAÑOLA DE LAS J.O.N.S.“

Bis zum 4. März 1934 hatten in Spanien zwei faschistische Gruppierungen bestanden. Die eine nannte sich „Juntas de Ofensiva Nacionalsindicalista“, abgekürzt J.O.N.S. (nationalsyndikalistische Angriffsgruppen). Diese J.O.N.S. waren das Ergebnis des im Oktober 1931 erfolgten Zusammenschlusses des Madrider Kreises um Ramiro Ledesma Ramos und des Valladolider Kreises um Onésimo Redondo Ortega. Mit der Falange unter José Antonio konstituierte sich neben den J.O.N.S. die zweite faschistische Gruppe. Nach langen, den ganzen Winter über währenden Gesprächen schließen sich Falange und J.O.N.S. am 4. März 1934 zusammen. Fortan heißt die Falange offiziell: „Falange Española de las Juntas de Ofensiva Nacionalsindicalista " (Spanische Falange der nationalsyndikalistischen Angriffsgruppen).

Der Zusammenschluß ist die Konsequenz gemeinsamer Vorstellung und Leitbilder. Er findet in Valladolid statt. Die J.O.N.S. bringen ihre vom spanischen Anarchosyndikalismus übernommene, jedoch zur Unterscheidung und zur nationalen Akzentuierung mit dem Emblem der Katholischen Könige, Joch und Pfeile, versehene Fahne mit. Fahne und Emblem werden von der Falange übernommen, ebenso wie der „römische Gruß".1 Die Kundgebung zum Zusammenschluß war, wie ein Chronist der Falange berichtet, „in Wirklichkeit der erste rein faschistische Akt". ${ }^{2}$ Nach dem Treffen kam es zu einer Schießerei mit sozialistischen Jugendgruppen, bei der ein Jugendlicher getötet und mehrere verwundet wurden. In einer Rede, die José Antonio ein Jahr später, am 3.3.35, an der gleichen Stelle hält, erinnert er an das Ende dieses Treffens der nun mit den J.O.N.S. vereinigten Falange: „Jene Tat war die erste ihrer Propaganda, und sie endete mit der Heftigkeit aller kraftvollen Handlungen, mit Schüssen ${ }^{3}$.

Bloß keinen Beifall, bloß keine Hochrufe für diesen oder jenen! Niemand ist hier ein einzelner Mensch, jeder nur ein Baustein, ein Soldat an dem Werk, das unser Werk und das Spaniens ist.

Ich kann demjenigen, der mir noch einmal zujubelt, versichern, daß ich ihm nicht dafür danke. Wir sind nicht hierhergekommen, um uns bejubeln zu lassen; wir wollen belehrt werden, wir wollen etwas lernen.

Viel müssen wir von diesem Boden und von diesem Himmel Kastiliens lernen, wir, die wir so häufig fern von ihm leben. Dieser Boden Kastiliens, dieser Boden

1 Julián Pemartín, Teoría de la Falange, Madrid 1947. S. 43; Nellessen, a. a. O., S. 79.

2 Bravo, a. a. O., S. 26.

3 Siehe S. $63 \mathrm{ff}$. 
ohne Prunk, ohne hervorstechende Einzelheiten, dieser Boden schlechthin! Er bedeutet nicht Lokalkolorit, gemeint ist damit nicht der Fluß, nicht der Grenzstein, nicht der Hügel. Mit diesem Boden ist noch viel weniger die Summe einiger Landgüter gemeint. Er ist auch nicht das Objekt landwirtschaftlicher Interessen, um das in den Versammlungen gefeilscht wird. Er ist einfach der Boden, der Boden als Hüter ewiger Werte. Er bedeutet für uns die Strenge in der Lebensführung, den frommen Sinn im Leben, die Muttersprache und das Schweigen, die innige Verbundenheit mit den Ahnen und mit den Nachkommen.

Über diesem absoluten Boden wölbt sich der absolute Himmel!

Der Himmel so blau, so wolkenlos und ohne den grünlichen Schimmer sich spiegelnder Wälder. Man könnte fast sagen, er ist weiß vor lauter Bläue. Und mit diesem herben absoluten Boden und seinem erhabenen absoluten Himmel, die sich einander anschauen, hat es Kastilien noch niemals vermocht, nur ein bloßes Stück Land zu sein. Stets hat Kastilien danach streben müssen, ein Imperium zu werden, Kastilien hat nie Verständnis für die Enge der Landschaft gehabt; Kastilien konnte nur das Weltumspannende begreifen, und deshalb verzichtete Kastilien stets auf sich selbst. Denn es endet nicht dort, wo seine Grenzen sind, vielleicht, weil es Grenzen gar nicht kennt, weder in der Tiefe, noch in der Breite, noch in der Höhe. Nur so läßt sich Kastilien begreifen, dieses Land im Strahlenglanz wunderbarer Namen: Tordesillas, Medina del Campo, Madrigal de las Altas Torres - dieses Land der Kanzleien, der Jahrmärkte und der Burgen, der Boden der Gerichtsbarkeit, des Soldatentums und des Handelns; dieses Land läßt uns ahnen, wie jenes Spanien beschaffen war, das wir nicht mehr besitzen. Unser Herz krampft sich zusammen in der schmerzlich-wehmütigen Sehnsucht nach dem Entschwundenen.

Unter großen Mühen und bisweilen nicht ohne Gefahr - doch das ist ja völlig bedeutungslos - haben wir uns auf den Weg gemacht, Euch die frohe, neue Lehre zu verkünden. Es geschieht, wie alle Vorredner gesagt haben, weil wir Spanien verloren haben. Spanien ist auf dreifache Weise gespalten: durch den regionalen Separatismus, durch den Parteienhader und durch die Klasseneinteilung.

Der regionale Separatismus ist ein Zeichen des Verfalls, das hauptsächlich dann zutage tritt, wenn man vergißt, was das Vaterland bedeutet. Es ist ja nicht etwas unmittelbar Physisches, das wir im primitivsten Zustand der Ursprünglichkeit wahrnehmen könnten. Das Vaterland ist nicht der Geschmack des Wassers einer bestimmten Quelle, nicht die Farbe der Erde im Wald; das Vaterland ist eine Aufgabe in der Geschichte, eine Sendung im Weltgeschehen. Das Leben eines jeden Volkes ist ein tragischer Kampf zwischen dem Ungebärdig-Urwüchsigen und dem Geschichtlichen. Primitive Völker spüren fast wie Pflanzen die Eigenarten des Bodens. Wenn sie diese primitive Empfindung überwunden haben, wissen sie bereits, daß das, was sie formt, nicht durch die Eigenart des Bodens bestimmt wird, sondern durch die Sendung, die sie im Weltgeschehen von den anderen Völkern unterscheidet. Wenn dann - ein Zeichen des Verfalls - das Gefühl für die Mission im Weltgeschehen erlischt, blüht wiederum der Separatismus auf, wendet sich das Volk wiederum seiner Erde, seinem Boden, seiner Musik, seiner Mundart zu, und 
wiederum ist dieses ruhmreiche Ganze in Gefahr, jenes Ganze, das Spanien in den Zeiten seiner Größe dargestellt hat.

Aber außerdem ist unser Land gespalten durch die politischen Parteien. Sie sind voller trüber Machenschaften. Aber ganz abgesehen von diesem schmutzigen Geschäft gibt es für die Existenz der Parteien eine tiefere Erklärung, die allein genügen müßte, sie uns verhaßt zu machen.

Die politischen Parteien entstehen an dem Tage, an dem man vergißt, daß es über den Menschen eine Wahrheit gibt, in deren Zeichen Völker und Menschen ihre Sendung im Leben zu erfüllen haben. Vor dem Entstehen der politischen Parteien wußten sie das; sie glaubten an die ewige Wahrheit und an deren Gegensatz: die absolute Lüge. Aber dann kam der Augenblick, in dem man dem Menschen sagte, weder Lüge noch Wahrheit seien absolute Begriffe, alles könne vielmehr in Frage gestellt werden, alles lasse sich durch Wahlen entscheiden, also auch die Frage, ob das Vaterland vereint bleiben oder ob es sich zerstören soll, oder ob es einen Gott gibt oder nicht. Die Menschen scheiden sich in Parteien, treiben Propaganda, erregen sich, beleidigen sich und schließlich stellt man an einem schönen Sonntag eine gläserne Urne auf einen Tisch und beginnt, Zettelchen hineinzuwerfen, auf denen vermerkt ist, ob es einen Gott gibt oder nicht, ob das Vaterland Selbstmord begehen soll oder nicht.

Und so entsteht etwas, das im Abgeordnetenhaus gipfelt.

Ich für meine Person bin, neben anderen Gründen, hierhergekommen, um diese reine Luft $\mathrm{zu}$ atmen. Denn meine Lungen tragen $\mathrm{zu}$ viele Krankheitskeime aus dem Leben der Volksvertretung. Wenn Ihr doch einmal sähet, wie es dort zugeht, jetzt, in dieser Zeit der Unruhe und der Angst! Ihr, die Ihr auf dem Lande wohnt und die Felder bebaut, Ihr solltet einmal sehen, wie man sich dort in den Wandelgängen in dichten Reihen um das Bekannteste und Älteste schart, sofern es nur Anlaß zu Witzen gibt! Neulich wurde diskutiert, ob sich ein weiteres Stück Spaniens vom Mutterland lossagen werde. $\mathrm{Da}$ gab es nur Reden voller juristischer Spitzfindigkeiten darüber, ob dieser oder jener Artikel der Verfassung, ob dieser oder jener Prozentsatz an Stimmen bei der Volksabstimmung zur Lostrennung berechtige! Das hättet Ihr einmal erleben sollen! Das solltet Ihr einmal mitanhören! Stellt Euch nur vor: ein Baske, seiner Gesinnung nach Spanier und Baske zugleich, zählte auf, was seine Heimat zum Ruhm Spaniens beigetragen habe. Da wagte es doch einer von denen, die bei Herrn Lerroux ${ }^{1}$ auf der Regierungsbank sitzen, darüber seine Witze zu machen und den Namen Uzcudun in einem Atemzug mit dem Namen Loyolas und Elcanos ${ }^{2}$ zu nennen!

Aber damit nicht genug. Dieses Jahrhundert, das uns den Liberalismus bescherte

1 Alejandro Lerroux war Führer dex „Radikalen Partei“ (eine Partei der Mitte), Ministerpräsident von Dezember 1933 bis September 1935.

2 Uzcudun war ein gefeierter Boxer aus dem Baskenland während der Zweiten Republik. Wie Ignatius von Loyola stammte auch der berühmte spanische Seefahrer Juan Sebástian de Elcano aus dem Baskenland. Er wurde in Spanien als der erste Mensch gefeiert, der die Welt umsegelt habe. 
und mit dem Liberalismus die Parteien des Parlaments, hinterließ uns darüber hinaus noch die Erbschaft des Klassenkampfes. Der wirtschaftliche Liberalismus lehrte, jedermann könne arbeiten, wie und wann er wolle, die Zeit der Knechtschaft sei vorüber, vorbei sei die Zeit, in der man den Arbeiter noch mit dem Stock regieren könne. Doch da die Arbeiter nur das zu essen hatten, was man ihnen gab, da die Arbeiter keine Unterstützung erhielten und der Macht des Kapitalismus hilflos ausgeliefert waren, konnte der Kapitalismus die Arbeitsbedingungen bestimmen. Dem Arbeiter blieb nichts anderes übrig, als sich damit abzufinden oder zu verhungern. So bot sich folgendes Bild: Der Liberalismus schrieb wunderbare Erklärungen über die Rechte des Menschen auf ein Stück Papier, das kaum jemand las, unter anderem deshalb, weil niemand dem Volk das Lesen beigebracht hatte. Der Liberalismus verfaßte diese Erklärungen, führte uns aber zugleich das unmenschlichste Schauspiel vor, das je zu erleben war: in den besten Städten Europas, in den Hauptstädten von Staaten mit den schönsten liberalen Einrichtungen, drängten sich scharenweise menschliche Wesen zusammen - unsere Brüder! - in dunklen, schmutzigen, scheußlichen, nahezu unbewohnbaren Wohnlöchern, eingepfercht zwischen Elend und Schwindsucht und der Blutarmut ihrer hungernden Kinder. Und von Zeit zu Zeit gab man ihnen sarkastisch zu verstehen, sie seien ja frei und völlig unabhängig.

Natürlich mußten sich die Arbeiter eines Tages gegen diesen Hohn erheben; der Klassenkampf war nicht zu vermeiden. Sein Beweggrund war gerecht, der Sozialismus hatte zuerst durchaus seine Berechtigung. Wir haben nicht die geringste Veranlassung, dies zu leugnen. Nur hat sich der Sozialismus, anstatt sein ursprüngliches Bemühen um soziale Gerechtigkeit fortzusetzen, zu einer rein theoretischen Doktrin gewandelt, so gefühlskalt, daß es einem Schauer über den Rücken jagt. Er denkt ja überhaupt nicht an die Befreiung der Arbeiter! Überall ziehen die Arbeiter durch die Straßen und verkünden stolz, sie seien Marxisten. Viele Straßen in vielen Dörfern Spaniens wurden schon nach Karl Marx benannt. Dieser Karl Marx aber war ein deutscher Jude', der von seinem Zimmer aus mit furchtbarer Gefühlslosigkeit die dramatischsten Ereignisse seiner Zeit beobachtete. Angesichts des Geschehens in den Fabriken von Manchester stellte dieser deutsche Jude unerbittliche Gesetze auf über die Akkumulation des Kapitals, über die Produktion und über die Interessen der Unternehmer und Arbeiter. Zur gleichen Zeit schrieb er Briefe an seinen Freund Friedrich Engels und meinte, die Arbeiter seien nur Pöbel und Pack und nur insofern müsse man sich mit ihnen abgeben, als es zum Beweise der Lehre diene.

Der Sozialismus hörte auf, eine Bewegung zur Erlösung der Menschen zu sein, er wurde, wie ich Euch sage, eine unerbittliche Lehre, und statt nach der Wiederherstellung sozialer Gerechtigkeit zu streben, trachtete er, nur auf Vergeltung be-

1 Trotz mehrmaliger Betonung, daß Karl Marx Jude gewesen sei, finden sich in der Ideologie José Antonios keine antisemitischen Tendenzen. Auch der Falangismus kannte keine Rassenlehre analog zum Nationalsozialismus. José Antonio verdammt Karl Marx als den Lehrex des Sozialismus, nicht als Juden. 
dacht, danach, seine Ungerechtigkeit ebensoweit zu treiben, wie es die Bourgeoisie mit ihrer ungerechten Wirtschaftsform getrieben hatte. Außerdem stellte der Sozialismus die These auf, der Klassenkampf werde niemals aufhören. Er behauptet auch, die Geschichte müsse materialistisch gedeutet werden, das heißt nur wirtschaftliche Phänomene seien für die Erklärung der Geschichte maßgebend. Und wenn der Marxismus in einer Organisation wie der russischen gipfelt, dann sagte man den Kindern vom ersten Schuljahr an, Religion sei Opium fürs Volk, das Vaterland sei ein leeres Wort, nur erfunden, um sie zu unterdrücken. Sogar die Scham und die Liebe der Eltern zu ihren Kindern seien bürgerliche Vorurteile, die es um jeden Preis auszurotten gelte.

Das ist aus dem Sozialismus geworden. Glaubt Ihr, die Arbeiter würden sich zu einer solch schrecklichen, schaudererregenden unmenschlichen Sache, die jener Jude Karl Marx in seinem Hirn ausgeklügelt hat, hingezogen fühlen, wenn sie sich über dies alles im klaren wären?

Als die Welt so aussah, als Spanien so aussah, da traten wir, jetzt etwa Dreißigjährige, in das Leben Spaniens ein. Es wäre uns nicht schwergefallen, uns zu dieser Gesellschaftsform zu bekennen und uns in die Wandelgänge des Abgeordnetenhauses zu drängen. Wir konnten uns auch Ausschweifungen hingeben, welche die proletarischen Massen noch mehr in ihrem Klassenkampf und Klassenhaß bestärkt und vergiftet hätten. Das wäre gar nicht schwer gewesen, und auf den ersten Blick hätte es auch seine Vorteile gehabt. Jeder von uns, der sich in eine der Parteien, bei den konservativen Republikanern, bei den Radikalen, bei den Liberalen oder der Volksaktion hätte einschreiben lassen, hätte große Aussichten, Minister zu werden. Wir haben ja alle 14. Tage eine neue Krise, und dauernd kommen neue Minister. Da muß man sich ja geradezu fragen, ob es in Spanien überhaupt noch jemanden gibt, der nicht Minister gewesen ist.

Doch darin sahen wir nicht unser Ziel. Wir haben es vorgezogen, den bequemen Weg zu verlassen und - wie es unser Kamerad Ledesma Ramos ${ }^{1}$ gesagt hat, den Weg der Revolution zu gehen, den Weg einer anderen, den Weg der echten Revolution. Denn bis jetzt waren alle Revolutionen unvollständig, weil keine dem nationalen Gedanken des Vaterlandes und der Idee der sozialen Gerechtigkeit gedient hat. Wir vereinigen beides: das Vaterland und die soziale Gerechtigkeit, und wir sind bedingungslos und rückhaltslos entschlossen, auf dem Fundament dieser beiden unumstößlichen Prinzipien unsere Revolution zu führen. Man sagt uns nach, wir seien Nachahmer. Onésimo Redondo ${ }^{2}$ hat darauf bereits geantwortet. Wir sollen Imitatoren sein, weil unsere Bewegung, diese Bewegung der Rückkehr zum echten, inneren Wesen Spaniens, eine Bewegung darstelle, die es schon in

1 Ramiro Ledesma Ramos. Siehe Anm. S. 33.

2 Onésimo Redondo Ortega, Führer der ersten faschistischen, nur aus jugendlichen Mitgliedern bestehenden Gruppe, die er nach einem Aufenthalt in Deutschland 1931 in Valladolid gegründet hatte. Er gab das besonders den Nationalsozialismus verherrlichende Wochenblatt "Libertad" heraus und unterstellte sich mit seiner Gruppe José Antonio. Er selbst erhält in der Falange die Mitgliedsnummer 3. Am 25.7.36 wird er in einen Hinterhalt gelockt und erschossen. S. auch S. 13. 
anderen Ländern gegeben habe! Italien und Deutschland haben zu sich selbst zurückgefunden und sich in einem Akt der Verzweiflung von den Märchen losgesagt, die sie unfruchtbar machen wollten. Aber sollten wir sagen, nur weil Italien und Deutschland sich selbst wiedergefunden haben, wir ahmten sie nach, weil nun auch Spanien sich selbst sucht? Diese Länder sind zu ihrer echten, eigenen Wesensart zurückgekehrt, und wenn wir das gleiche tun, so werden wir unsere eigene Wesensart und nicht etwa die Italiens oder Deutschlands wiederfinden. Gerade wenn wir das tun, was Italiener und Deutsche vor uns getan haben, werden wir bessere Spanier werden, als wir es je gewesen sind.

Dem Kameraden Onésimo Redondo möchte ich sagen: Mach Dir keine großen Sorgen über den Vorwurf, wir seien Nachahmer. Gelänge es uns, diesen Vorwurf zu entkräften, dann würden sie schnellstens neue erfinden. Niemals versiegt die Quelle böswilliger Verleumdung. Laßt sie doch ruhig behaupten, wir ahmten die Faschisten nach! Schließlich gibt es im Faschismus wie in den Bewegungen aller Zeiten außer den spezifischen, nur für ein Land geltenden Merkmalen unveränderliche Züge, die das Erbteil jedes menschlichen Geistes sind, überall gleich in der Welt. So war es zum Beispiel mit der Renaissance. So war es, wenn man so will, auch mit dem Elfsilbner. Er kam aus Italien zu uns, doch schon bald besangen Garcilaso de la Vega und Fray Louis de Léon im kastilischen Elfsilbner Spaniens Felder, und es rühmte in diesem Versmaß Fernando de Herrera den Herrn der weiten Meere, der Spanien den Sieg von Lepanto schenkte.

Wir sollen, so heißt es auch, reaktionär sein. Manche behaupten das in böswilliger Absicht, damit die Arbeiter nicht zu uns kommen und uns nicht anhören. Die Arbeiter werden uns dennoch anhören, und wenn sie uns anhören, werden sie denen keinen Glauben mehr schenken, die solche Behauptungen aufstellen. Wer wie wir den Gedanken der unzerstörbaren Schicksalsgemeinschaft neu beleben will, kann doch gar nicht reaktionär sein. Reaktionär ist man vielmehr dann, wenn man im Widerstreit lebt, wenn eine Klasse die andere besiegt hat und die besiegte Klasse danach trachtet, Vergeltung zu üben. Wir aber beteiligen uns nicht an dem Spiel der Vergeltung zwischen Klasse und Klasse und zwischen Partei und Partei. Wir stellen einen Grundsatz für alle unsere Handlungen auf. Dieser Grundsatz erhebt sich über die Interessen der Klassen und Parteien, er - und darin liegt das Tiefgründigste unserer Bewegung - dokumentiert unsere Vorstellung von einer totalen Schicksalsgemeinschaft, Vaterland genannt. Wird das Vaterland so verstanden, und ist ein starker Staat nichts anderes als das Instrument im Dienste dieses Vaterlands, dann fügt sich dieser Staat weder einer Klasse noch einer Partei, dann siegt nur ein Interesse, nämlich das der Schicksalsgemeinschaft, und nicht das augenblickliche, vorübergehende, partikuläre Interesse irgendeines Siegers. Dies werden die Arbeiter erfahren, und dann werden sie einsehen, daß unsere Lösung die einzig mögliche ist.

Andere wiederum halten uns für reaktionär, weil sie sich der ungewissen Hoffnung hingeben, wir würden, während sie in den Kasinos tuscheln und sich nach alten Vorrechten zurücksehnen, die sie zum Teil schon verloren haben, die Vorhut der Reaktion bilden und für sie die Kastanien aus dem Feuer holen. Wir würden 
uns abmühen, um denen in den Sattel zu helfen, die uns behaglich zuschauen. Täten wir dies, dann allerdings verdienten wir wirklich den Fluch der fünf Toten, die wir für das höchste Ziel geopfert haben ${ }^{1}$.

Und schließlich wirft man uns vor, wir hätten ja kein Programm. Kennt Ihr irgend etwas Ernsthaftes und Tiefes, das jemals nach einem festen Programm verlaufen wäre? Wann habt Ihr je gesehen, daß die entscheidenden, die ewigen Dinge, wie Liebe, Leben und Tod sich programmgemäß abgewickelt hätten? Das einzige, was man braucht, ist eine umfassende Vorstellung von dem, was man will. Eine ganzheitliche Auffassung vom Vaterland, vom Leben, von der Geschichte, dieses totale Gefühl sagt uns in jedem Augenblick, was wir zu tun und zu lassen haben. In den besten Zeiten hat es nicht so viele Untersuchungsausschüsse, nicht so viele Statistiken, nicht so viele Wählerlisten gegeben und auch nicht so viele Programme. Hätten wir ein konkretes Programm, so wären wir nur eine Partei mehr und würden - den anderen ähnlich - zur Karikatur unserer selbst. Ein jeder weiß, daß sie lügen, wenn sie von uns sagen, wir seien ein Abklatsch des italienischen Faschismus, wir seien keine Katholiken und keine Spanier. Aber gerade diejenigen, die diese Lügen verbreiten, formen in aller Eile mit der linken Hand einen Abklatsch unserer Bewegung. So werden sie ihre Männer vor dem Escorial aufmarschieren lassen, wenn wir in Valladolid aufmarschieren. So werden sie, wenn wir vom ewigen Spanien, vom imperialen Spanien sprechen, ebenfalls behaupten, sie sehnten sich nach dem großen Spanien und dem korporativen Staat. Diese Bewegungen können der unsrigen allerdings nur ähneln wie ein aufgewärmtes Gericht vom Vorabend einem guten Essen². Denn unser Streben und unser Unternehmen kennzeichnet das Feuer, der Geist. Was kümmert uns der korporative Staat. Was liegt uns an der Beseitigung des Parlaments, wenn dies alles doch nur geschieht, damit andere Institutionen eine ebenso tatenarme, bleichgesichtige, aalglatte, stereotyp lächelnde Jugend großziehen, die unfähig ist, sich begeistern, sich von der Vaterlandsliebe, ja nicht einmal von der Religion mitreißen zu lassen!

1 Die Gruppen, die sich in Valladolid zur Falange de las J. O. N. S. zusammenschlossen, standen in der haßgeladenen Atmosphäre der Zweiten Republik in dauernden Auseinandersetzungen mit sozialistischen und anarchosyndikalistischen Gruppen. Schlägereien (bewußt gesucht) waren an der Tagesordnung, Totschlag, Verletzungen mit Todesfolge, aber auch Mord waren keine Seltenheit. Auf die Toten dieser Auseinandersetzungen weist José Antonio hin. Bis zum Mai 1934 zählte die Falange bereits neun Tote (Bravo, a. a. O., S. 39, S. 49; Nellessen a. a. O., S. 77 ff.). Den Zusammenschluß der verschiedenen Gruppen kommentiert José Antonio in der FE-Ausgabe vom 22. 2. 34. Sein Artikel schließt mit den Worten: „Das Blut unserer Toten hat uns verbunden, es hat unseren Pakt gesiegelt . . . (die Toten) ... sind gegenwärtig in unseren Reihen."

2 1934 wird unter der straffen Führung des Generalsekretärs Manuel Fal Conde die milizähnliche Organisation der carlistischen Basken, die sogenannten Requetés, modernisiert. Zur gleichen Zeit versucht José Mariá Gil Robles, der Führer der katholischen Volksaktion, die den Gedanken des Ständestaates vertritt, eine Jugendorganisation seiner Partei aufzubauen. Die Requetés wie die Volksaktion plädieren für einen autoritären Staat, verneinen jedoch den Staat totalitärer Prägung. José Antonio distanziert sich in seiner Rede von beiden Strömungen. Nellessen, a. a. O., S. $130 \mathrm{ff}$., Thomas, a. a. O., S. 73. 
Äußerste Vorsicht bei dem Gerede vom korporativen Staat! Äußerste Vorsicht bei all diesen kalten, inhaltslosen Worten, die Ihr von vielen hören werdet, die aber nichts anderes wollen, als uns zu einer der üblichen Parteien herabzuwürdigen. Auf diese Gefahr hat bereits Onésimo Redondo aufmerksam gemacht. Uns genügt es nicht, den Staat umzuformen. Wir wollen Spanien die Zuversicht, den Glauben an sich selbst und eine klare und energische Führung für das gemeinsame Leben wiedergeben. Deshalb ist unsere Bewegung keine Partei. Sie ist eine Kampfgruppe. Deshalb auch stehen wir nicht hier, um uns zu Abgeordneten wählen zu lassen, zu Staatssekretären oder Ministern. Wir sind hierhergekommen, damit jeder an seinem Platz den ihm zugewiesenen Auftrag erfüllt. Und so, wie wir fünf jetzt hinter diesem Tisch sitzen ${ }^{1}$, kann der Tag kommen, an dem der bescheidenste unter den Kämpfern dazu berufen sein wird, den Befehl zu übernehmen. Dann wird es an uns sein, ihm zu gehorchen. Wir haben keinen persönlichen Ehrgeiz, höchstens den, in der Stunde der Gefahr die ersten zu sein. Wir wollen einzig und allein, daß Spanien wieder zu sich zurückfindet, daß es in Ehren, in sozialer Gerechtigkeit, mit jugendlicher und vaterländischer Begeisterung die Worte wiederholt, die diese Stadt im Jahre 1516 in einem Brief an Kaiser Karl V. richtete:

Euer Gnaden mögen in die eine Hand dieses Joch nehmen, das der katholische König, Euer Großvater, Euch hinterließ und unter das so viele Tapfere und Stolze sich beugen mußten, und in die andere Hand die Pfeile jener unvergleichlichen Königin, Eurer Großmutter, Dona Isabel, mit denen sie die Mauren in die Ferne trieb!

Hier, hier in dieser Stadt Valladolid - denn darum hat sie gebeten - habt Ihr nun das Joch und die Pfeile: das Joch als Sinnbild der Arbeit und die Pfeile als Sinnbild der Macht. So, unter diesen Zeichen des Jochs und der Pfeile, sagen wir hier, gerade hier in Valladolid:

„Kastilien, noch einmal für Spanien!“

O. C., a. a. O., S. $29 \mathrm{ff}$.

\section{1}

SPANIEN IST UNWIDERRUFLICH!

\section{Die Schicksalseinheit}

Niemand wird uns Engstirnigkeit gegenüber der katalanischen Frage² vorwerfen können. Vor allen Dingen in den Spalten dieser Wochenzeitung und darüber hinaus von vielen maßgebenden Männern aus unseren Reihen wurde der Überzeugung

\footnotetext{
1 Am Vorstandstisch saßen: José Antonio, Ramiro Ledesma Ramos, Onésimo Redondo Ortega, Ruiz de Alda, Juan Aparicio.

2 Im Frühsommer 1934 flackern in Katalonien, nachdem Lluys Companys Präsident der autonomen katalonischen Generalidad (Regierung) geworden war, wieder größere Unruhen auf, in denen, von Companys unterstützt, die Forderung erhoben wird, die ohnehin politisch nur schwache Verbindung Kataloniens mit der Zentralregierung in Madrid weiter zu lockern. Vgl. Madariaga, $280 \mathrm{ff}$.
} 
Ausdruck gegeben, daß Spanien eine Schicksalseinheit ist. Wir in der Falange verstehen unter Spanien nicht einfach ein physisches Gebilde, nicht einfach eine Ansammlung verschiedener angeborener Attribute (Boden, Sprache, Rasse), die häufig unvereinbar sind mit den angeborenen Attributen der einzelnen Landesteile. Wir von der Falange spotten nicht über die schöne katalanische Sprache, noch beleidigen wir die Gefühlsregungen Kataloniens (die zwar gänzlich irregeleitet, dennoch aber Gefühlsregungen sind), indem wir dahinter ein wirtschaftliches Motiv suchen. Wir meinen, daß nichts von alledem einen Nationalismus zu rechtfertigen vermag, denn eine Nation ist kein physisches Gebilde, dessen Wesen durch rein zufällige äußere Merkmale geographischer, ethnischer oder linguistischer Art geprägt wird, sondern eine geschichtliche Wesenheit, die sich im Weltgeschehen von den anderen unterscheidet, weil sie Schicksalsgemeinschaft ist.

Spanien ist also Schicksalsgemeinschaft; es ist nicht nur der Name irgendeines der Völker, aus denen es sich zusammensetzt. Spanien ist die Nation schlechthin und nicht die Nation irgendeines der Völker, aus denen sie sich zusammensetzt. Als diese Völker sich zusammentaten, fanden sie die geschichtliche Berechtigung ihrer eigenen Existenz im Weltgeschehen. Spanien war Nation als die Gesamtheit aller Komponenten.

\section{Die Unwiderruflichkeit Spaniens}

Der Geist muß schon verseucht sein, wenn Männer, die sich guten Gewissens als Patrioten ausgeben, die Möglichkeit einräumen, daß sich Spanien unter gegebenen Umständen in seine einzelnen Bestandteile auflösen könne. Manche sprechen dem Separatismus die Rechtmäßigkeit ab, weil er nach ihrer Ansicht nicht die Zustimmung der Mehrheit des katalanischen Volkes findet. Andere hingegen behaupten, eine semi-separatistische Situation sei unzulässig; man müsse wählen (wählen!) zwischen der absoluten Solidarität mit Madrid oder der absoluten Unabhängigkeit. "Entweder Brüder oder Fremde" sagt „ABC“ und behauptet auch noch, Hunderte von Telegrammen zu erhalten, in denen man sie zu diesem Ausspruch beglückwünscht. Es ist überaus seltsam (und haarsträubend dazu), daß ein Blatt wie "ABC", in dem noch nie auch nur der geringsten Andeutung antispanischer Haltung Raum gegeben wurde, einer Pflicht zu genügen glaubt, wenn es eine solche Blasphemie veröffentlicht. „Brüder oder Fremde" - mit anderen Worten: es gibt zwei Möglichkeiten: man ist entweder das eine oder das andere. Nein! Das letztere ist auf jeden Fall ungesetzlich, ob Katalonien nun auf die Zölle verzichtet oder nicht und ob nur einige, viele oder alle Katalanen dafür sind. Mehr sogar: und wären alle Spanier darin einig, daß Katalonien ein fremdes Land werden solle, es bliebe ein Verbrechen, das den Zorn des Himmels auf sich ziehen müßte.

Spanien ist unwiderruflich. Entscheiden kann das spanische Volk über sekundäre Angelegenheiten, nicht entscheiden darf es über das eigentliche Wesen Spaniens. Spanien gehört uns nicht als ererbter Besitz; unsere Generation ist nicht unbeschränkter Eigentümer Spaniens. Sie hat Spanien erhalten durch das Bemühen 
unzähliger vorausgegangener Generationen, und ihre Pflicht ist es, Spanien als heiliges Pfand den folgenden Generationen zu übergeben. Wenn unsere Generation. den Augenblick ihres Weges durch die Kontinuität der Jahrhunderte dazu benutzte, Spanien aufzuteilen, so würde sie sich den nachfolgenden Generationen gegenüber des schlimmsten nur denkbaren Frevels, des schändlichsten Verrats schuldig machen.

Nationen sind keine aufkündbaren Verträge; sie sind Stiftungen eigener Art, unabhängig von der Zustimmung vieler oder weniger.

\section{Volljährigkeit}

Von verschiedener Seite ist die Auffassung vertreten worden, eine Region dürfe kein Statut erhalten, solange sie nicht „volljährig" sei. Die Volljährigkeit zeige sich darin, daß die Region sich hinreichend ihrer eigenen Persönlichkeit bewußt geworden sei.

Das ist ebenfalls ein ungeheuerlicher Trugschluß. Entsprechend dieser Theorie muß eine Region ein eigenes Statut erlangen, das heißt, es müssen die Bande der Einheit dann gelockert werden, wenn die Region ein genügend starkes Selbstbewußtsein gewonnen hat. Mit anderen Worten: wenn sie sich von der Persönlichkeit des Ganzen genügend losgelöst fühlt. Es ist kaum möglich, selbst jetzt nicht, sich einen größeren Trugschluß vorzustellen. Und es ist dringend notwendig, einmal zu klären, was „Volljährigkeit" einer Region bedeutet und wann es nicht mehr rechtmäßig ist, einer Region ein eigenes Statut zu verleihen.

Die echte Volljährigkeit zeigt sich nicht darin, daß eine Region ein ausgeprägtes eigenes Persönlichkeitsbewußtsein aufweist. Ganz im Gegenteil. Eine Region ist volljährig, wenn ihr Bewußtsein, innerhalb des gemeinsamen Vaterlandes einer Schicksalsgemeinschaft anzugehören, so stark geworden ist, daß die Einheit auch dann nicht gefährdet ist, wenn sich die Bande der zentralen Verwaltung lockern.

Wenn das Wissen um die Schicksalsgemeinschaft bis zum Grunde der Seele einer Region durchgedrungen ist, ist es nicht mehr gefährlich, der Region ein Statut und damit die Autonomie zu verleihen. Andalusien und Léon dürfen sich in dem Augenblick der Verwaltungsautonomie erfreuen, wenn die Sicherheit gegeben ist, daß nicht hinterrücks versucht wird, die Vorteile des Statuts zum Schaden der untrennbaren Einheit Spaniens auszunutzen. Aber es ist und bleibt ein Verbrechen, den von separatistischen Bestrebungen unterwanderten Regionen ein Statut zuzubilligen, mit dessen Hilfe sich die gegen die Einheit Spaniens arbeitenden Kräfte vervielfachen lassen, und es ist und bleibt auch ein Verbrechen, wenn der Staat auf das Amt verzichtet, unablässig alle separatistischen Tendenzen zu kontrollieren.

\section{Symptome}

Alle Symptome bestätigen unsere Auffassung. Das autonome Katalonien erlebt ein Anwachsen der Separationsbestrebungen. Sie können von niemandem gezügelt werden, erst recht nicht vom Staat, weil er das Wesentliche des katalanischen 
Lebens, nämlich die geistige Bildung der neuen Generationen, die öffentliche Ordnung und das Gerichtswesen aus der Hand gegeben hat. Zu zügeln sind sie auch nicht von der Generalidad, weil diese die Separationsbestrebungen nicht ablehnt, sondern sie ihr sogar sympathisch sind.

So wuchert der Keim der Zerstörung Spaniens, diese unter so großer Mühsal zustande gebrachte Einheit, weiter. Es ist wie bei einem Brand, bei dem man nicht nur haufenweise Brennstoff in den lodernden Schlund wirft, sondern bei dem man dazu noch die Feuerwehr daran hindert, einzugreifen. Was wird in wenigen Jahren aus dem kunstvoll gefügten Bau Spaniens?

Und währenddessen sperrt man uns ein, die wir diese Dinge in ganz Spanien ausschreien, mit lauter Stimme anklagen wollen. Man schließt unsere Büros, man hindert uns daran, Propaganda zu machen ${ }^{1}$. Die Unverschämtheit der Separation aber wächst weiter. Und was tut die Regierung? Sie sucht nach der besten juristischen Formulierung! Die Regierung aber möge bedenken, daß, wenn ihr Spanien zwischen den Fingern zerrinnt, sie sich nicht auf das Argument berufen kann, sie sei lediglich ein wenig nachlässig gewesen. Wenn die Nachlässigkeit gewisse Grenzen erreicht und dadurch Heiliges in Frage gestellt wird, dann nennt man das Verrat. FE Nr. 15, 19. Juli 1934; O. C., a. a. O., S. $649 \mathrm{ff}$.

\section{BRIEF AN GENERAL FRANCO}

José Antonio schreibt diesen Brief an General Francisco Franco während einer großen politischen Streikwelle im September 1934, die sich dann am 5. Oktober 1934 $\mathrm{zu}$ einem allgemeinen Generalstreik verdichtet und am 6. Oktober in einen bewaffneten Aufstand übergeht. An diesem Aufstand beteiligten sich zum erstenmal die Kommunisten; die Erhebung in Madrid wird von Largo Caballero, dem Führer des revolutionären Flügels der Sozialistischen Partei, angeführt. Der Aufstand ist von langer Hand vorbereitet. In Asturien erheben sich 30000 Minenarbeiter; in Barcelona wird am 6. Oktober die katalanische Republik ausgerufen. Die Regierung ist gezwungen, zur Niederschlagung des Aufstandes Militär einzusetzen. Zur Vorbereitung der notwendigen militärischen Aktionen gegen den auch von der Regierung erwarteten Aufstand war General Franco, zu jener Zeit Leiter der Militärakademie in Madrid, ins Kriegsministerium berufen worden. Franco stand als einer der jüngsten Generäle in hohem Ansehen, als Mitbegründer des „Tercio Extranjero", der besten spanischen Truppe, hatte er sich einen Namen gemacht. Unter seinem Kommando wurde der asturische Aufstand dann niedergeschlagen.

Der Brief José Antonios wurde von General Franco nicht beantwortet. Die Falange war in jenen Tagen mit der Vorbereitung ihres ersten Kongresses beschäftigt, auf

1 Es war in das Ermessen der Lokal- oder Regionalbehörden gestellt, politische Demonstrationen zu verbieten, zeitweilig Parteilokale zu schließen oder Versammlungsverbote auszusprechen. So stand die Falange dauernd am Rande der Illegalität. Wegen illegaler Treffen werden im Juni 1934.60 Falangisten verhaftet; in Madrid mußten die Zentren geschlossen werden. In Valladolid wurde, Juni 1934, nach einer Schießerei ein örtliches Verbot über die Falange verhängt. Sie tarnt sich dort fortan als Sportclub. Die Zeitschrift „FE“ wird nach Erscheinen der Nr. 15 endgültig verboten. Bravo, a. a. O., S. 52 f. 
dem dann José Antonio zum unabsetzbaren Führer der Falange gewählt werden sollte. Der Kongreß wurde vom 4. bis zum 7. Oktober nach Madrid einberufen und fiel zeitlich mit dem Oktoberaufstand zusammen. Als er ausbrach, wiederholte José Antonio der Regierung gegenüber den auch in dem Brief an General Franco geäußerten Wunsch, die Falange bei der Niederwerfung des Aufstandes einzusetzen. Das Angebot wurde abgelehnt'.

\section{Sehr geehrter Herr General!}

Madrid, 24. 9. 1934

Vielleicht sind diese Augenblicke, die ich dazu verwende, Ihnen zu schreiben, die letzte uns noch verbleibende Verständigungsmöglichkeit, die letzte mir noch bleibende Gelegenheit, Spanien den Dienst zu erweisen, Ihnen zu schreiben. Ich zaudere daher nicht, sie auch zu nutzen, mag dies nach außen hin noch so anmaßend erscheinen. Ich bin sicher, daß Sie angesichts des Ernstes des Augenblicks den eigentlichen Beweggrund meines Handelns von der ersten Zeile an erkennen, und es Ihnen nicht allzu schwerfallen wird, mir die Freiheit nachzusehen, die ich mir genommen habe.

Dieser Vorsatz kam mir, mehr oder weniger unbestimmt, als ich vor einigen Tagen mit dem Innenminister sprach. Sie wissen ja, was sich da zusammenbraut: keine lautstarke Erhebung auf der Straße, wie sie die "Guardia civil“ mühelos niederzuschlagen pflegt, sondern ein technisch perfekter Staatsstreich trotzkistischer Schule, und wer weiß, ob er nicht von Trotzki selbst geleitet wird (es besteht hinreichender Anlaß dafür, ihn in Spanien zu vermuten ${ }^{2}$ ). Der Waffenschmuggel hat uns zweierlei gebracht: einerseits den Beweis dafür, daß es wirklich Waffenarsenale gibt, andererseits die Tatsache, daß bei den Durchsuchungen eine lächerlich geringe Anzahl Waffen gefunden wurden. Mit anderen Worten: Die Waffenarsenale sind immer noch da. Und sie enthalten hervorragende Waffen, die vielfach sogar besser sind als die des Heeres. Und das in den Händen von geschulten Kräften unter wahrscheinlich sehr geschickter Leitung! Alles dies vor dem Hintergrund absoluter sozialer Zügellosigkeit (Sie kennen ja den wilden Ton der Arbeiterzeitungen), kommunistischer Propaganda in den Kasernen und sogar mitten unter der „Guardia civil" sowie des vollständigen Verzichts des Staates auf jedes ernsthafte und tiefe Autoritätsbewußtsein (man darf Autorität nicht verwechseln mit dem leeren Gerede des Innenministers und seinen niemals bis zum Ende konsequent durchgeführten Polizeiaktionen). Es hat den Anschein, als beabsichtige die Regierung nicht, das Heer bei Ausbruch der Revolution auf die Straße zu schicken. Sie zählt also lediglich auf die "Guardia civil" und die „Guardia de Asalto". Aber so ausgezeichnet diese Truppen auch sein mögen, sie sind bis zur Grenze des Möglichen auseinander-

1 Zur politischen Situation im Oktober 1934: Almargo, a. a. O., S. $116 \mathrm{ff}$; Antonio Ramos Oliveira: La revolución española de octubre, Madrid 1935; Franz Borkenau: Der europäische Kommunismus, München 1952, S. 151; Thomas, a. a. O., S. $75 \mathrm{ff}$. Zur Situation der Falange sowie Literatur: Nellessen S. $85 \mathrm{ff}$.

2 Trotzki befand sich weder zur Vorbereitung des Oktoberaufstandes noch bei Ausbruch des Bürgerkrieges in Spanien. 
gezogen, denn sie müssen ja die gesamte Fläche Spaniens sichern. Und da man auf die eigene Initiative verzichtet hat, sieht man sich in der unvorteilhaften Lage, abwarten zu müssen, bis der Feind seine Angriffspunkte wählt. Ist es etwa übertrieben anzunehmen, daß an bestimmten Stellen die Angreifer den ordnungswahrenden Kräften zahlen- und ausstattungsmäßig überlegen sein könnten? Meiner Ansicht nach ist dies von der Wahrheit nicht allzu weit entfernt. Und in der Überzeugung, damit nur meiner Pflicht Genüge zu tun, ging ich zum Innenminister und bot ihm die Truppen unserer Bewegung für den Fall an, daß er sie, wenn Not am Mann wäre, mit Waffen ausstatte (ich gab natürlich mein Ehrenwort, diese Waffen bei erster Gelegenheit zurückzugeben) und sie als Hilfstruppen einzusetzen. Ich weiß nicht, ob meine Worte ihn überhaupt zum Nachdenken veranlaßten. Fr war so optimistisch wie immer; seine Zuversicht gründete aber nicht auf dem gewissenhaften Abwägen des Kräfteverhältnisses und auf der Überzeugung, seine Truppen seien denen der Gegenseite überlegen. Sie war naiv. Glauben Sie mir: als ich ihm meine Ansichten über die vorstehende Gefahr, die ich auch Ihnen mitgeteilt habe, und noch einiges mehr darlegte, machte er ein so erstauntes Gesicht, als hätte er an diese Dinge zum erstenmal gedacht.

Nach Beendigung dieser Unterredung war ich nach wie vor entschlossen, mit dem Gewehr zur Verteidigung Spaniens auf die Straße zu gehen. Doch mir schien es schon sicher, daß wir, die wir auf die Straße gehen würden, trotz aller Würde eine Niederlage nicht vermeiden könnten. Denen gegenüber, die - wahrscheinlich sehr genau kalkulierend und sehr geschickt agierend - den spanischen Staat angreifen, kann sich dieser Staat trotz der Hilfe einiger weniger begeisterter Anhänger nicht behaupten.

Kann man einen Sieg der Sozialisten als einen einfachen Szenenwechsel in der Innenpolitik betrachten? Nur bei oberflächlicher Betrachtung läßt sich diese Frage mit Ja beantworten. Ein Sieg der Sozialisten kommt einer Invasion des Auslandes gleich, nicht nur, weil das Wesen des Sozialismus ganz und gar dem ewigen Geist Spaniens widerspricht, nicht nur, weil im sozialistischen Regime das Vaterland mit Füßen getreten wird, sondern weil - und das ist ein ganz konkreter Grund - der Sozialismus seine Anweisungen von einer Internationalen erhält. Jede vom Sozialismus eroberte Nation wird zur Kolonie oder zum Protektorat herabgewürdigt.

Außerdem droht die Gefahr, daß sich ein internationaler Konflikt entwickeln kann. Die sozialistische Erhebung wird nämlich die - wahrscheinlich endgültige Lostrennung Kataloniens von Spanien mit sich bringen. Der spanische Staat hat nahezu sämtliche Verteidigungsmittel der Generalidad übergeben und ihr freie Hand gelassen, den Angriff vorzubereiten. Die Verbindung zwischen dem Sozialismus und der Generalidad ist ein offenes Geheimnis ${ }^{1}$. So braucht sich in Katalonien die Revolution der Macht nicht einmal zu bemächtigen. Sie hat sie bereits. Und in erster Linie gedenkt sie davon Gebrauch zu machen, um die Unabhängigkeit

1 Lluys Companys, der Präsident der Generalidad, gehörte der katalanischen "Esquerra“, der "Linken", an; er rief am 6. Oktober die katalanische Republik aus. Thomas, a. a. O., S. 74,81 . 
Kataloniens zu proklamieren. Unwiderruflich, wie ich noch darlegen werde. Es ist mir klar, daß der spanische Staat, wenn er nicht gerade eine vollständige Niederlage erleidet, das katalanische Gebiet mit Gewalt zurückgewinnen könnte. Aber jetzt kommt das Großartige: es steht fest, daß die Generalidad sich in weiser Voraussicht wohl kaum auf den Plan der Revolution eingelassen haben dürfte, ohne vorher mit anderen Ländern Fühlung genommen zu haben. Thre Beziehungen zu einem gewissen benachbarten Staat sind bekannt ${ }^{1}$. Nun denn, wenn die unabhängige Republik Katalonien proklamiert wird, ist es keineswegs unwahrscheinlich (ganz im Gegenteil), daß die neue Republik von einer fremden Macht anerkannt wird. Und wie will man sie dann noch zurückgewinnen? Ein Einmarsch in Katalonien würde von Europa bereits als Aggression gegen ein Land aufgefaßt, das sich in einem Akt der Selbstbestimmung unabhängig erklärt hat. Spanien hätte in diesem Fall nicht nur Katalonien, sondern alle antispanischen Kräfte der europäischen Mächte gegen sich.

Alle diese düsteren Möglichkeiten, die normale Konsequenz eines chaotischen Augenblicks, eines deprimierenden und absurden Augenblicks, in dem Spanien jede Vorstellung von seiner geschichtlichen Bestimmung und jede noch mögliche Hoffnung, sie zu erfüllen, verloren hat, haben mich dazu bewogen, das Schweigen Thnen gegenüber durch diesen Brief zu brechen. Sicherlich haben Sie Überlegungen darüber angestellt, ob die augenblicklichen Gefahren noch innerpolitischer Art sind, oder ob sie schon als Bedrohung von außen aufgefaßt werden müssen, da sie das Fortbestehen Spaniens als Einheit in Frage stellen.

Ich teile Thnen diese Gedanken mit, weil sie Ihnen vielleicht bei Thren Überlegungen von Wert sein können. Ich habe eigene Vorstellungen darüber, was Spanien braucht. Und ich hoffte auf einen evolutionären Reifeprozeß. Jetzt aber, angesichts des Unvermeidlichen, glaube ich mit der Übermittlung dieser Zeilen eine Pflicht zu erfüllen. Gebe Gott, daß wir alle im Dienst an Spanien das Richtige tun.

Ich grüße Sie sehr herzlich.

José Antonio Primo de Rivera. O. C., a. a. O., S. $709 \mathrm{ff}$.

Auf dem ersten Nationalkongreß, den die Falange während des Oktober-Aufstandes vom 4. bis 7. Oktober 1934 in Madrid veranstaltete, gab sie sich ihre organisatorische Form. José Antonio wurde mit einer Stimme Mehrheit zum unabsetzbaren Führer gewählt, dem alle zu absolutem Gehorsam verpflichtet sind. Mit ausge-

1 Gemeint ist Frankreich, wo die katalanischen Anarchisten und Sozialisten einen starken Rückhalt hatten. Jedoch gibt es keinen Hinweis darauf, daß die Generalidad Kataloniens die Ausrufung der katalanischen Republik bereits durch Kontakte mit der Regierung Gaston Doumergue abgesichert hatte. Schon der Verlauf des Aufstandes in Katalonien widerspricht dieser Vermutung. Thomas, a. a. O., S. $75 \mathrm{f}$. 
strecktem Arm mußte ihm Treue geschworen werden. Die Frage der Uniform wurde entschieden. Anstelle des geforderten Schwarzhemdes befahl José Antonio die "strenge", proletarische blaue Hemdfarbe ${ }^{1}$. Außerdem ernannte José Antonio den politischen Ausschuß der Partei; ihm wurde der Auftrag gegeben, die programmatischen Grundlagen der Bewegung auszuarbeiten. Unter dem bestimmenden Einfluß von José Antonio wird dann im November 1934 das 27 Punkte umfassende Parteiprogramm verkündet ${ }^{2}$. Doch die nach außen so stark betonte Geschlossenheit wie der so viel geschworene Gehorsam erweisen sich nicht stark genug, die Gegensätze innerhalb der Falange ausgleichen zu können. Seit José Antonio an der Spitze der Partei steht, unterliegt die Falange einer inneren Zerreißprobe. Sie gesellt sich zur ständigen gewalttätigen Auseinandersetzung mit den Gruppen der politischen Linken.

Das Mißtrauen eines Teiles der mit der Falange vereinten ehemaligen J.O.N.S. gegen den Adligen und Intellektuellen und seinen Freundeskreis verschwindet nicht. Andererseits behagt einigen Freunden José Antonios weder sein radikales Programm noch die Nähe zu den radikalen, meist aus Arbeiterfamilien stammenden Mitgliedern der alten J.O.N.S. Die Folge ist, daß die als politische Potenz ohnehin noch nicht zählende Falange im Winter 1934/35 sowohl auf ihrem rechten wie auf ihrem linken Flügel zahlreiche Austritte zu verzeichnen hat. Es kommt im Januar 1935 zur Rebellion gegen José Antonio unter der Führung Ledesma Ramos; er scheidet mit einer Schar von Anhängern aus der Falange aus. Die Mehrheit bleibt jedoch bei José Antonio. Dessen Führungsposition wird dadurch gefestigt. Fortan wird sie in der Partei nicht mehr in Frage gestellt. Vor diesem Hintergrund muß die Rede gesehen werden, die José Antonio am 3. März 1935, am Vortag des vor einem Jahr erfolgten Zusammenschlusses von J.O.N.S. und Falange im Calderon-Theater zu Valladolid, vor seinen Anhängern hielt.

Morgen wird es ein Jahr her sein, daß sich in diesem Theater die spanische Falange der nationalsyndikalistischen Angriffsgruppen Spanien vorstellte. Vor einem Jahr fand die Verschmelzung des aus den J.O.N.S. und der Falange bestehenden Kerns statt. Beide zusammen bilden von jenem Zeitpunkt an unwiderruflich die Falange der nationalsyndikalistischen Angriffsgruppen. Jene Tat war die erste ihrer Propaganda und endete mit der Heftigkeit aller kraftvollen Handlungen, mit Schüssen. Der Beginn mit Schüssen ist fast stets die beste Art, zu gegenseitigem Verständnis zu gelangen. In diesem Jahr sind wir sehr viel weitergekommen. Wir müssen danach streben, uns in einem gewissen Reifezustand vorzustellen. 1934 war er vielleicht noch unausdenkbar. Nach Ablauf eines Jahres muß unsere Bewegung ihr geistiges Profil gefunden haben. Beim Gedanken an uns glaubten manche, auf der Straße den Stoßtrupp einer Bewegung zu sehen, die später einmal von besonnenen Männern in ruhigere Bahnen gelenkt würde. Den Gedanken haben sie aber bald wieder aufgegeben, und wir fühlen uns - das sei hier in aller Deutlichkeit

1 „Der italienische Faschismus gab sich als Uniform das Schwarzhemd. Als José Antonio die Falange gründete, schuf er eine politische Bewegung, welche die universalen Werte des Faschismus aufnahm, um sie für die spanische Nation anzuwenden . . . Auch die Uniform der Falange ist ein Hemd." Pemartín., a. a. O., S. 42.

2 Siehe S. 113 ff. Von der Veröffentlichung des Programms nimmt die spanische Presse keine Notiz. Als es erlassen wird, besitzt die Falange kein eigenes Presseorgan. Nellessen, a. a. O., S. 90, Anm. 1. 
gesagt - keineswegs als bloßer Vortrupp, sondern als die eigentliche Streitmacht einer Neuen Ordnung, die es in Spanien einzuführen gilt. Jawohl, die es in Spanien einzuführen gilt, sage ich, und dem füge ich noch hinzu - ehrgeizig wie Spanien selbst -: Wir sind die Streitmacht einer Neuen Ordnung, die Europa und der Welt gerade von Spanien geschenkt werden soll.

Die Zeitalter kann man einteilen in klassische Perioden und in Zeiten des Übergangs. Die ersteren erkennt man daran, daß sie die Einheit anstreben, letztere haben diese Einheit bereits gefunden. Die klassischen, in sich geschlossenen Zeitalter gehen einzig und allein durch Auszehrung, durch eine Katastrophe, durch Einfälle der Barbaren zugrunde. Ein gutes Beispiel dafür ist Rom. Seine Übergangszeit, seine Wachstumsperiode reicht von Canne bis Actium, seine klassische Zeit von Actium bis zum Tode Marc Aurels; die Zeit seines Niedergangs von Commodus bis zum Einfall der Barbaren. Als in Rom die beiden zersetzenden Kräfte, die den Untergang der Stadt herbeiführen sollten, zu wirken begannen, da war Rom in sich geschlossen, da war Rom die Einheit des Erdkreises; es blieb ihm nichts mehr zu tun übrig. Alles Äußere war verwirklicht, und Rom durchpulste kein inneres Leben mehr. Seine Religion beschränkte sich auf die Wahrung festgelegter Riten, seine Ethik war die eines Volkes unter Waffen, wie geschaffen für die Zeit des Aufbaues, nutz- und sinnlos jedoch, als der Bau einmal fertig war. Aus diesem Grunde mußte das ermüdete Rom seine Zuflucht zu zwei Bewegungen der Umkehr zum inneren Leben nehmen: zum Stoizismus des Seneca, die noch eine vernunftbetonte, jeden Gefühlsüberschwang unterdrückende Haltung ist, zweitens zum Christentum, das die völlige Verneinung der römischen Lebensgrundsätze darstellte, war es doch die Religion der Niedrigen und Verfolgten, die dem Cäsar seine Göttlichkeit und seine priesterliche Würde absprachen. Das Christentum untergrub schon die Grundmauern des erschütterten Roms, doch um es völlig verschwinden zu lassen, bedurfte es noch der Katastrophe, des Einfalls der Barbaren.

Nunmehr stehen wir gerade am Ende eines Zeitalters, das auf die klassische Zeit Roms folgte. Nach der Zerstörung Roms entsteht gleichsam geschichtliches Brachland. Alsbald wagen sich neue Kultursprößlinge hervor. Die Einheit streckt ihre Wurzeln immer weiter in Europa aus. Und es kommt das dreizehnte Jahrhundert, das Jahrhundert des Thomas von Aquin. In dieser Zeit ist das Denken aller auf die metaphysische Einheit, auf die Einheit in Gott gerichtet. Besitzt man die absoluten Wahrheiten, so hat man die Antwort auf alle Fragen, und das gesamte Weltgeschehen, in diesem Falle die Geschichte Europas, verläuft nach der vollkommensten Ordnung aller Zeiten. Die Universitäten von Paris und Salamanca stellen die gleichen Überlegungen über die gleichen Fragen in demselben Latein an. Die Welt hat sich selbst gefunden. Bald wird das spanische Imperium entstehen, das die geschichtliche, physische, geistige und theologische Einheit darstellt.

Um das dritte Jahrzehnt des 18. Jahrhunderts nehmen die Angst und die Unruhe ihren Anfang: die Gesellschaft glaubt nicht mehr an sich, ebensowenig glaubt sie mit der alten Kraft an irgendein höheres Prinzip. Dieser Glaubensmangel im Gegen- 
satz zur Glaubensfestigkeit einer einst vollkommenen Gesellschaft treibt die schwächlichen Geister in die Flucht, zur Rückkehr zur Natur.

Jean Jacques Rousseau stellt diese Verneinung dar, und weil er den Glauben an absolute Wahrheiten verliert, schreibt er seinen "Contrat social“, in dem er die These aufstellt, alles Geschehen müsse nicht nach den Gesetzen der Vernunft, sondern nach den Gesetzen des Wollens ablaufen. Es kommen die Volkswirtschaftler und beginnen, die Geschichte mit Hilfe der Begriffe: Ware, Preis und Tausch zu deuten. Die Großindustrie entsteht, und mit ihr beginnt die Umformung des Handwerkerstandes zum Proletariat. Es kommt der Demagoge, der eine zur Verzweiflung getriebene proletarische Masse vorfindet, und was man für unbegrenzten Fortschritt gehalten hatte, führt zum Weltkrieg von 1914, zum Selbstmordversuch Europas.

Das Europa des Heiligen Thomas wurde durch ein allen gemeinsames Denken bestimmt; das Europa von 1914 tritt mit der Behauptung auf, daß es nicht eins sein will. Das Ergebnis des europäischen Krieges sind Scharen von unzähligen Arbeitslosen. Nach jener Katastrophe werden die Fabriken stillgelegt, sie werden zu ungeheuren Ansammlungen von Arbeitslosen; die Industrie sieht jegliche Wirtschaftsordnung umgestoßen, zwischen den einzelnen Unternehmen tobt der Konkurrenzkampf; und es werden Zollschranken errichtet. Was steht Europa in dieser Situation bevor, in der zudem noch jeder Glaube an ewige Prinzipien verlorengegangen ist? Bevor steht zweifellos ein neuer Einfall der Barbaren.

Es gibt nun zwei Auffassungen: Die eine betrachtet den Zusammenbruch, den Einfall der Barbaren, als unvermeidlich und sieht das Gute als hinfällig und verloren an; sie vertraut nur darauf, daß nach der Katastrophe eine neue Übergangszeit anbrechen wird. Daneben steht unsere Auffassung. Wir trachten danach, eine Brücke über den Einfall der Barbaren zu schlagen. Wir wollen, ohne daß es zum völligen Zusammenbruch kommt, alles übernehmen, was das Neue Zeitalter an Fruchtbarem besitzt, dabei aber alle geistigen und kulturellen Werte der Zeit, in der wir leben, mit hinüberretten.

Dies ist unsere Aufgabe gegenüber dem russischen Kommunismus, er bedeutet für uns den drohenden Einfall der Barbaren. Der Kommunismus hat durchaus etwas, das wir übernehmen können, nämlich seine Selbstlosigkeit, sein Solidaritätsgefühl. Doch ist der Kommunismus, dieser Einfall der Barbaren, maßlos; er verwirft alles, was einen geistigen oder geschichtlichen Wert darstellen könnte. Er ist das Anti-Vaterland, und es fehlt ihm der Glaube an Gott. Hier setzt unser Bemühen ein, die absoluten Wahrheiten, die geschichtlichen Werte zu retten, sie nicht verlorengehen zu lassen.

Wie ist das möglich? Die Antwort auf diese Frage wollen wir hier finden, hier, in Kastilien und Spanien.

Eine der angeblichen Lösungen ist die Sozialdemokratie. Die Sozialdemokratie behält den Kapitalismus im wesentlichen bei, bemüht sich aber, Sand ins Getriebe zu streuen. Das ist eine reine Torheit.

Eine andere angebliche Lösung sind die totalitären Staaten. Aber totalitäre 
Staaten gibt es nicht. Einige Nationen haben zwar geniale Diktatoren gefunden, fähig, den Staat zu ersetzen, doch dies läßt sich nicht nachahmen, und in Spanien jedenfalls im heutigen Spanien - ist ein solches Genie leider noch nicht vorhanden. Beispiele für den sogenannten totalitären Staat sind Deutschland und Italien. Doch dabei ist zu bedenken, daß diese beiden nicht nur nicht ähnlich, sondern sogar von Grund auf verschieden sind; sie sind entgegengesetzter Art. Der deutsche totalitäre Staat wurzelt in der Glaubenskraft des Volkes an seinem Rasseninstinkt. Vor Begeisterung fiebernd gibt sich das deutsche Volk seiner eigenen Wesensart hin; Deutschland lebt in einer Super-Demokratie. Rom hingegen ist in der glücklichen Lage, einen Genius von klassischem Geist zu besitzen, der ein Volk von oben her gestalten will. Die deutsche Bewegung ist romantischer Natur, ihre Richtung ist stets die gleiche. Von Deutschland ging die Reformation aus, ja sogar die französische Revolution, denn die Erklärung der Menschenrechte ist ein getreues Abbild der Verfassungen der Vereinigten Staaten, die ihrerseits ein geistiger Ableger des deutschen protestantischen Denkens sind.

Weder die Sozialdemokratie noch der Versuch, ohne ein Genie einen totalitären Staat $\mathrm{zu}$ errichten, würden ausreichen, um die Katastrophe abzuwenden. Es gibt auch noch eine andere Art von Heilmitteln, an denen ist Spanien reich. Ich meine die Vereinigungen, die Blocks, die Bündnisse. Sie alle gehen von der Annahme aus, der Zusammenschluß mehrerer Zwerge könnte einen Riesen ergeben. Diesen Arten von Heilmitteln gegenüber ist äußerste Vorsicht geboten. Wir dürfen uns nicht durch Worte blenden lassen. So gibt es Bewegungen, in deren Programm zwar als erster Punkt die Religion angegeben wird, deren Haltung aber erst dann entschieden wird, wenn ein materieller Vorteil herausspringt. Als Tausch für eine Mäßigung bei der Agrar-Reform oder für eine winzige Beschneidung der Kirchenpfründe verzichten sie etwa auf das Kreuz in der Schule und auf die Abschaffung der Ehescheidung.

Andere Bewegungen nennen sich zum Beispiel korporativ. Das ist nichts als eine Floskel; man braucht nur den ersten besten, der davon redet, zu fragen: „Was verstehen Sie unter Korporativismus? Wie funktioniert er? Welche Lösungen bietet er denn für internationale Probleme?" Bis jetzt ist der beste Versuch in Italien unternommen worden, und dort ist es nur eine Zugabe zu einer vollkommenen politischen Maschinerie. Um Reibungen zwischen Arbeitnehmern und Arbeitgebern zu mindern, gibt es dort so etwas wie unsere gemischten Schiedsgerichte, nur weitaus größer, nämlich einen Verband der Arbeitgeber und einen solchen der Arbeitnehmer, und darüber ein Verbindungsstück. Heutzutage gibt es weder einen korporativen Staat, noch weiß man, ob er gut ist. Das Korporationsgesetz in Italien ist, wie Mussolini selbst gesagt hat, ein Ausgangspunkt und nicht etwa ein Endziel, wie es unsere Politiker vielfach vom korporativen System behaupten.

Wenn die Welt aus den Fugen geht, lassen sich die Risse nicht mit künstlichen Mitteln kitten; es bedarf dann vielmehr einer völlig neuen Ordnung. Und diese Ordnung $m u ß$ wieder vom Individuum ausgehen. Die uns vorwerfen, wir huldigten einer Staatsvergottung, sollten sich dies merken: wir betrachten das Individuum 
als die Grundeinheit, denn so empfindet Spanien; es betrachtet stets den Menschen als Träger ewiger Werte. Der Mensch muß frei sein; Freiheit ist jedoch nur innerhalb einer Ordnung möglich.

Der Liberalismus sagte dem Menschen, er könne tun und lassen, was er wolle, doch er gab ihm keine wirtschaftliche Ordnung, die ihm diese Freiheit garantiert hätte. Eine organisierte wirtschaftliche Garantie ist also nötig; angesichts des augenblicklichen Chaos ist aber eine organisierte Wirtschaft ohne einen starken Staat ein Ding der Unmöglichkeit, und stark - ohne deshalb zur Tyrannei zu werden kann nur der Staat sein, der einer Schicksalsgemeinschaft dient. Der starke Staat, der Diener des Bewußtseins der Einheit, ist also der eigentliche Garant für die Freiheit des Individuums. Der Staat hingegen, der sich nicht als Diener einer übergeordneten höchsten Einheit fühlt, fürchtet ständig den Vorwurf des Machtmißbrauchs. Das ist auch der Fall bei unserem spanischen Staat: was seinen Arm, der nach einer blutigen Revolution strafende Gerechtigkeit üben will, zurückhält, ist nichts als das Wissen um das Fehlen einer inneren Berechtigung, das Fehlen einer echten Aufgabe, in deren Dienst er sich stellen kann.

Spanien kann einen starken Staat besitzen, denn Spanien ist eine Schicksalsgemeinschaft im Weltgeschehen. Und der spanische Staat kann sich auf die Ausübung seiner wesentlichen Machtfunktionen beschränken. Die Schiedsrichterfunktion und sogar die vollständige Regelung großer Teile der Wirtschaft kann er Einrichtungen überlassen, die auf eine ehrwürdige Tradition zurückblicken können. Die Syndikate dürfen nicht mehr, wie es beim augenblicklichen Gesetzentwurf zur Regelung der Arbeitsfragen der Fall ist, eine parasitäre Fassade bilden, sie werden vielmehr zu geschlossenen, vertikalen Einheiten, denen alle angehören, die in dem jeweiligen Produktionszweig wirtschaftlich tätig sind ${ }^{1}$.

Der neue Staat wird, immer das Ziel der Einheit vor Augen, den spanischen Boden neu verteilen müssen ${ }^{2}$. Nicht ganz Spanien ist bewohnbar; viele Gebiete, die nur dazu dienen, das Elend derer, die sie bebauen, zu verewigen, müssen zur Steppe und besonders zum Wald gerechnet werden. Deshalb müssen große Menschenmassen auf anbaufähigen Boden umgesiedelt werden, und dieser Boden muß Objekt einer gründlichen Wirtschaftsreform und einer gründlichen sozialen Agrarreform werden. Steigerung der Produktivität, Rationalisierung der Landwirtschaft, Bewässerung, fachliche Schulung auf den Gebieten des Ackerbaus und der Viehzucht, lohnende Preise, Schutzzölle für die Landwirtschaft, billige Kredite einerseits und andererseits vererbbarer Familienbesitz sowie auch Anbau nach dem Syndikatsprinzip - das wird die wahre Rückkehr zur Natur sein, nicht im Sinne der Vergil-

1 Punlst 9 des Programms der Falange spricht von einem System vertikaler Syndikate, geordnet nach Produktionszweigen. Mit dieser Forderung ging die Falange über das faschistische Vorbild hinaus, indem sie nicht mehr Arbeitgeber und -nehmer getrennt lie $\beta$, sondern sie gleich innerhalb desselben Produktionszweiges zusammenfassen wollte, s. S. 115.

2 José Antonio bezieht sich in den folgenden Partien seiner Rede auf Punkt 17-22 des Falange-Programms. Diese Punkte enthalten die Einzelforderungen der Falange zu den Fragen von Kapital, Grund und Boden, s. S. 116 f. 
schen Eklogen wie es auch Rousseau auffaßte, sondern im Sinne der Georgica ${ }^{1}$, in der der Boden tiefernst und ehrfurchtgebietend verstanden wird.

Nach demselben Prinzip der Einheit, nach dem der Boden neu geordnet wird, muß auch die gesamte Wirtschaft neu geordnet werden. Was heißt das: den Gegensatz zwischen Kapital und Arbeit aufheben? Die Arbeit ist eine Funktion des Menschen, wie das Eigentum ein Attribut des Menschen ist. Aber Eigentum ist nicht gleichbedeutend mit Kapital; das Kapital ist ein wirtschaftliches Mittel, und als solches muß es im Dienst der Gesamtwirtschaft stehen, darf es nicht für das persönliche Wohlergehen eines einzelnen benutzt werden. Für die riesigen Kapitalanhäufungen gilt das gleiche wie für die Stauseen: Die Stauseen wurden nicht gemacht, damit nur wenige darauf ihre Regatten veranstalten können, sie wurden gemacht, um den Lauf der Flüsse zu regeln, um die Turbinen der Wasserkraftwerke anzutreiben.

Um alle diese Reformen durchführen zu können, müssen wir natürlich unzählige Hindernisse überwinden. Egoismus jeglicher Art wird sich uns in den Weg stellen. Wir müssen uns daher immer von dem Bewußtsein leiten lassen, daß es sich nicht um die Rettung materieller Güter handelt. Das Eigentum, so, wie es bisher verstanden wurde, nähert sich einem Ende; es wird beseitigt werden mit oder gegen seinen Willen, und zwar von Menschenmassen, die zu einem großen Teil durchaus im Recht sind und überdies auch die Kraft dazu besitzen. Das Materielle vermag niemand zu retten. Wichtig ist allein, daß das Materielle in seinem Sturz nicht auch wesentliche geistige Werte mit sich reißt. Und die sind es gerade, die wir retten wollen, koste es, was es wolle, und sollten wir dafür auch alle wirtschaftlichen Vorteile opfern müssen. Das wird mehr als wettgemacht durch den Ruhm, daß Spanien, unser Spanien, den endgültigen Einfall der Barbaren aufhält.

O. C., a. a. O., S. $41 \mathrm{ff}$.

14

WORTE AN DIE GEFALLENEN

Bis zum Frühsommer 1935 beläuft sich die Zahl der Falangisten, die bei Auseinandersetzungen mit politischen Gegnern aus dem sozialistischen oder anarchosyndikalistischen Lager getötet wurden, bereits auf 192. Die Falange sucht - sie als „Dienst für das Vaterland“, als „Akt des Dienens“ interpretierend - die gewalttätige Auseinandersetzung ebenso wie sie von ihren meist jugendlichen Gegnern gesucht wird. Sie besteht meist im Angriff auf Partei- oder Gewerkschaftslokale, in Straßenschlägereien, in der Störung von Filmveranstaltungen oder politischen Zusammenkünften. Einige Falangisten kommen auch beim Straßenverkauf falangistischer Flugblätter und Zeitungen ums Leben. Der Sinn, den die Falange ihren direkten Aktionen wie auch dem Tod ihrer Mitglieder unterlegt, verdeutlicht sich in den nachfolgend veröffentlichten Ansprachen, die José Antonio am Grabe getöteter Falangisten hielt.

1 José Antonio meint den Unterschied zwischen der dichterischen Verherrlichung des Landlebens durch Vergil in den Eklogen und der strengen Georgica als reinem Lehrgedicht.

2 Bravo, a. a. O., S. 96. 
Bei der Beerdigung des Falangisten Angel Montesimos Carbonell, am 10. 3. 1934

Stillgestanden! Wieder einer! Auch dieser war ein einfacher Mensch. Diejenigen, die uns für unfähig halten, den Schmerz der Armen zu verstehen, sollen wissen, daß die Falange von heute an nicht nur durch ihren entschlossenen Willen, sondern auch durch das heroische Todesopfer der einfachen Menschen unauflöslich vereinigt ist.

Der Tod! Einige werden glauben, daß wir ihn benötigen als Ansporn, andere, daß er uns niederdrücken wird. Aber weder das eine noch das andere stimmt. Der Tod ist ein Akt des Dienstes. Wenn einer von uns fällt, gebt ihm, wie diesem hier, ein Stück geweihter Erde und sagt ihm: Bruder, für Deine Seele den Frieden, wir aber: Vorwärts für Spanien.

„Stillgestanden! Angel Montesimos!“

Alle antworten: „Gegenwärtig!“

O. C., a. a. O., S. 261.

Beim Begräbnis des Falangisten Matias Montero, am 10. 2. 1934

Hier liegt jetzt einer unserer besten Kameraden bestattet. Er gab uns durch sein Schweigen ein großartiges Beispiel. Andere haben es leicht, uns aus der Sicherheit ihrer Häuser heraus zu raten, mutiger, kämpferischer, härter zu sein in unseren Vergeltungsschlägen. Doch Matias Montero gab keine Ratschläge und schwieg. Er begnügte sich damit, auf die Straße zu gehen und seine Pflicht zu erfüllen, obwohl er wußte, daß auf der Straße wahrscheinlich der Tod auf ihn lauert. Er wußte es, weil man ihm den Tod angedroht hatte. Kurz bevor er starb, sagte er: Ich weiß, ich bin vom Tod bedroht, aber es kümmert mich nicht, wenn es zum Wohle Spaniens geschieht. Es dauerte nicht lange, da traf ihn eine Kugel mitten ins Herz, das seine Liebe zu Spanien und zur Falange geläutert hatte. Kamerad Matias Montero Rodriguez! Dank für Dein Beispiel!

Gott möge Dir ewige Ruhe schenken, sie uns aber verweigern, bis wir die Ernte Spaniens eingefahren haben, die Dein Tod säte.

Zum letzten Male: Matias Montero Rodriguez!

Alle antworten: „Gegenwärtig! “

"Hoch lebe Spanien!"

Alle antworten: „Hoch!“

O. C., a. a. O., S. 259.

Am Grabe des Falangisten José Garcia Vara (April 1935)

Noch ein ruhmreich Gefallener! Noch ein Märtyrer, der wie selbstverständlich alles auf dem Altar des unsterblichen Spaniens darbot: Sein Leben und sein Blut!

Ein Gefallener mehr in dem Himmel der Liebe. Er erfüllte eine heilige Mission in der spanischen Falange der nationalsyndikalistischen Angriffstruppen. Die Kugel der Marxisten machte seinem Leben ein Ende, bevor er die Schwelle des wiedergeborenen Vaterlandes überschreiten konnte. 
Ihn, der für die Liebe kämpfte, mordete der Haß. Kamerad! Dein Opfer wird nicht vergeblich sein. Wir alle, die wir Dich jetzt noch vor Deinem Grab mit ausgestrecktem Arm grüßen können, wollen Deinem großartigen Beispiel folgen. Wir alle sind wie Du dazu bereit, das höchste Opfer darzubringen, um unsere Mission zu erfüllen. Mission im reinen, im religiösen Sinn des Wortes! Spanien ist ja kein Territorium, ist kein Phantasiegebilde im Fieberwahn; es ist eine unantastbare, höchste Wirklichkeit. Sie zeigt sich in der Kraft unserer Brüder, in den ruhmreichen Heldentaten unserer Väter, im starken Blutstrom unserer Ahnen. Sie ist heute vom Tod bedroht, feige ist sie preisgegeben. Wir Nationalsyndikalisten sind berufen, ihr zu Hilfe zu eilen, sie zu stützen, zu helfen, damit sie wieder werde.

Gesegnet sei die Falange, wenn sie uns dazu führt, für Spanien zu sterben! Uns sei immer gegenwärtig, daß Spanien eine Schicksalsgemeinschaft der Kommenden ist. Wir wollen, frank und frei, das Gesicht der Sonne zugewandt und mit dem Stolz der Spanier beweisen, daß wir zwar jung an Jahren, aber dennoch Männer sind, bereit, für Spanien zu sterben und zu leben, für Spanien eine heilige Pflicht zu erfüllen.

Wir sind jung. Zu oft ist uns mit emphatischer Arroganz nachgesagt worden, wir kämpften so, weil wir nichts zu verlieren hätten. Nichts? Diejenigen, die so etwas sagen, fühlen es nicht; sie können es nicht fühlen. Sie wissen nur zu gut - denn auch sie waren einmal jung -, daß eine Zukunft, die noch zu gestalten ist, mehr gilt als eine schon festgelegte: etwas schaffen zu wollen, gilt mehr, als Vorhandenes zu übernehmen!

Ich rate Euch: Verschließt Eure Ohren vor diesem Volk. Jetzt beklagt es den Tod unseres Kameraden, und vielleicht wird es Euch auch raten, die Vergeltungsschläge bis zum Äußersten zu treiben. Ich bitte Euch, zeigt ihnen durch Eure Haltung, daß wir alles zu ertragen bereit sind, daß der unternehmende Geist aus dem Blut unserer Brüder auf uns überströmt - Blut, das den Boden Spaniens für eine künftige Ernte düngt -, und daß dieser Geist uns unerschütterlich unseren Weg verfolgen läßt.

Vielleicht auch sagen sie in unerträglicher Arroganz, daß Ihr nicht in unseren Reihen bleiben, daß Ihr dem Rat folgen sollt, „menschlich" zu sein und mit diesen Verrücktheiten aufzuhören. Erwidert ihnen, daß Menschen weder an ihrer Erscheinung noch an ihren Worten zu messen sind, sondern daß man sie mißt und erkennt an ihren Taten, an ihren Handlungen auf diesem unserem Boden! Wenn es denn wahr ist, daß wir verrückt sind - nun denn: Gesegnet sei diese verrückte Liebe, die uns dem Vaterland das Kostbarste darbringen läßt, was es uns gab: Unser Blut!

Zeigt ihnen klar und unmißverständlich, wie die unmittelbar Verantwortlichen für den Mord an unseren Kameraden beschaffen sind: Egoistisch, unfähig und feige. Sagt ihnen, daß die Frage von Leben und Tod Spaniens nicht mehr mit Worten zu erledigen ist. Während jene in den Häusern oder in den Cafés über Spanien theoretisieren, stehen wir auf den Straßen unseres Spaniens. Sie sind geheiligt für immer durch das Blut ihrer Söhne, die dort grausam und feige gemeuchelt 
wurden, nur weil sie das Verbrechen begingen, ein Herz zu haben, ein übervolles Herz, das jenen anderen fehlt. Wir alle, vom ersten bis zum letzten, ziehen es vor, eher zu sterben als jenen dreckigen Lästerern in Schimpf und Schande zu folgen.

Noch einmal müssen wir unserem gefallenen Kameraden die Ehre erweisen. Niederträchtig, feige, grundschlecht ist derjenige, der sich jetzt aus der ersten Reihe zurückzieht. Er ist unwürdig, in dieser edelsten Bruderschaft der Falange noch Todeskamerad genannt zu werden.

Noch einmal, Falangisten: Stillgestanden! Alle in den Sturm- und Stoßtrupps, jetzt erst recht und wie stets! Spanien hat einen Märtyrer mehr. José García Vara: Gegenwärtig. Hoch lebe Spanien!

$$
\text { „Arriba“1, Nr. 4i vom 11. 4. 1935; O. C., a. a. O., S. } 265 \mathrm{ff} .
$$

\section{5}

\section{VOR EINEM KREUZWEG IN DER POLITISCHEN UND WIRTSCHAFTLICHEN} GESCHICHTE DER WELT

Diesen Vortrag hielt José Antonio am 9. 4. 1935 im "Círculo mercantil" zu Madrid, einer gesellschaftlichen Vereinigung spanischer Kaufleute und Industrieller. Sie baten gelegentlich Politiker, Diplomaten oder Wissenschaftler zu einem Referat.

Glaubt nicht, ich bildete mir ein, diese Beifallsrufe zu verdienen, mit denen Ihr mich empfangen habt. Dies verbietet mir einerseits die tiefempfundene Dankbarkeit über die Einladung, hier an dieser Stelle zu sprechen, wo schon so viele und bekannte Männer gestanden haben, andererseits aber auch das Bewußtsein der Verantwortung, die ich damit übernehme. Diese Verantwortung ist groß, einmal wegen der geistigen Höhe des Lehrstuhls, dann auch, weil mich Herr Mariano Matesanz ${ }^{2}$ durch seine freundlichen Worte zu großem Dank verpflichtet hat. Und schließlich auch, weil es für mich kein leichtes ist, gerade am heutigen Abend für meine Ausführungen den richtigen Ton zu treffen.

Wohl keiner von Euch erwartet von mir eine politische Propagandarede. Das hieße die Gastfreundschaft dieses freien Lehrstuhls schlecht vergelten. Doch davon ganz abgesehen: wenn einige Spanier oder auch viele - wie im Augenblick hier versammelt sind und auf einem jeden von uns und auf uns allen die drückende Beklemmung Spaniens lastet, wäre es, so glaube ich, wenig angebracht, die Diskussion auf Äußerlichkeiten, auf politische Wechselfälle zu beschränken; denn auf diese Weise würden wir uns völlig von der Aufgabe einer großen und schicksalhaften Politik entfernen. Suchte ich heute abend eine Antwort auf die Frage zu

1 „Arriba" wurde die zweite, ein Jahr nach dem Verbot von „FE" aufgelegte Wochenzeitschrift der Falange. Auch sie erschien nux sporadisch und wurde dann verboten. Die erste Ausgabe erschien am 21.3.1935; die letzte am 5.3.1936, insgesamt wurden in diesem Zeitraum nur 34 Ausgaben veröffentlicht.

2 Mariano Matesanz, spanischer Großkaufmann, der den Vorsitz führte. Matesanz gehörte als konservativer Unabhängiger den spanischen Cortes an. 
geben, wann die Cortes wieder zusammentreten müßten oder ob und wann die Gruppen, die bis vor kurzem noch befreundet waren, ihre augenblicklichen Streitigkeiten wieder beilegen sollten, so könnten wir uns zwar darin ergehen, aber ich bin überzeugt, wir hätten eine Gelegenheit sinnlos vergeudet, uns mit aller Kraft für die Lösung der tragischen und zur Entscheidung drängenden Fragen einzusetzen.

Eine politische Propagandarede darf ich also nicht halten, ebensowenig aber einen akademischen Vortrag. Das würde weder mir zustehen noch Euch sehr zusagen; außerdem ist jetzt nicht Zeit für gelehrte Vorträge aus Laienkreisen. Wenn ernste Schicksalsfragen in gelehrten Abhandlungen und Vorträgen erörtert werden, steht meist ein großes Opfer an Menschen bevor. Und gerade dieses Opfer, das Europa droht, das demzufolge auch Spanien droht, nimmt seinen Ausgang von Salons, vielleicht von den erlesensten Salons, welche die Geschichte aufzuweisen hat. Wenn Thr nichts dagegen habt, können wir (und damit können wir diese ersten Augenblicke, die im Moment noch durch eine gewisse Nervosität gekennzeichnet sind, zum Teil weil Eure Spannung und Euer Wohlwollen so groß sind, zum Teil weil ich selbst etwas aufgeregt bin, zum Teil vielleicht auch durch dieses Mikrofon hier) - wenn Ihr also nichts dagegen habt, können wir uns mit unserer Phantasie in die erwähnten Salons versetzen.

Stellen wir uns für einen Augenblick vor, wir befänden uns im letzten Drittel des 18. Jahrhunderts. Vom 13. bis zum 16. Jahrhundert kannte die Welt ein festes, solidarisches Leben totaler Harmonie; die Welt drehte sich um eine Achse. Im 16. Jahrhundert begann man schon, dies anzuzweifeln. Das 17. Jahrhundert führte die Gewissensfreiheit ein, man begann, alles in Zweifel zu ziehen. Das 18. Jahrhundert glaubte an nichts mehr, das heißt, eigentlich glaubten die vornehmsten und erlesensten Geister des 18. Jahrhunderts an nichts mehr, nicht einmal an sich selbst. Es wurde Mode, den Vorstellungen und Vorlesungen der Schriftsteller und Philosophen jener Zeit beizuwohnen, die sich über eben diese Gesellschaft mokierten, welche es sich als Ehre anrechnete, ihnen den Hof zu machen. Die besten Satiren gegen die Gesellschaft des 18. Jahrhunderts werden, so sehen wir, von eben dieser Gesellschaft umjubelt und gefeiert, die darin verspottet wird. In dieser Atmosphäre des 18. Jahrhunderts, in diesem 18. Jahrhundert, in dem alles zu Konversation wird, zu Ironie, zu scharfsinniger, spitzfindiger Sophisterei, in diesem 18. Jahrhundert begegnen wir zwei gänzlich verschiedenen Gestalten : einem Genfer Philosophen und einem schottischen Volkswirtschaftler.

Der Genfer Philosoph ist ein kränklicher, überaus empfindlicher, etwas überzüchteter Mensch. Er ist ein Philosoph, den es - Spengler behauptet, dies träfe für alle Romantiker zu, und der Mann aus Genf ist bereits ein unmittelbarer Vorläufer der Romantik - ermüdet, sein Leben in einer allzu gesunden, allzu männlichen, allzu kraftstrotzenden Gesellschaft zu verbringen. Ihn bedrückt die Last dieser bereits endgültig geformten Gesellschaft, und er spürt in sich das unwiderstehliche Verlangen zu fliehen, zur Natur zurückzukehren, sich vom äußeren Zwang, von der Harmonie, von der Norm zu befreien. Dieses wehmütige Verlangen nach der Natur bildet gleichsam den Grundton all seiner Schriften: die Rückkehr zur Frei- 
heit. Das berühmteste seiner Bücher, das Buch, das dem gesamten 19. Jahrhundert seinen Stempel aufprägt und dessen Einfluß eigentlich erst heute, in unseren Tagen, zu verblassen beginnt, fängt zwar nicht ganz wörtlich, wie es vielfach zu lesen ist, aber doch in etwa mit einem Satze an, der wie ein Seufzer klingt. Er lautet: „Der Mensch wird frei geboren, und doch ist er von allen Seiten gebunden." Dieser Philosoph - Thr wißt es ja schon alle - heißt Jean Jacques Rousseau, und das Buch „Le contrat social“.

Der "Gesellschaftsvertrag" will jeglicher Autorität die Berechtigung absprechen, die uns von alters her entweder durch eine für göttlich gehaltene oder aber durch eine auf die Tradition sich stützende Institution überliefert worden ist. Er will die Berechtigung dieser Mächte bestreiten und, ausgehend von seinem Freiheitsverlangen, die Gesellschaft neu ordnen. Er sagt: Der Mensch ist frei; der Mensch ist von Natur aus frei und kann in keiner Weise auf diese seine Freiheit verzichten; es darf kein anderes Herrschaftssystem geben als das, welches er aus seiner Willensfreiheit heraus akzeptiert; auf diese seine Freiheit kann und darf er niemals verzichten, denn das hieße auf sein Menschtum verzichten. Außerdem würde er, verzichtete er dennoch auf seine Freiheit, einen nichtigen Vertrag eingehen, da ja jegliche Gegenleistung fehlen würde; er kann nur frei, unwiderruflich frei sein. Demzufolge kann sich gegen den freien Willen derer, die eine Gesellschaft ausmachen, keine Staatsform bilden; es muß der Vertrag der Ursprung der politischen Gesellschaft gewesen sein. Dieser Vertrag, die einheitliche Äußerung des freien Willens, erzeugt seinerseits einen höheren Willen, einen Willen, der nicht etwa die Summe der Willensäußerungen der einzelnen ist, sondern durch und für sich allein besteht. Er ist ein anderes, höhergeordnetes Ich, unabhängig von den Einzelwesen, die ihn durch ihre Mitwirkung gebildet haben. Nur dieser souveräne Wille also, dieser von allen anderen unabhängige Wille, kann und darf die Legislative ausüben. Dieser Wille hat immer recht; nur dieser Wille darf den Menschen aufgezwungen werden, ohne daß die Menschen jemals gegen ihn im Recht wären; denn wendeten sie sich gegen ihn, so würden sie sich gegen sich selbst wenden; dieser souveräne Wille kann niemals irren, er kann auch nie gegen das Wohl seiner Untertanen gerichtet sein.

Auf der anderen Seite steht der schottische Volkswirtschaftler. Er stellt einen anderen Menschenschlag dar: er ist gewissenhaft, ordnungsliebend, einfach in seinem Geschmack und in seinen Neigungen, ein wenig ketzerisch und ungläubig, ziemlich zerstreut und ein wenig melancholisch. Bevor er Volkswirtschaftler wurde, lehrte er an der Glasgower Universität zunächst Logik und danach Moralphilosophie. $\mathrm{Zu}$ der damaligen Zeit setzte sich diese Disziplin aus recht verschiedenartigen Gebieten zusammen, nämlich aus Theologie, Ethik, Jurisprudenz und Politik. Er hatte sogar im Jahre 1759 ein Buch mit dem Titel "Theorie der moralischen Gefühle“ geschrieben. Aber nicht dieses Buch öffnete ihm die Pforten zur Unsterblichkeit; unsterblich wurde er durch sein Buch „An Inquiry into the Nature and Causes of the Wealth of Nations". Der schottische Volkswirtschaftler - Ihr habt es sicher schon erraten - hieß Adam Smith. 
Für Adam Smith nun war die Welt der Wirtschaft eine natürliche, aus der Arbeitsteilung erwachsene Gemeinschaft. Diese Arbeitsteilung war kein bewußter Vorgang, nicht wissentlich herbeigeführt von denen, welche die Arbeiten untereinander verteilt hatten; es war vielmehr ein unbewußter, spontaner Vorgang. Die Menschen hatten die Arbeit im Laufe der Zeit ohne vorherige Abmachung untereinander aufgestellt. Keiner hatte sich dabei von dem Interesse der anderen, sondern ausschließlich von dem eigenen Nutzen leiten lassen. Daraus ergab sich aber zwangsläufig, daß, während ein jeder seinen eigenen Vorteil suchte, dieser Vorteil zu einem harmonischen Ganzen mit dem Vorteil der anderen verschmolz, so daß sich in dieser natürlich entstandenen, freien Gesellschaft folgendes zeigte: 1. die Arbeit als einzige Quelle jeglichen Reichtums; 2. der Tausch, d. h. der Umtausch der Güter, die wir erzeugen, gegen Güter, welche die anderen erzeugen; 3. das Geld, eine Ware, von der jeder wußte, daß die anderen sie in Zahlung nehmen würden; und schließlich 4. das Kapital, d. h. das Geld, das wir von dem, was wir nicht auszugeben brauchten, erspart haben, oder aber die Ersparnisse an Produkten, mit deren Hilfe neue, lebenskräftige Unternehmungen geschaffen werden können. Adam Smith hält das Kapital für die „conditio sine qua non“ der Industrie „Das Kapital schafft die notwendige Voraussetzung für die Industrie“, so sagt er. Doch alles dies geschieht, wie gesagt, spontan, nichts ist zu diesem Zweck vereinbart worden, und dennoch geschieht es so, und es muß so geschehen. Außerdem ist Adam Smith der Ansicht, diese Entwicklung gehe zwangsläufig vor sich, und er ist von dieser Beweisführung so überzeugt und so sehr mit dieser von ihm eingefädelten Beweiskette zufrieden, daß er angesichts des Staates, den er auch souveränen Herrscher nennt, ausruft: „Das beste, was Du tun kannst, ist, dich in nichts einzumischen, den Dingen ihren freien Lauf zu lassen. Wirtschaftsfragen sind ein Kräutchen-rühr-mich-nicht-an; rühre sie also nicht an; wenn du sie in Ruhe läßt, werden sie sich selber regeln, und alles wird in bester Ordnung sein."

Das Buch Rousseaus wurde 1762 veröffentlicht, das Buch von Adam Smith erschien im Jahre 1776, also in einem Abstand von nur wenigen Jahren. Bis dahin sind es zwei gelehrte Abhandlungen: die eine Behauptung stellt ein Philosoph, die andere ein Volkswirtschaftler auf; doch nun ereignet sich in dem bewegten Ausklang des 18. Jahrhunderts, was geschehen mußte, um diese beiden Theorien sogleich auf die Probe zu stellen. Stellt Euch einmal vor, wir befänden uns in einem Lichtspieltheater vor einem dieser Filme, die vor unseren Augen verschiedene Ereignisse abrollen lassen und in dem die Jahreszahlen 1908, 1911, 1917 gleichsam aus einem fernen Hintergrund heraus immer näher auf uns zukommen. Heute abend also - so können wir es uns vorstellen - tauchen auf der Leinwand die folgenden Jahreszahlen auf: 1765, 1767, 1769, 1770, 1785 und schließlich 1789. Die ersten fünf dieser Zahlen entsprechen dem unaufhaltsamen Eindringen der Maschine in das Leben der Menschen, Maschinen, welche die Industrie von Grund auf ändern werden, vor allem die Spinnereien und Webereien. Sie entsprechen der Erfindung der ersten Spinnmaschine, der ersten Dampfmaschine, des ersten maschinellen Webstuhls . . . Die letzte Jahreszahl - das erübrigt sich fast zu sagen - gibt 
nichts Geringeres an als die französische Revolution. Die französische Revolution findet die bereits fertig ausgearbeiteten Prinzipien Rousseaus vor und übernimmt sie. In der Verfassung von 1789, in der von 1791, in der von 1793, in der vom dritten und in der vom achten Jahr wird das Prinzip der nationalen Souveränität fast mit Rousseaus eigenen Worten wie folgt definiert: „Das Prinzip jeder Souveränität ruht dem Wesen nach im Volk. Keine Körperschaft, kein Einzelwesen kann und darf irgendeine Autorität ausüben, die ihm nicht ausdrücklich vom Volk selbst zugesprochen wurde. " Das heißt aber keineswegs, mit dieser Erklärung wäre gleichzeitig das allgemeine Wahlrecht eingeführt. Lediglich in eine der französischen Revolutionsverfassungen, in die vom Jahre 1793, die nie inkraft getreten ist, wird das allgemeine Wahlrecht aufgenommen, in den anderen nicht. In den übrigen wird das Wahlrecht eingeschränkt, im achten Jahr verschwindet es sogar völlig. Doch bestehen bleibt das Prinzip : „Jegliche Souveränität liegt grundsätzlich beim Volk. “

Etwas aber gab es in den Revolutionsverfassungen, das im „contrat social“ nicht enthalten war, nämlich die Erklärung der Menschenrechte. Wie bereits gesagt, ließ es Rousseau nicht $\mathrm{zu}$, daß sich der einzelne irgend etwas gegenüber diesem souveränen Willen vorbehielt, gegenüber diesem durch den Willen des Volkes geschaffenen souveränen Ich. Rousseau gestattete es nicht, wohl aber die revolutionären Verfassungen. Wer recht hatte, war Rousseau. Es sollte und mußte sich mit der Zeit die Macht der Versammlungen derart ausweiten, daß die Persönlichkeit des Menschen in Wirklichkeit völlig aufgehoben wurde, daß es keinen Zweck mehr hatte, gegen jene Macht auf Rechte irgendwelcher Art zu pochen, die der einzelne sich vorbehalten hätte.

Der Liberalismus - so kann man ihn wohl nennen, denn die revolutionären Verfassungen wollten nichts anderes als der Tyrannei eine Grenze setzen - der Liberalismus hat seine große Zeit, damals nämlich, als er alle Menschen vor dem Gesetz gleichmachte, ein umwälzender Fortschritt, der niemals mehr rückgängig gemacht werden kann noch darf. Nach diesem Fortschritt aber und nach jener Glanzzeit ermangelt es dem Liberalismus an einer eigentlichen Aufgabe, und er beschäftigt sich damit, sich selbst zugrunde zu richten. Es war durchaus natürlich, daß das, was Rousseau als souveränen Willen bezeichnete, letztlich mit dem Willen der Mehrheit identisch wurde. Nach Auffassung Rousseaus mußte die Meinung der Mehrheit allen anderen aufgezwungen werden, theoretisch, weil sie der wahrhafte Ausdruck des souveränen Willens, praktisch, weil sie gegenüber einer andersdenkenden Minderheit siegreich geblieben war. Um diese Mehrheit zu gewinnen, mußten zuvor die Parteien miteinander kämpfen, um mehr Stimmen als die anderen zu erhalten. Sie mußten, nachdem sich das Volk in einzelne Parteien aufgespalten hatte, gegeneinander Propaganda machen. Das bedeutet, daß gerade durch die Proklamierung der nationalen Souveränität, von der angenommen wurde, sie sei unteilbar, die Meinungen am weitesten auseinandergehen; denn da alle Gruppen danach trachten, daß ihre Meinung als der mutmaßliche souveräne Wille angesehen wird, müssen sie die eigenen Merkmale immer deutlicher hervortreten lassen, ihr eigenes Wesen immer stärker betonen, müssen sie sich bekriegen, sich gegen- 
seitig zu vernichten suchen, um in den Wahlschlachten siegreich zu bleiben. So kommt es, daß während des Zerfalls des liberalen Herrschaftssystems - selbstverständlich handelt es sich bei diesem Übergang, den ich hier auf einige Minuten zusammengedrängt habe, um einen Prozeß, der sich über viele Jahre erstreckt - so kommt es also, daß während des Zerfalls des liberalen Herrschaftssystems die Parteien so weit aufgesplittert werden, daß es, als das System in den letzten Zügen lag, in einem Land Europas', nämlich in Deutschland, einige Tage vor der Machtübernahme Hitlers, nicht weniger als 32 Parteien gab. Ich würde es nicht wagen, die Parteien zu zählen, die es hierzulande gibt, da mir nicht einmal alle Namen bekannt sind. Ich weiß selbst nicht, welche Parteien alle in den Cortes vertreten sind; denn abgesehen von den offiziell dort vertretenen Gruppen und von den in parlamentarische Gruppen aufgegangenen kleineren Grüppchen, abgesehen von den Abgeordneten, die für sich oder mit ein paar guten Freunden eine eigene, sogenannte "wilde" Gruppe bilden, abgesehen von allen diesen gibt es in unserem Parlament etwas außerordentlich Merkwürdiges, nämlich zwei jeweils aus ungefähr zehn Abgeordneten bestehende Minderheiten, die sich unabhängig nennen. Aber stellt Euch vor, nicht etwa, weil sie als eine solche Minderheit unabhängig von den anderen sind, nein, einfach weil jeder einzelne Abgeordnete dieser Minderheiten sich von den anderen Mitgliedern der eigenen Gruppe unabhängig fühlt. Das einigende Band der Angehörigen dieser Minderheiten - dazu gehören weder Herr Matesanz noch ich selbst, denn wir beide sind absolut unabhängig - besteht gerade darin, daß sie sich nicht einig sind, $d$. h. einig sind sie sich nur darin, daß sie sich eben über nichts einig sind. Gelegentlich hört diese Pulverisierung der Parteien auf, indem sich einige Minderheiten zusammentun. Dann tritt der Fall ein, daß die Mehrheit - die Hälfte, vermehrt um eine Stimme, oder die Hälfte plus drei der Abgeordneten - sich im Besitz der vollen Volkssouveränität und berechtigt glaubt, nicht nur den Rest der Abgeordneten, sondern auch das restliche spanische Volk auszusaugen und zu knebeln. Diese Hälfte glaubt dann, sie sei unbeschränkt befugt, alle Handlungen selbst zu rechtfertigen; mit anderen Worten: sie meint, alles für gut halten zu dürfen, was ihr gerade einfällt. Und was den armseligen Rest der Sterblichen betrifft, so gilt für ihn kein persönliches Ansehen mehr, sei es juristischer oder menschlicher Natur.

Jean Jacques Rousseau hatte dergleichen bereits vorausgesehen und sagte: „Gut, da aber der souveräne Wille unteilbar ist und unfehlbar, so ist, sollte tatsächlich einmal der Wille eines Menschen im Widerstreit zu dem souveränen Willen stehen, dieser Mensch im Irrtum befangen, und wenn ihn dann der souveräne Wille zwingt, sich ihm zu unterwerfen, tut er nichts anderes, als ihn zu seiner Freiheit zwingen." Beachtet den spitzfindigen Trugschlu $\beta$ und bedenkt einmal folgendes: Wenn wir Abgeordnete der Republik, unleugbar die Vertreter des Volkswillens, Euch zu hohe Steuern auferlegen oder irgendein unbequemes Gesetz aufstellen, das Euch gegen den Strich geht, würde Euch da etwa der Gedanke kommen, wir wollten Fuch dadurch nur die Wohltat erweisen, Euch mit oder gegen Euren Willen ein wenig freier zu machen? 
Dies war eine ganz kurze, vielleicht auch ein wenig wirre Zusammenfassung der Geschichte des politischen Liberalismus. Ähnlich verläuft die Geschichte des wirtschaftlichen Liberalismus.

Rousseaus Prinzipien wurden nach kurzer Zeit von der französischen Revolution übernommen. Smith hatte das Glück, das nur selten einem Schriftsteller zuteil wird: England stellte sich positiv zu seinen wirtschaftlichen Lehren. England verkündete bald darauf die vollständige wirtschaftliche Freiheit; es ließ das freie Spiel von Angebot und Nachfrage zu, das nach Adam Smith ohne weiteres Zutun, ohne Drängen von irgendeiner Seite zum wirtschaftlichen Gleichgewicht führen würde. Und tatsächlich, auch der wirtschaftliche Liberalismus erlebte seine Heldenzeiten, eine glänzende, heroische Zeit. Wir haben es nicht nötig, die Toten zu schmähen, weder die wirklich Gefallenen - wären sie auch unsere Feinde gewesen, sie würden doch, da sie Menschen sind, all unsere Achtung verdienen, die ihnen aufgrund ihrer Eigenschaft als Mensch und aufgrund ihrer Menschenwürde gebührt, noch die Gedankensysteme. Der wirtschaftliche Liberalismus hatte eine große Zeit, eine großartige, glänzende Zeit; seinem ungestümen Vordringen, seiner Initiative verdanken wir die Ausbreitung bis dahin ungenutzter Reichtümer, viele Bequemlichkeiten und viele Fortschritte auch für die ärmeren Schichten; für viele bedeutete die Konkurrenz und der Überfluß zweifellos eine Steigerung ihrer Lebensmöglichkeiten. Der wirtschaftliche Liberalismus erhielt seinen Todessto $\beta$ dadurch, daß sehr bald - gleichsam als sein eigener Sproß - jenes fürchterliche Phänomen, vielleicht das fürchterlichste Phänomen unserer Zeit, in Erscheinung trat, nämlich der Kapitalismus - und von diesem Augenblick an bewegen wir uns nicht mehr in der Vergangenheit.

Ich möchte, daß wir uns ein für allemal über die Terminologie einigen. Wenn von Kapitalismus die Rede ist, so ist damit nicht das Privateigentum gemeint; diese beiden Dinge sind nicht nur wesensmäßig verschieden, fast ließe sich sagen, sie stünden im Gegensatz zueinander. Eine der Auswirkungen des Kapitalismus bestand gerade darin, das Privateigentum in seiner traditionellen Form nahezu völlig zu vernichten. Darüber dürfte bei allen Klarheit bestehen, dennoch aber ist es, so glaube ich, nicht unangebracht, der Klärung dieser Sachlage einige Worte zu widmen. Der Kapitalismus ist die mehr oder weniger rasche Transformation dessen, was das unmittelbare Band zwischen Mensch und Sache ist: ein technisches Instrument zur Ausübung der Macht. Das herkömmliche Eigentum, das handwerkliche Eigentum, das Eigentum des kleinen Produzenten, des kleinen Kaufmannes ist glejchsam eine Projektion des Individuums auf seine Sache: er ist Eigentümer, sofern er diese Sache besitzen, sie benutzen, sich ihrer erfreuen, sie tauschen kann. Fast mit den gleichen Worten, wenn Thr es so wollt, war in den römischen Gesetzen jahrhundertelang der Begriff des Eigentums definiert; doch in dem Maße, in dem der Kapitalismus perfektioniert und immer verwickelter wird, wird auch - und das ist sehr bemerkenswert - das Verhältnis zwischen Mensch und Sache lockerer, und es schiebt sich zwischen Mensch und Sache eine Reihe von technischen Instrumenten zur Beherrschung der Mitmenschen. Und was zunächst ein unmittelbares, 
elementares Verhältnis des Menschen zu seiner Sache war, wird nunmehr kompliziert. Es werden Zeichen eingeführt, die eine Eigentumsbeziehung darstellen, Zeichen aber, die jedoch die wirkliche Gegenwart des Menschen in steigendem Maße ersetzen. Wenn der Kapitalismus zu seiner letzten Perfektion gelangt, ist der eigentliche rechtmäßige Eigentümer des Eigentums im herkömmlichen Sinne des Wortes nicht mehr ein Mensch, nicht mehr eine Vereinigung von Menschen, sondern eine durch Papierscheine dargestellte Abstraktion, so z. B. bei der sogenannten Aktiengesellschaft. Die Aktiengesellschaft ist der wahre Eigentümer oder Inhaber einer ganzen Reihe von Rechten, und in einem solchen Maße ist sie entmenschlicht, ist ihr der Mensch als Träger dieser Rechte gleichgültig, daß die Besitzer der Aktien ohne weiteres wechseln können, ohne daß sich dadurch die juristische Organisation und die Funktionsfähigkeit der gesamten Gesellschaft in irgendeiner Weise ändert.

Dieses Großkapital also, dieses technische Kapital, dieses Kapital, das schließlich ungeheure Ausmaße annimmt, hat - wie bereits gesagt - mit dem Eigentum im ursprünglichen, menschlichen Sinne nichts zu tun, es ist vielmehr sein Feind. Wenn ich sehe, wie Arbeitgeber und Arbeitnehmer in blutigen Kämpfen so weit gehen, sich auf offener Straße umzubringen, oder wie sie Attentaten zum Opfer fallen, in denen eine zügellose Grausamkeit zutage tritt, dann kommt mir häufig der Gedanke, daß beide Parteien gar nicht wissen, gar nicht ahnen, daß sie in Wirklichkeit an einer wirtschaftlichen Auseinandersetzung beteiligt sind, einer Auseinandersetzung allerdings, in der beide Parteien nahezu auf der gleichen Seite stehen, daß sie gar nicht ahnen, daß die Gegenseite, sowohl gegen Unternehmer als gegen Arbeiter gerichtet, die Macht des Kapitalismus, die Technik des Finanzkapitalismus ist. Wenn dem nicht so wäre, dann sagt Ihr mir doch, die Ihr besser bewandert seid in diesen Dingen; sooft Ihr Euch an die großen Kreditinstitute wenden mußtet, um eine wirtschaftliche Hilfe zu erbitten, mußtet Ihr - das wißt Ihr ganz genau 7 bis $8 \%$ Zinsen zahlen. Und es ist Euch ebenfalls bekannt, daß dieses Geld, das Ihr als Kredit erhaltet, nicht dem Geldinstitut selbst gehört, sondern den Leuten, die es gegen $1 \frac{1}{2}$ oder $2 \%$ Zinsen dort deponiert haben. Und dieser enorme Differenzbetrag, der Euch dafür abverlangt wird, daß das Geld von Hand zu Hand wandert, lastet in gleicher Weise auf Euch und Euren Arbeitern, die Euch vielleicht hinter einer Straßenecke auflauern und umbringen wollen.

Gerade diese Hochfinanz siecht seit den letzten fünf Jahren dem Zusammenbruch entgegen, einem Zusammenbruch, der sich auf zweierlei Weise vollzieht: erstens in sozialer Hinsicht (was eigentlich zu erwarten war) und zweitens durch die Technik des Kapitalismus selbst. Das werde ich im folgenden beweisen.

Was den sozialen Aspekt des Kapitalismus betrifft, so muß ich sagen, da $\beta$ ich ohne meinen Willen - in mehr als einem Punkt mit der Kritik von Marx übereinstimme. Seitdem wir uns alle auf die Politik geworfen haben, ist tatsächlich sein Name zwangsläufig ständig in unser aller Munde. Und da wir alle uns entweder zu Marx oder gegen ihn bekennen mußten, wird er von manchen - selbstverständlich von keinem von Euch - gleichsam als eine Art von Gründer utopischer Gesell- 
schaften hingestellt. Sogar gedruckt war die Behauptung von den „utopischen Träumen des Karl Marx" schon zu sehen. Ihr wißt es genau: Wenn jemand auf dieser Welt kein Träumer war, so war das Karl Marx; seine einzige unerbittliche Tat bestand darin, die lebendige Realität einer Wirtschaftsordnung ins Auge zu fassen, nämlich die englische Wirtschaftsordnung der Fabriken in Manchester. Daraus folgerte er, daß innerhalb dieser Wirtschaftsform einige inhärente Kräfte am Werke waren, die letztlich die Zerstörung dieser Form zur Folge haben mußten. Dies sagte Karl Marx in einem schrecklich dicken Buch, so dick, daß ex es zu Lebzeiten gar nicht mehr vollenden konnte. Das Buch war allerdings ebenso interessant wie dick, das muß man schon zugeben, ein Werk von zwingendster Dialektik und außerordentlicher Genialität, ein Buch rein kritischer Art, in dem er zwar verkündete, daß die auf diesem System aufgebaute Gesellschaft sich letztlich selbst zerstören würde, sich aber nicht einmal die Mühe machte anzugeben, wann oder wie dieser Fall eintreten würde. Er sagte lediglich: Angesichts dieser und jener Voraussetzung folgere ich, daß das ein böses Ende nimmt. Und danach starb er, ehe er noch den zweiten und dritten Band seines Werkes veröffentlicht hatte. Und er ging ins Jenseits ein (ob in die Hölle, das wage ich nicht zu beurteilen - diese Schlußfolgerung wäre etwas voreilig), ohne auch nur im geringsten zu ahnen, daß eines guten Tages ein spanischer Antimarxist daherkommen und ihn in die Reihe der Dichter einreihen würde.

Dieser Karl Marx sagte bereits den sozialen Zusammenbruch des Kapitalismus voraus, über den ich jetzt gerade mit Euch spreche. Er sah das Auftreten zumindest der folgenden Phänomene voraus: erstens : die Akkumulation des Kapitals, eine zwangsläufige Begleiterscheinung der Großindustrie. Die Kleinindustrie arbeitete kaum mit mehr als zwei Faktoren: der Arbeitskraft und den Rohstoffen. Wenn in Krisenzeiten der Absatz sank, ließen sich diese beiden Faktoren leicht reduzieren; es wurden weniger Rohstoffe eingekauft und Arbeitskräfte entlassen, und es ergab sich wieder ein ungefähres Gleichgewicht zwischen Produktion und Nachfrage. Doch nun kommt die Großindustrie, und diese legt - abgesehen von dem Teil, der von Marx selbst als variables Kapitel bezeichnet wird - einen ungeheuren Teil ihrer Reserven in festem Kapital an, einen ungeheuren Teil, der bei weitem den Wert der Rohstoffe und der Arbeitskraft übersteigt. In der Großindustrie gibt es riesige und kostspielige Maschinenanlagen, deren Umfang nicht von einem Augenblick auf den anderen reduziert werden kann. Um diese Anhäufung von totem Kapital, von nicht reduzierbarem Kapital durch Produktion auszugleichen, gibt es für die Großindustrie nur die eine Möglichkeit, in einem ungeheuren Umfang zu produzieren, wie sie es ja auch tut. Und da sie durch die erzwungene Produktionssteigerung billiger produzieren kann, bricht sie in die Absatzgebiete der kleinen Produzenten ein, richtet sie einen nach dem anderen zugrunde, um sie sich schließlich alle einzuverleiben.

Dieses Gesetz von der Anhäufung des Kapitals wurde von Marx vorausgesagt, und wenngleich manche behaupten, es habe sich nicht erfüllt, sehen wir doch, daß es zutrifft, denn Europa und die ganze Welt sind voll von "Trusts", Syndikaten 
mit riesigen Produktionsziffern und ähnlichen Gebilden, die Ihr besser kennt als ich. Als Beispiel nenne ich die prächtigen Einheitspreiskaufhäuser, die es sich leisten können, "Dumping-Preise“ zu nehmen, da sie genau wissen, daß Ihr nach einigen Monaten einen solchen Konkurrenzkampf einfach nicht mehr durchhalten könnt. Die anderen hingegen gleichen ein Geschäft mit dem anderen aus, kompensieren den Verlust einer Filiale durch den Gewinn einer anderen, so daß sie getrost Eure völlige Vernichtung abwarten können.

Das zweite soziale Phänomen ist die Proletarisierung. Den aus ihren Werkstätten vertriebenen Handwerkern, vormals Eigentümer ihrer Produktionsmittel, bleibt natürlich keine andere Wahl, als diese Produktionsmittel jetzt zu veräußern, da sie ihnen ja nichts mehr nutzen. Die kleinen Produzenten, die kleinen Kaufleute, alle werden sie durch das gewaltige, ungeheure, unaufhaltsame Vordringen des großen Kapitalismus wirtschaftlich vernichtet und landen schließlich beim Proletariat, werden schließlich proletarisiert. Karl Marx beschreibt dies mit einer außerordentlichen Dynamik: diese Menschen verkaufen ihre Erzeugnisse, ihre Produktionsmittel, zuletzt ihre Häuser. Und in dem Augenblick, da sie nichts mehr zu verkaufen haben, da fällt ihnen ein, daß auch sie selbst, auch ihre Arbeitskraft, eine Ware sein könnte. So stürzen sie sich auf den Markt, um sich für eine zeitweilige Knechtschaft zu verdingen. Dieses Phänomen der Proletarisierung ungeheurer Volksmassen und ihrer Zusammenballung in den Städten um die Fabriken ist ein weiteres Symptom für den sozialen Bankrott des Kapitalismus.

Und noch ein drittes Phänomen tritt zutage: die Arbeitslosigkeit. Als die Maschinen eingeführt wurden, weigerten sich die Arbeiter, sie in die Werkstätten aufzunehmen. Sie befürchteten, von diesen Maschinen, die die Arbeit von zwanzig, hundert oder zweihundert Arbeitern leisten konnten, verdrängt zu werden. Da man zu jener Zeit dem Glauben an den „unbegrenzten Fortschritt" anhing, lächelten die damaligen Volkswirtschaftler und sagten: „Diese dummen Arbeiter wissen nicht, daß dadurch gerade die Produktion sich erhöhen, die Wirtschaft sich entwickeln und der Umsatz sich steigern wird; der Platz reicht aus für Mensch und Maschine." Doch es stellte sich heraus, daß dieser Platz nicht vorhanden war, daß die Maschinen nahezu die gesamte Arbeiterschaft verdrängt haben. In den Flaschenfabriken der Tschechoslowakei zum Beispiel - das ist ein Beispiel, das mir einfällt -, wo 1920, nicht im Jahre 1880, 8000 Arbeiter beschäftigt waren, arbeiten zur Zeit nur mehr 1000, und dennoch ist die Flaschenproduktion gestiegen.

Für die Verdrängung des Menschen durch die Maschine erfolgte nun nicht der poetische Ausgleich, den man in den ersten Zeiten von der Maschine erhofft hatte, jener Ausgleich, der darin bestehen sollte, den Menschen von einer ungeheuren Last zu erlösen. Man sagte: „Nein, die Maschinen werden unsere Arbeit verrichten; sie werden uns von unserer Mühsal erlösen. " Dieser poetische Ausgleich fand nicht statt, weil die Einführung der Maschine keine Arbeitszeitverkürzung zur Folge hatte; die Arbeitszeit ist vielmehr im wesentlichen gleich geblieben (die tatsächlich aufgetretene Verkürzung der Arbeitszeit hatte andere Ursachen). Die Einführung der Maschine bewirkte die Verdrängung aller überflüssig gewordenen Menschen. 
Ebensowenig, wie die Maschine den Ausgleich gewährt hat, hat sie als Entschädigung eine Lohnerhöhung herbeigeführt. Die Löhne der Arbeiter sind zwar offensichtlich gestiegen, aber auch hier müssen wir die Daten den Statistiken und der Wirklichkeit entnehmen. Wißt Ihr, um wieviel das Gesamtvolumen der Arbeiterlöhne in der Prosperitätsperiode der USA, in der wirtschaftlichen Blütezeit von 1922 bis 1929, angestiegen ist? Nun, um 5 Prozent. Und wißt Ihr, um wieviel die Rendite der Kapitalisten im gleichen Zeitraum anstieg? Um 86 Prozent. Sagt selbst, heißt das die Vorteile des Maschinenzeitalters gerecht verteilen?

Ja, dieser soziale Bankrott des Kapitalismus war vorauszusehen. Weniger vorauszusehen war allerdings ein Bankrott in technischer Hinsicht, durch den die Lage des Kapitalismus geradezu verzweifelt wird.

Zum Beispiel: die in periodischen Abständen auftretenden Krisen wurden von der Großindustrie hervorgerufen, und zwar eben aus dem Grunde, den ich Euch eben dargelegt habe, als ich von dem Gesetz der Kapitalakkumulation sprach. Die fixen Kosten für die erste Einrichtung eines Unternehmens sind tote Kosten, deren Umfang unter keinen Umständen verringert werden kann, wenn der Absatz sinkt. Die Überproduktion, jene Produktion in schwindelerregendem Tempo, von der ich eben sprach, führt nun eine vollkommene Sättigung des Marktes herbei. Dadurch entsteht ein zu geringer Konsum, denn der Markt nimmt weniger auf als in ihn hineingepumpt wird. Hätte man jetzt noch die Wirtschaftsstruktur der Kleinindustrie, so würde man einfach die Produktion allmählich der sinkenden Nachfrage anpassen, und zwar durch Beschränkung des Rohstoffeinkaufs und durch die Entlassung von Arbeitskräften. Doch da dies in der Großindustrie nicht möglich ist, da sie diesen Klotz der fixen, toten Kosten am Bein hat, richtet sie sich selbst zugrunde. Das heißt, daß - technisch gesehen - die Großindustrie weniger gegen Krisenzeiten gefeit ist als die kleine Industrie. Das ist der erste Zacken aus ihrer Krone.

Aber dann versagt der Kapitalismus auch noch in anderer Beziehung. Einer seiner sympathischsten und anziehendsten Züge in der Heldenzeit des liberalen Kapitalismus war der unnahbare Stolz seiner Frühzeit, der ihn sagen ließ: „Ich habe öffentliche Hilfe nicht nötig, ja, ich verlange sogar vom Staat, mich in Ruhe zu lassen und sich nicht in meine Angelegenheiten einzumischen." Mit einem Wort, der Kapitalismus mußte sich auch hier geschlagen bekennen; mit einem Wort, als Krisenzeiten kamen, erbat er die Hilfe der Öffentlichen Hand, und so stellte sich bald heraus, daß die wirtschaftlich robustesten Unternehmungen sich an das Wohlwollen des Staates klammerten, entweder um die Errichtung von Schutzzöllen durchzusetzen oder um finanzielle Subventionen zu erlangen. Wie es ein Schriftsteller, Gegner des kapitalistischen Systems, einmal ausdrückte: Der Kapitalismus, der eine eventuelle Sozialisierung seiner Gewinne so empört und entrüstet von sich weist, ist der erste, der eine Sozialisierung seiner Verluste fordert, wenn die Dinge sich zum Schlechten wenden.

Ein weiterer Vorteil des Freihandels, der liberalen Wirtschaft, bestand schließlich darin, den Wettbewerb zu fördern. Es wurde behauptet, durch den Wett- 
bewerb aller Produzenten auf dem freien Markt würden die Erzeugnisse immer besser und die Lage der Konsumenten immer günstiger. Nun, dadurch, daß der Großkapitalismus die Produktion in die Hände einiger weniger Mächtigen legte, hat er automatisch die Möglichkeit eines Wettbewerbs ausgeschaltet.

Und nun zeigen sich die Ergebnisse, die wir alle kennen: die Krisen, die Lähmung, das Schließen der Fabriken, die nicht enden wollende Reihe der arbeitslosen Proletarier, der Weltkrieg, die Nachkriegstage... Und der Mensch, der trachtete, innerhalb einer liberalen Wirtschaft und einer liberalen Politik, innerhalb eines liberalen Prinzips zu leben, der Mensch, der eine Politik und eine Wirtschaft mit Kraft und Optimismus erfüllte, mußte erleben, daß es in schrecklicher Weise mit ihm bergab ging: vorher war er Handwerker, ein kleiner Erzeuger, Mitglied einer Korporation, die vielleicht einige Vorrechte besaß, Einwohner einer starken Gemeinde; jetzt ist er nichts mehr. Man hat den Menschen langsam, aber sicher all seiner menschlichen Attribute beraubt, ihn chemisch gefiltert, so daß nur mehr der nackte Mensch bleibt. Er hat nichts mehr, nur noch Tag und Nacht. Weder ein Stück Land hat er, auf das er seine Füße stellen, noch nennt er ein Haus sein eigen, in dem er Obdach finden könnte. Die alte vollkommene Staatsgemeinschaft, so menschlich, in sich geschlossen und reich, ist zusammengeschrumpft auf diese beiden Dinge: eine Nummer in den Wählerlisten und eine Nummer in den Schlangen vor den Toren der Fabriken.

Nur zwei mögliche Lösungen gibt es für Europa: einerseits die drohende Gefahr eines Krieges: vielleicht stürzt sich Europa - verzweifelt, verstört und reizbar wie es ist - in einen neuen Krieg. Der andere Ausweg: die Anziehungskraft Rußlands, die Anziehungskraft Asiens; wir dürfen nämlich den asiatischen Einschlag im sogenannten russischen Kommunismus nicht vergessen, in dem der typisch anarchistische, asiatische Einfluß ebenso spürbar oder sogar noch deutlicher spürbar ist als die Marxsche Geisteshaltung. Lenin verkündete - und zwar in einem Buch, das kurz vor dem Sieg der russischen Revolution veröffentlicht wurde, die letzte Etappe des neu zu errichtenden Herrschaftssystems werde eine Gesellschaft ohne Staat und ohne Klassen sein. Diese Schlußetappe besaß alle Merkmale des Anarchismus Bakunins und Kropotkins, doch um dorthin zu gelangen, müßte man zunächst eine andere, sehr harte Periode durchmachen, die Zeit der marxistischen Diktatur des Proletariats. Und mit unerhörtem ironischem Zynismus sagte Lenin: „Diese Etappe wird weder frei noch gerecht sein. Der Staat hat die Aufgabe zu unterdrücken. Alle Staaten unterdrücken. Der Staat der arbeitenden Klasse wird ebenfalls zu unterdrücken wissen, und zwar die kurz vorher expropriierte Klasse, das heißt also die Klasse, von der sie bis dahin unterdrückt wurde. Der Staat wird weder frei noch gerecht sein. Und außerdem wissen wir gar nicht, wann der Übergang zum letzten Abschnitt, zu jener Zeit des Glücks des kommenden Anarchismus erfolgen wird." Diese Stunde ist noch nicht gekommen; wahrscheinlich kommt sie überhaupt nie. Für europäisches Empfinden, für das Empfinden eines europäischen Bourgeois oder Proletariers ist ein solches Zukunftsbild greulich, hoffnungslos. Dort wird man tatsächlich zu einer bloßen Nummer und von einem eisernen Staat unter- 
jocht. Doch das verzweifelte europäische Proletariat, das für sein eigenes Entstehen in Europa keine Erklärung weiß, sieht in den Vorgängen in Rußland gleichsam eine mystische Heilsbotschaft, eine mögliche Befreiung, wenn auch in weiter Ferne. Da seht Thr also, wohin uns zuguterletzt der Zerfall des politischen und wirtschaftlichen Liberalismus gebracht hat: in ganz Europa sind ungeheure Menschenmassen vor diese furchtbare Entscheidung gestellt: entweder ein neuer Krieg, gleichbedeutend mit dem Selbstmord Europas, oder der Kommunismus, gleichbedeutend mit der Auslieferung Europas an Asien.

Und was wird inzwischen aus Spanien? Unser politischer und wirtschaftlicher Liberalismus hat sich in Wirklichkeit die Mühe des Zerfalls nahezu ersparen können; beide haben ja kaum jemals richtig existiert. Der politische Liberalismus, nun, wie der war, wißt Thr ja. Die Wahlen wurden bis vor sehr kurzer Zeit im Innenministerium organisiert, und darüber waren viele Spanier noch froh. Angel Ganivet ${ }^{\mathbf{1}}$, einer der besten Köpfe ganz Spaniens, sagte um 1887 etwa folgendes : „Glücklicherweise besitzen wir hier in Spanien eine bewunderungswürdige Einrichtung. Es müssen nämlich die Kandidaten für die Cortes durch die Regierung in die Kandidatenliste aufgenommen werden. An dem Tage aber, an dem tatsächlich Wahlen stattfinden, wird die Lage endlich ernst. Will man sich des Willens der breiten Volksmasse versichern, so darf man begreiflicherweise nur sehr unkomplizierte und leicht verständliche Gedanken in Umlauf bringen; schwierige Gedankengänge kommen bei der Masse nicht an. Und da die begabteren Männer wohl kaum Lust verspüren werden, durch die Straßen zu gehen, den ehrbaren Wählern die Hand zu drücken und ihnen einfältige Plattheiten zu sagen, werden schließlich die den Sieg davontragen, aus deren Munde ein solches Geschwätz passend und natürlich klingt."

Und Jahre danach - ich glaube, es war 1893 - behauptete Angel Ganivet, der immer noch beharrlich und widerspenstig an seinem antidemokratischen Standpunkt festhielt: „Ich bin ein begeisterter Bewunderer des allgemeinen Wahlrechts, allerdings unter der einen Bedingung, daß keiner davon Gebrauch macht. " Und dem fügte er hinzu: „Das soll nicht etwa ein geschmackloser Witz sein. Im Grunde, im Prinzip müssen meiner Ansicht nach alle Menschen an den Geschicken ihres Landes teilnehmen, ebenso wie es nach meiner Auffassung zum vollkommenen Menschsein gehört, Familienvater zu werden. Doch da beides überaus schwierig ist, rate ich denen, die eine Ehe eingehen wollen, es lieber nicht $\mathrm{zu}$ tun, und denen, die bei der Wahl ihre Stimme abgeben wollen, es doch lieber zu unterlassen. Zum Glück bedarf das spanische Volk dieses Rates nicht, da es sich entschlossen hat, sich der Stimme zu enthalten."

Dieser Art war tatsächlich unser politischer Liberalismus, und als sich diese Lage änderte, als wirklich einige Wahlen stattfanden, erlebten wir ein böses Schauspiel:

1 Angel Ganivet (1862-1898) schrieb u. a. das berühmte Werk „Idearium Español“, das die Zustände Spaniens scharf kritisierte. Er war einer der großen Anreger für die "Generation der 98er". 
die Cortes - in der Überzeugung, ihr Wahlsieg berechtige sie dazu, nach Lust und Laune schalten und walten zu können - handelten entsprechend, bis sie den Rest der Sterblichen sozusagen überrollten.

Doch abgesehen von diesem Hin und Her zwischen der liberalen Verfassung, die eigentlich nur auf dem Papier stand, und den Cortes, die es leider nur allzusehr gab, müssen wir feststellen, daß es den spanischen Staat, daß es den konstitutionellen spanischen Staat, so wie er uns im Grundgesetz sowie in den Ergänzungsgesetzen vorgezeichnet ist, in Wirklichkeit gar nicht gibt. Er ist ein reiner Witz, ist lediglich ein Zerrbild seiner selbst. Der spanische Staat ist in keiner seiner wesentlichen Institutionen existent. Wir sind zum Beispiel parlamentarische Abgeordnete; das Parlament hat eine vordringliche Aufgabe, die darin besteht, jedes Jahr den Haushaltsplan zu verabschieden. Zur Zeit leben wir nach einem Haushaltsplan, der wie Ihr alle wißt, denn es wurde Euch ja schon von berufenerer Seite gesagt - für das Jahr 1934, verabschiedet wurde. Dieser Voranschlag schloß mit einem Defizit von 592 Millionen Peseten. In Wirklichkeit ist dieses Defizit auf etwa 800 Millionen zu beziffern, da noch einige Staatsschuldverschreibungen zu begleichen sind. Nun, mit diesem Etat, der von allen Abgeordneten der Cortes als horrend bezeichnet wurde, gingen wir in das Jahr 1935. Aber wir waren zu träge, einen neuen Haushaltsplan auszuarbeiten, so daß wir begannen, den alten alle Vierteljahre zu verlängern. Doch bereits im ersten Vierteljahr fügten wir - wir wollten ja auch etwas leisten! - Ausgaben in Höhe von etwa 73 Millionen hinzu, und dazu kommen jetzt noch eine Reihe außerordentlicher Kredite. Wenn dieser Etat einmal verrechnet wird, können wir dank all dieser Maßnahmen voller Stolz Europa einen Haushaltsplan vorlegen, der im Verlauf von nur zwölf Monaten dem Land eine Schuldenlast von rund einer Milliarde Peseten aufgebürdet hat.

In einer solchen Lage befanden wir uns. Wir mußten uns noch dazu mit der Frage des Weines befassen, die keinen Aufschub duldete, mit der Frage des Getreides, mit der Frage der Arbeitslosigkeit, die eine wahrhafte Not und eine echte Schande war; in einer solchen Notlage kamen wir Abgeordneten überein, uns doch Fastnachtsferien zu bewilligen. Sonst feiert zwar keiner Fastnacht, die Abgeordneten aber müssen feiern. Aus welchem Grunde? Das allerdings vermag ich nicht zu sagen.

Und die Arbeitslosigkeit? Wie steht es damit? Wir haben 700000 Arbeitslose. 700000 Arbeitslose in einem Volk, das sich nicht einmal von einem Krieg zu erholen braucht, das nicht einmal eine Großindustrie besaß, sich demzufolge auch nicht mit der Krise des Großkapitalismus herumzuschlagen hatte! Wir haben 700000 Arbeitslose, deren physische Existenz jeden Morgen von neuem ein reines Wunder ist. Ich weiß nicht, wie lange schon von diesen 700000 Arbeitslosen geredet wird. Eine stattliche Minderheit in den Cortes sagte, sie werde zur Hilfe oder zur Unterstützung dieser 700000 Arbeitslosen 100000000 Peseten bereitstellen, sie werde in den Cortes den Antrag einbringen, 100000000 Peseten zu bewilligen. Daraufhin wurde von einer anderen Minderheit, die sich in dieser Beziehung nicht schlagen lassen wollte, von einer Minderheit, die jetzt bereits Minderheit und Gesamtheit zugleich 
ist, da sie die ganze Macht besitzt, erklärt: „Hundert Millionen? Eine Milliarde! Wir geben eine Milliarde! "

Und seht, was geschieht: Über diese Milliarde und über ihre Verteilung stellte unsere augenblickliche Regierung tiefschürfende Untersuchungen an. Von dieser Milliarde, durch die man der Arbeitslosigkeit abhelfen wollte, wurden 750000000 für die Errichtung öffentlicher Bauten verwendet. Ihr werdet sicherlich zugeben, $\mathrm{da} ß$ dies kaum das geeignete Mittel ist, die Wirtschaft zu normalisieren. Es ist zu hoffen, daß wir nicht jährlich 750000000 für die Errichtung öffentlicher Bauten ausgeben werden. Wenn man aber die Arbeitslosenstatistiken einmal überprüft, ergibt sich noch etwas viel Wesentlicheres, nämlich, daß von den 700000 Arbeitslosen, die wir im Augenblick haben, 400000 Landarbeiter sind, die noch nicht einmal in den Genuß eines einzigen Pfennigs dieser 750000000 kommen.

Dies ist unser Staat, ein Staat, dessen jährliche Ausgaben für Personal - abgesehen von den 313 Millionen Peseten für Pensionäre - laut zuverlässigen Berechnungen 1350 Millionen Peseten betragen. Nebenbei gesagt, ich halte es für durchaus richtig, daß Angestellte und Beamte ihr Geld bekommen. Nicht sie waren es, die sich nach diesen Ämtern gedrängt haben; in den Staatsdienst sind sie eingetreten, weil die Verwaltung ihre Pforten öffnete. Meine Kritik ist also in keiner Weise gegen die Angestellten und Beamten des Staates gerichtet.

Und ich sage, das wäre alles ganz gut, wenn der Staat zu irgend etwas diente. Aber dieser kostspielige, kostenverschlingende Staat, dieser Staat, der zu nichts dient, dieser Staat, den wir erhalten mit all den Steuern, all den Abgaben und noch dazu mit all dem, was wir ihm leihen - nebenbei gesagt, er wird bald gar nichts bekommen können, weil ihm keiner mehr vertraut -, dieser Staat leistet nicht das geringste. Eines allerdings muß ich zugeben, er hat eine großartige Bürokratie eingeführt! Man hat mir erzählt (nachgeprüft habe ich es nicht; und was ich nicht selbst nachgeprüft habe, sage ich Euch unter diesem Vorbehalt, nur damit Ihr Euch in etwa ein Gesamtbild formen könnt), man hat mir erzählt, daß Mißstände auf dem Land vom Staat auf folgende Art und Weise beseitigt werden: Wenn auf dem Land irgendein Mißstand auftritt, macht der Eigentümer des Bodens eine Eingabe, damit Abhilfe geschaffen wird. Wenn die Eingabe den Dienstweg durchlaufen hat, ist eine Beseitigung natürlich längst nicht mehr erforderlich.

Auch der wirtschaftliche Liberalismus brauchte in Spanien eigentlich nicht zu. scheitern, denn das spanische Kapital hat im allgemeinen die Glanzzeit des wirtschaftlichen Liberalismus, die Heldenzeit des Frühkapitalismus nie erlebt. Hierzulande erbaten die großen Unternehmungen von Anfang an die Hilfe des Staates. Sie wiesen Hilfe nicht nur nicht zurück, sie wollten sie sogar, und oft - das wißt Ihr ganz genau, das wissen alle - forderten sie nicht nur den Beistand des Staates, bewirkten sie nicht nur die Erhöhung der Schutzzölle, sondern machten sie sogar aus diesen Verhandlungen drohende Waffen, mit denen sie vom spanischen Staat jedes nur mögliche Zugeständnis erpreßten. Doch davon jetzt genug.

In diesem Spanien, das niemals überindustrialisiert war, das nicht überbevölkert ist, das nicht unter den Folgen eines Krieges zu leiden hatte, in dem wir die Mög- 
lichkeit besitzen, einen Handwerkerstand wieder aufzubauen, der ja zum großen Teil noch besteht, in diesem Land, das eine große, einheitliche, disziplinierte und geduldige Masse kleiner Produzenten und kleiner Kaufleute besitzt, das eine Reihe unberührt gebliebener geistiger Werte aufzuweisen hat - worauf warten wir in einem solchen Spanien eigentlich noch, um unsere Gelegenheit zu nutzen und uns noch einmal - so ehrgeizig dies auch klingen mag - innerhalb weniger Jahre an die Spitze Europas zu stellen?

Worauf warten wir? Einzig und allein darauf, daß die politischen Parteien endlich ihre Streitigkeiten darüber einstellen, ob sie ihre innerhalb und außerhalb des Parlaments bestehenden Meinungsverschiedenheiten beilegen sollen. Das ist die Wahrheit! Ich habe feierlich versprochen, meinen Worten auch nicht einen einzigen Augenblick lang den Charakter einer politischen Wahlrede zu geben, aber sagt doch selbst, ist es um die spanischen Parteien nicht arg bestellt? Betrachtet doch das Wesen - Ihr seht, ich will die Dinge von möglichst hoher Warte sehen -, betrachtet doch einmal selbst das Wesen der Tragödie Spaniens und das der Tragödie Europas, deren Entwicklung Thr heute abend freundlicherweise mit mir verfolgt habt: Der Mensch ist desintegriert, entwurzelt worden, ist, wie ich Euch vorher sagte, zu einer Nummer auf den Wählerlisten, zu einer Nummer in den Schlangen vor den Fabriktoren geworden. Dieser desintegrierte Mensch fleht nun mit erhobener Stimme, man möge ihn wieder mit seinen Füßen auf den Boden der Wirklichkeit stellen, man möge ihn wieder eins werden lassen mit einem kollektiven Schicksal, mit einer Schicksalsgemeinschaft, kurz, um die Dinge bei ihrem wahren Namen zu nennen, eins werden zu lassen mit dem Schicksal des Vaterlandes. Das Vaterland ist das einzig mögliche Gemeinschaftsschicksal. Beschränken wir es auf etwas Kleineres, auf das Haus, auf den heimatlichen Boden, dann bleibt nur noch eine fast physische Beziehung. Wenn wir es auf das Weltall ausdehnen, verlieren wir uns in unerreichbaren, nebelhaften Vorstellungen. Gerade das Vaterland stellt auf physischer Grundlage ein Gebilde unverkennbarer Eigenart, einen eigenen Wert im Weltgeschehen dar; gerade das Vaterland vereint in sich das Schicksal des gesamten Volkes und unterscheidet es von den übrigen. Es ist, wie wir stets sagen, eine Schicksalsgemeinschaft im Weltgeschehen.

Nun, worauf warten wir noch, um dieses Einswerden von Mensch und Vaterland zu vollziehen? Wir warten darauf, daß die Parteien der Linken und die der Rechten sich darüber klar werden, daß diese beiden Dinge untrennbar sind. Thr seht, ich greife die Parteien nicht wegen irgendeiner Kleinigkeit an, ich greife sie an wegen ihrer Unfähigkeit, sich das ganze, vollständige Problem des mit seinem Vaterland einswerdenden Menschen klar vor Augen zu führen.

Die Parteien der Linken sehen zwar den Menschen, doch sehen sie ihn entwurzelt. Es ist das ständige Ziel der linken Parteien, sich um das Schicksal des Individuums zu bemühen, wobei sie sich gegen jeglichen geschichtlichen und politischen Überbau wenden, als wäre der Mensch damit unvereinbar. Die von den Linksparteien vertretene Auffassung wirkt daher auflösend, sie ist zersetzend, sie ist ironisch, und wenngleich die Linke über eine Reihe glänzender Köpfe verfügt, liegen doch ihre 
Fähigkeiten meist im Destruktiven und fast nie im Konstruktiven. Die Rechtsparteien sehen die Dinge genau von der entgegengesetzten Seite. Sie versteifen sich darauf, mit nur einem einzigen Auge zu schauen, anstatt den Dingen die Stirn zu bieten und mit beiden Augen hinzusehen. Die Rechte will das Vaterland bewahren, will die Einheit wahren, will die Autorität wahren. Sie achtet dabei aber nicht der Not des Menschen, des Individuums, des Nächsten, der nichts zu essen hat.

So sehen sie in Wirklichkeit aus, nur verkleiden beide Richtungen ihre Unzulänglichkeit mit einem Haufen schönklingender Worte: die einen rufen das Vaterland an, ohne das Vaterland überhaupt echt zu empfinden und ohne ihm überhaupt in irgendeiner Weise zu dienen; die anderen vertuschen ihre Geringschätzung, ihre Indifferenz gegenüber dem so tiefgreifenden Problem eines jeden Individuums mit Redensarten und Phrasen, die in Wirklichkeit nichts als eine Hülle sind, in der nichts steckt. Wie oft habt Ihr die Vertreter der Rechten sagen hören: „Wir stehen in einer neuen Zeit, wir brauchen einen starken Staat, wir müssen den Gegensatz zwischen Kapital und Arbeit wieder aufheben, wir müssen eine korporative Lebensform suchen!" Ich sage Euch, das ist nichts als leeres Geschwätz, das sind Worte ohne Inhalt. Was heißt zum Beispiel starker Staat? Ein Staat kann nur dann stark sein, wenn er einem großen Schicksal dient, wenn er sich als Vollstrecker des großen Schicksals eines Volkes fühlt. Andernfalls ist der Staat ein Tyrann. Und im allgemeinen sind die tyrannischen Staaten die nachgiebigsten, die kompromißbereitesten. Wenn Philipp II. sah, wie ein Ketzer dem Scheiterhaufen überantwortet wurde, so war er davon überzeugt, daß er dem göttlichen Willen diene, wenn er das Urteil vollstrecken ließ. Wenn jedoch eine liberale Regierung unserer Tage jemanden erschießen lassen muß, der sein Vaterland verraten hat, dann wagt sie es nicht, den Befehl auch ausführen zu lassen, weil sie sich im Innern nicht hinreichend dazu berechtigt fühlt.

Ein anderes Schlagwort lautet, man müsse den Gegensatz zwischen Kapital und Arbeit aufheben. Mit diesen Worten glauben sie gegenüber der sozialen Frage eine überaus kluge, menschliche Haltung eingenommen zu haben. Den Gegensatz zwischen Kapital und Arbeit aufheben ... Genau so gut ließe sich sagen, ich werde den Gegensatz zwischen mir und diesem Stuhl aufheben. Das Kapital - ich habe vorhin genügend Zeit darauf verwendet, das Kapital vom Privateigentum zu unterscheiden - ist ein Wirtschaftsinstrument, das der Gesamtwirtschaft dienen muß und infolgedessen nicht dazu mißbraucht werden darf, einigen wenigen, die das Glück hatten, zuerst da zu sein, Vorteile und Vorrechte zu verschaffen. Wenn also gesagt wird, man müsse den Gegensatz zwischen Kapital und Arbeit aufheben, so behaupten wir damit nicht - besser gesagt, so behaupten die anderen damit nicht, denn ich selbst sage so etwas nie -, daß der Gegensatz zwischen Euch und Euren Arbeitern aufgehoben werden soll. Arbeitet Ihr nicht auch? Seid Ihr etwa keine Unternehmer? Tragt Ihr nicht das finanzielle Risiko? Ihr gehört somit auch zur Seite der Arbeitenden. Nein, man spricht zwar davon, den Gegensatz zwischen Kapital und Arbeit aufzuheben, in Wirklichkeit aber bemüht man sich, eine unbedeutende Minderheit Bevorrechtigter auch weiterhin durch die Anstrengungen 
aller, durch die Arbeit sowohl der Arbeitnehmer als auch der Arbeitgeber zu unterhalten. Das ist mir eine schöne Lösung der sozialen Frage, eine schöne Auffassung von wirtschaftlicher Gerechtigkeit!

Und der korporative Staat? Das ist auch so ein Schlagwort. Jetzt schreit alles nach dem korporativen Staat. Sie meinen, wenn sie jetzt nicht für den korporativen Staat wären, würfe man ihnen vor, sie hätten sich zum Beispiel diesen Morgen nicht rasiert.

Das Schlagwort vom korporativen Staat ist ebenso nichtssagend wie die anderen. Als Mussolini, der doch bestimmt eine Vorstellung davon hat, was ein korporativer Staat ist, vor einigen Monaten die 22 Korporationen institutionalisierte, sagte er in seiner Rede: „Dies ist lediglich ein Ausgangspunkt, es ist kein Endziel." Grob umrissen ist bis heute die korporative Organisation eigentlich nichts anderes als das: die Arbeiter bilden einen großen Verband, die Unternehmer (in Italien nennt man sie Arbeitgeber) ebenfalls, und zwischen diesen beiden großen Verbänden errichtet der Staat sozusagen ein Verbindungsstück. Als Übergangslösung ist das gut und schön, doch bedenkt, daß diese Lösung weitgehend unseren paritätischen Schiedsgerichten entspricht, nur daß sie hier ins Riesenhafte gesteigert sind. Diese Lösung wahrt bis jetzt die Beziehung zur Arbeit in der Form, wie sie von der kapitalistischen Wirtschaftsordnung geprägt wurde. An der Stellung dessen, der Arbeit gibt, und dessen, der seine Arbeit für Geld hingibt, um zu leben, ändert sich nichts. In einer zukünftigen Entwicklung, die sehr revolutionär scheint, dennoch aber sehr alt ist - denkt nur einmal an die Form der alten europäischen Korporationen -, wird man so weit kommen, daß die Arbeit nicht mehr wie eine Ware veräußert wird, daß dieses bipolare Verhältnis endlich fallengelassen wird, damit alle, die an der Erfüllung der wirtschaftlichen Aufgabe beteiligt sind, alle, welche die nationale Wirtschaft bilden und vervollständigen, in vertikalen Syndikaten zusammengefaßt werden. In diesen Syndikaten wird man werder paritätische Ausschüsse noch Verbindungsstücke benötigen, denn sie werden organisch arbeiten, so wie zum Beispiel das Heer funktioniert, ohne daß es jemandem einfiele, aus einfachen Soldaten und Offizieren paritätische Ausschüsse zu bilden.

Mit diesen nebulösen, unklaren Vorstellungen von einer korporativen Gliederung des Staates, von einem starken Staat, von der Aufhebung der Gegensätze zwischen Kapital und Arbeit glauben die Vertreter der Rechtsparteien die soziale Frage gelöst $\mathrm{zu}$ haben und noch dazu eine ausgesprochen moderne und gerechte politische Haltung zu demonstrieren.

Geschwätz ist das alles! Die einzige Art und Weise, die soziale Frage zu lösen, besteht darin, die augenblickliche Wirtschaftsordnung von oben bis unter umzuformen. Diese Revolution der Wirtschaft wird auf keinen Fall zu einem Untergehen des Individuums im Staat, zur Staatsvergottung führen, mögen auch manche, die alles nachplappern, was ihnen zu Ohren kommt, ohne daß sie sich die Zeit nehmen, das Gehörte auch nur kurz zu überprüfen, dies als unseren Wunsch hinstellen.

Gerade die totale Revolution, die totale Reorganisation Europas muß beim Individuum anfangen; denn schließlich war es das Individuum, das am meisten zu 
leiden hatte, als die Welt aus den Angeln gehoben wurde, das zu einem Atom wurde, ohne Persönlichkeit, ohne Substanz, ohne Inhalt, ohne eigentliche Existenz, denn schließlich war es das Individuum, das zuletzt kam, als es darum ging, die Vorteile des Lebens wahrzunehmen. Die ganze Organisation, die ganze neue Revolution, die ganze Stärkung des Staates und die ganze wirtschaftliche Umstrukturierung wird nur das einzige Ziel haben, daß endlich auch die ungeheuren, durch die liberale Wirtschaft und durch den kommunistischen Versuch entwurzelten Menschenmassen in den Genuß dieser Vorteile kommen.

Und das nennt man Untergehen des Individuums im Staat? Im Gegenteil, das Individuum hat dann das gleiche Schicksal wie der Staat. Der Staat hat zwei klarumrissene Ziele, wie wir schon immer gesagt haben: eines nach außen hin, das Vaterland stark zu erhalten und zu behaupten, das andere nach innen, eine größere Anzahl Menschen glücklicher, menschlicher zu machen, sie intensiver am menschlichen Leben teilnehmen zu lassen. Und an dem Tage, an dem das Individuum und der Staat in totaler Harmonie vereint sind, wieder zur totalen Harmonie zurückgefunden haben, nur noch ein einziges Ziel, ein einziges Schicksal, ein einziges Los kennen, ja, an dem Tage kann der Staat stark sein, ohne zu tyrannisieren, denn nur dem Wohl und dem Glück seiner Untertanen wird er seine Stärke weihen. Das ist es, wozu sich Spanien in diesen Stunden aufraffen sollte: das Schicksal des Menschen und das Schicksal des Vaterlandes wieder in harmonischen Einklang zu bringen. Spanien müßte sich darüber klar werden, daß der Mensch nicht frei sein kann, nicht frei ist, wenn er nicht als Mensch leben kann, wenn man ihm nicht ein Existenzminimum zusichert; daß ihm dieses Existenzminimum nicht gewährt werden kann, solange nicht die Wirtschaft auf anderen Grundlagen aufgebaut ist, die es in stärkerem Maße ermöglichen, Millionen und aber Millionen von Menschen das Leben genießen zu lassen; daß die Wirtschaft nicht geordnet werden kann ohne einen starken Staat, der straff die Zügel führt; und daß es schließlich einen solchen starken Staat nur im Dienst einer großen Schicksalsgemeinschaft geben kann, nur im Dienste des Vaterlandes. Und dann seht, wie alles besser geht, seht, wie dieser titanische, tragische Kampf zwischen dem Individuum und dem Staat, der sich als Tyrann vorkommt, endlich ein Ende nimmt! Wenn dies einmal gelingt - und gelingen kann es; es ist dies der Schlüssel für die Existenz Europas, denn so war Europa, als es sich noch mit Recht so nannte, und so müssen Europa und Spanien auch wieder werden - wenn dies einmal gelingt, dann werden wir das sichere Gefühl haben: in jeder unserer Handlungen, in der einfachsten unserer Handlungen, in der unscheinbarsten unserer Alltagspflichten, stets dienen wir - abgesehen von dem bescheidenen Schicksal unserer eigenen Person - dem Schicksal Spaniens, dem Schicksal Europas, dem Schicksal der Welt, dem allumfassenden, harmonischen Schicksal der Schöpfung.

O. C., a. a. O., S. $51 \mathrm{ff}$. 


\section{Worte José Antonios an einige Kameradinnen nach der Versammlung in Don Benito (Badajoz), 28. 4.1935}

Ihr habt uns, Ihr Frauen aus Estremadura, zum Abschied begleiten wollen. Vielleicht ahnt Thr gar nicht die so tiefe Verwandtschaft zwischen der Frau und der Falange. Keine andere Partei werdet Thr besser verstehen können, gerade weil wir in der Falange weder zur Galanterie noch zur Emanzipation der Frau neigen.

Die Galanterie war nichts anderes als ein kleiner Schwindel gegenüber der Frau. Man bestach sie mit einigen artigen Schmeicheleien, um sie dann in eine Ecke zu stellen, in der ihr keinerlei ernsthafte Beachtung mehr zuteil wurde. Man unterhielt sie mit süßlichem Wortgeklingel, man verehrte sie, obwohl und weil man sie für dumm hielt, um sie zur Rolle eines leichtfertigen und oberflächlichen Zierats zu verurteilen. Wir aber wissen, in welche Tiefen die Herzenswärme der Frau und ihre Aufgaben reichen. Wir werden uns sehr hüten, sie so zu behandeln, als verdiene sie nur dumme, fade Schmeicheleien.

Anhänger der Frauenbewegung sind wir ebensowenig. Wir sind nicht der Ansicht, daß man die Frau am besten dadurch ehren könne, daß man sie ihrer wunderbaren Bestimmung entzieht und ihr männliche Lebensaufgaben zuteilt. Mich hat es stets mit Trauer erfüllt, wenn ich eine Frau sich mit Mannesarbeit quälen sah, wenn sie sich in einem Konkurrenzkampf müht und abrackert, in dem sie von vornherein auf verlorenem Posten steht und in dem sie noch dazu der krankhaften Schadenfreude ihrer männlichen Mitbewerber ausgesetzt ist. Die echte Frauenbewegung dürfte nicht darin bestehen, für die Frauen diejenigen Lebensaufgaben zu erstreben, die man heutzutage für die höheren hält. Man müßte sich vielmehr darum bemühen, die Aufgabe der Frau mit immer größerer menschlicher und sozialer Würde zu umgeben.

Doch aus demselben Grunde, aus dem wir weder galant noch Anhänger der Emanzipation sind, ist unsere Bewegung zweifellos diejenige, welche von einem gewissen, wesentlichen Gesichtspunkt aus am besten einen weiblichen Sinn des Lebens erfaßt. Ihr habt ohne Zweifel diese Erklärung nicht aus dem Munde eines Mannes erwartet, der - unwürdiger darin als seine Gefolgsleute - so viele prächtige Scharen junger Männer führt.

Die geistigen Bewegungen des einzelnen oder der Menge entsprechen stets einem dieser beiden Worte: Selbstsucht oder Selbstverleugnung. Die Selbstsucht sucht die Befriedigung ihrer Sinne auf direktem Wege zu erreichen; die Selbstlosigkeit verzichtet auf sinnliche Befriedigung zugunsten einer höheren Ordnung. Wenn man nun entscheiden sollte, welches der beiden Geschlechter die eine dieser angeborenen Eigenschaften in stärkerem Maße aufweist, so zeigt sich deutlich, daß die Selbstsucht dem Manne und die Selbstlosigkeit der Frau entsprechen würde. Der Mann - leider muß ich, Thr Mädchen, mit diesem Bekenntnis ein wenig dazu beitragen, den Sockel, auf den Ihr ihn vielleicht gestellt hattet, ein wenig zu erniedrigen - 
ist selbstsüchtig wie ein reißender Strom. Die Frau dagegen nimmt fast immer ein Leben der Unterwerfung, des Dienens, der selbstlosen Hingabe an eine Aufgabe hin.

So ist auch die Falange. Wir, die wir in ihren Reihen kämpfen, müssen auf die Annehmlichkeiten, auf die Ruhe, ja sogar auf alte Freundschaften und tiefverwurzelte Zuneigungen verzichten. Wir müssen unseren Körper bereitwillig schmerzenden Wunden aussetzen. Wir müssen mit dem Tode rechnen als einem Akt des Dienens - viele unserer Besten haben es bewiesen. Und, was das schlimmste ist, wir müssen von Ort zu Ort gehen und uns heiser schreien inmitten der Verleumdung, der üblen Nachrede, der Gleichgültigkeit und der Selbstsucht, der Feindschaft derer, die uns nicht verstehen und uns aus ihrem Unverständnis heraus hassen. Mit Beleidigungen überschütten uns die, die uns der Verfolgung dunkler Ziele verdächtigen oder in unserer echten Sorge nur einen Vorwand sehen. Das ist das Los der Falange. Und als wäre ein Wunder geschehen: je weniger in ihr die Selbstsucht zu erwarten hat, desto stärker wächst und vermehrt sich die Falange. Für jeden von uns, der als Held fällt, für jeden, der, feige und kleinmütig geworden, die Fahne verläßt, kommen zehn, hundert, fünfhundert andere, um an seine Stelle zu treten.

Seht, Ihr Frauen, wie wir zu unserer Haupteigenschaft die Selbstlosigkeit gemacht haben, gerade jene Eigenschaft, die vor allem Euch auszeichnet. Gebe Gott, daß auch wir darin eine solche Höhe erreichten! Gebe Gott, daß wir darin einmal so weiblich würden, daß Ihr uns eines Tages wirklich betrachten könntet als „Männer"!

O. C., a. a. O., S. $167 \mathrm{ff}$.

VOR DEM VATERLAND IN TRÜMMERN

\section{Rede im Cervantes-Theater in Málaga 21. Juli 1935}

Diese von der spanischen Falange veranstaltete Kundgebung mag uns an frühere Tatsachen erinnern; sie ruft in uns neue Erregung hervor. Wenn wir Versammlungen auf Fußballspielplätzen mit bezahlten Reisen und prächtigen Festessen organisieren würden, würden sich selbstverständlich sehr viele Menschen einfinden. Aber niemals habe ich mich so befriedigt gefühlt wie in dieser Luft des Vertrauens, der Vertrautheit, der Hemdsärmeligkeit; es sind doch alles Zeichen reiner und einfacher Kameradschaft.

Angeregt durch den vertraulichen Ton, der bei dieser Kundgebung in Malaga herrscht, würde ich Euch einladen, in die Umgebung, auf das Feld zu wandern, Euch behaglich unter den Schatten eines Baumes zu setzen und die Beine übereinanderzuschlagen. Dann könnten wir unsere Eindrücke austauschen und von unseren frohen Stunden, unseren Sorgen und Hoffnungen plaudern.

Unter dem Schutz des Baumes und in dieser Luft des Vertrautsein würde ich 
meine Gedanken schweifen lassen, und vielleicht würde mir die Erinnerung an die Eroberer Amerikas durch den Kopf gehen, die weniger, viel weniger waren als wir. Sie landeten auf dem jungfräulichen Boden Amerikas, wo es noch keinen einzigen weißen Mann gab. Und auf der Höhe irgendeiner Gebirgskette - die Mondscheibe über ihren Häuptern und so weit das Auge reicht die unendliche Ausdehnung der Pampas - begannen sie, die Grundsteine zu legen für den künftigen goldenen Ruhm eines riesigen Reiches.

Laßt uns ruhig so sprechen, als ob wir im Schatten eines Baumes säßen.

Wißt Ihr, Kameraden, liebe Kameraden der Málaga-Sektion der spanischen Falange, wozu wir Euch riefen und Euch baten, wir, die alten Kämpfer aus der Frühzeit, wißt Thr, welches Eure Mission in der Falange sein soll? Ihr sollt es erfahren.

Uns, der Jugend von heute, hat es das Schicksal bestimmt, die Welt in diesem Zustand zu erblicken: die alte Welt und die soziale Ordnung zerbrechen, sie lösen sich auf, und ein Vaterland, einst groß und mächtig, liegt in Trümmern vor uns. Das kapitalistische System windet sich in Todeskrämpfen.

Die kapitalistische Wirtschaftsordnung war eine Notwendigkeit, als die Großindustrie wuchs; sie brachte zwangsläufig die Anhäufung des Kapitals mit sich. Aber die Großindustrie wuchs immer weiter und verschlang gleichzeitig die kleinen Kapitalien und die kleine Industrie. Von Beginn an war der Kapitalismus der große Feind des Arbeiters, den er für die namenlosen Reihen in der Fabrik anwarb. Ebenso war er der Feind des kleinen Kapitals; er saugte die Quellen der Produktion auf und vernichtete sie. Und an die Stelle des Menschen, des kleinen Gewerbetreibenden, setzte er ein paar seelen- und herzlose Papierschnitzel. Der Kapitalismus verwandelte die Menschen, die Arbeiter, in Proletarier, also in arme Wesen, die, von den Produktionsmitteln getrennt, auf eine Bezahlung warteten, weil sie drükkende und ermüdende Arbeit geleistet hatten.

Das Kapital verschlang den Arbeiter und die Industrie; es verschlang, was es erreichen konnte. Damit begann es auch, sich selbst zu verschlingen. Der Hunger wächst in den Proletarier-Schichten, die Zahl der Erwerbslosen nimmt beträchtlich zu. Aber das sterbende System bietet nicht die Möglichkeit auch nur eines geringen Schutzes.

Soviel zur sozialen und wirtschaftlichen Ordnung!

Wir haben nun außerdem ein Vaterland vorgefunden, das nicht einmal mehr die Erinnerung an seine große Zeit ehrt. Als Ihr Euch für die Reifeprüfung vorbereitetet, da gab es immer einen albernen Lehrer - erinnert Ihr Euch daran? -, der sich alle erdenkliche Mühe gab, Euch zu zeigen, daß der Apostel Santiago in der Schlacht von Clavijo zugegen war. Erinnert Ihr Euch nicht, wie die ganze Wissenschaft dieses Lehrers sich darauf beschränkte, die Wichtigkeit dieser Tatsache herauszustellen? Nichts lag ihm daran, und er bemühte sich nicht einmal darum, sich mit anderen Fragen zu beschäftigen, die von Spaniens Ruhm kündeten.

Sie erzählten uns von der Entdeckung Amerikas und zugleich von der Ungeschicklichkeit derer, die in jene Länder zogen, um sie zu erobern. Verurteilten sie nicht die Einmischung in die europäischen Religionskriege, wenn sie von Karl V. 
und Philipp II. erzählten? Der armselige Professor bekämpfte sie, ohne die bedauerliche Tatsache zu berücksichtigen, daß er selbst ihnen in den kritischen Augenblicken der Entscheidung nicht beigestanden hatte, um sie gut zu beraten!

Kein ehrendes Erinnern gab es mehr. Aber noch etwas kam hinzu: wir fanden ein morsches Vaterland vor, heruntergekommen, wehrlos, in Trümmern, die Küsten offen für die Feinde, ungeschützt gegen jeden möglichen Angriff.

Es war ein Vaterland, das sogar in seine Verfassung die Worte schreiben ließ: „Spanien verzichtet auf den Krieg." Spanien verzichtet auf den Krieg, mit anderen Worten, wenn es angegriffen, will es sich nicht verteidigen. Das ist gerade so als ob man sagte: „Du hast mir eine Ohrfeige gegeben, Du darfst mir noch eine geben, so viele wie Du magst, aber ich denke nicht daran, mich zur Wehr zu setzen." Das ist doch eine Schande, eine Schmach! Spanien ließ es zu, daß solche Worte in die Verfassung hineingeschrieben wurden!

Als wir die Augen aufschlugen, da sahen wir dieses niedergedrückte, in den äußersten Winkel gedrängte, waffenlose Vaterland, seine soziale und wirtschaftliche Ordnung, die es tatenlos zuließ, daß die Zahl der Hungrigen, der Hungerleider, der Elenden wuchs. Wir sahen, wie unsere Zeitgenossen in zwei Lager gespalten waren, in das der Rechten und das der Linken.

Die spanischen Rechtsparteien haben sich offenkundig bemüht, uns zu beweisen, daß der Apostel Santiago tüchtige Hiebe in der Schlacht bei Clavijo ausgeteilt hat. Diese Sorge beschäftigte sie sehr; aber sie hatten keinen Blick für die Nöte, die drückenden Sorgen, die qualvolle Lage des spanischen Volkes.

Als wir Tag für Tag durch die spanischen Lande zogen, hatten wir genug Gelegenheit, diese unglücklichen Verhältnisse zu beobachten. In der Provinz León, wo das Klima hart ist, nicht mild und weich wie in Málaga, haben wir gesehen, wie die Leute in Erdlöchern wohnten, in ausgehöhlten Erdhaufen, um ein Dach über dem Kopf zu haben.

Wie wir, so werdet auch Ihr bemerkt haben, daß der Mann vom Morgen bis zum Abend für eine armselige Gazpachosuppe arbeitet, und in den Brachfeldern öder steiniger Gegenden werdet Ihr Menschen angetroffen haben mit strahlenden Augen, wie in den besten Zeiten zu jedem Unternehmen fähig, Menschen aber, die ein elendes Leben unter Schmerzen führen. Wenn Haustiere so leben müßten, würden wir empört aufschreien.

Nun gut, Kameraden. Die Rechtsparteien haben zwar auch davon gesprochen, aber niemand hat sich Mühe gegeben, diese Verhältnisse zu ändern. Und doch wäre Abhilfe mit ein wenig Opferfreudigkeit möglich gewesen. Aber diejenigen, die den Ruhm des Vaterlandes so laut verkünden, kümmern sich gar nicht um diejenigen, die auf dem harten Boden der Provinz León ihr Leben fristen müssen.

Die Linksparteien haben in alle Welt hinausgeschrien, man müsse zu einer wahren sozialen Gerechtigkeit kommen, sie möge sein wie sie wolle. Aber gleichzeitig bemühten sie sich, in der Seele des Arbeiters jede geistige Regung, jedes religiöse Empfinden zu töten. $\mathrm{Haß}$ brachten sie den Arbeitermassen bei, aber nicht, weil sie das Vaterland besser gestalten, oder eine bessere soziale Gerechtigkeit ein- 
führen wollten, sondern weil sie selber aufzusteigen wünschten, und zwar auf dem Rücken der Massen. Sie begehrten als Herren ein großes Wort zu führen.

Unter diesen Verhältnissen hatten wir zu wählen, uns für die Rechts- oder Linksparteien zu entscheiden. Aber wir wußten nicht, wo wir uns einreihen sollten; die einen besaßen keinen Mut zur sozialen Tat, die anderen verschleuderten Größe und Ruhm des Vaterlandes. Da beschlossen wir, uns in unseren Elfenbeinturm einzuschließen; wir wollten die Dinge abwarten, und wir hielten es für schön, so abgekehrt von den Nöten des Volkes zu leben.

So lebten wir dahin. Aber da kam zum Glück die Revolution und weckte uns aus unserem Traum. Eine Revolution überraschte uns und packte uns so plötzlich, wie man unentschlossene Kinder faßt und ins Wasser wirft. Und nun müssen wir alle schwimmen, ob wir wollen oder nicht.

Ihr werdet sehen, wie wir schwimmen und wie weit wir kommen, denn wir haben jene beiden Forderungen vereinigt; darin besteht unser Ruhm und unsere Fruchtbarkeit. Was sollen Lieder und Geschrei auf der Straße, wenn nichts von sozialer Gerechtigkeit zu hören und zu sehen ist? Und was ist das für eine Art, die Arbeiter zu betrügen und ihnen zu verschweigen, daß man frei und stark sein kann in einem großen, freien und gerechten Vaterland!

Wir haben unsere Schläfrigkeit abgeschüttelt und unseren Beruf geopfert, um durch Spanien zu ziehen, an strengen Tagen, bei Hitze und bei Kälte, aber ehrlich und treu. Wir sagen den Arbeitern: „Viele von uns spüren nicht die Not und den Hunger, die Euer Heim zerstören und Euer Leben zugrunde richten. Trotzdem gehen wir auf die Straße, um Eure Sache zu verteidigen. Wir sind bereit, dafür unser Leben hinzugeben!" Das ist keine Unehrlichkeit, kein neuer Betrug; wir können auf eine Schar von Gefallenen zurückblicken.

Wie durch ein Wunder ist diese, unsere Jugend, auf eine Ader der Tapferkeit und des Heroismus gestoßen, die gleichsam tiefverborgen in der Erde ruhte und jetzt eine größere Kraft und eine größere Frische verleiht als in den besten Zeiten. Hier habt Ihr die Liste der Gefallenen. Da steht der Name Matias Monteros: er war der Gründer des Katholischen Studentensyndikates. Er wußte, daß ihm der Tod drohte, aber er schlug nicht einmal einen anderen Weg ein, um heimzugehen. Dann Jesus Hernandez, ein Junge von 15 Jahren. Eine Kugel traf ihn in der Schulter, doch auf der Unfallstation, schon wachsbleich und vom Todeskampf geschüttelt, konnte er noch das alte Lied der J.O.N.S. singen: „Einen spanischen Tod begehre ich."

Und dieser Manuel Garrión, Geschäftsführer eines Hotels in San Sebastian! Stellt Ihr ihn Euch nicht ruhig, mild und friedfertig vor, sehr gewandt in der Ausübung seines Berufes? Er muß wohl ein Vorbild an Liebenswürdigkeit und Herzenstakt gewesen sein. Dann spürte er den Ruf des Heldentums, er verfaßte einige Blätter auf Baskisch und Kastilisch und eilte hinaus, um sie auf der Straße zu verteilen. Er wurde mit dem Tode bedroht und eines Tages schoß man ihm durch die Schulter. Er starb, ohne dem Leben irgendeinen Wert beizumessen. Ihm lag nur am Sieg des Ideals, dafür vergoß er sein Blut. 
Aus diesem Holz sind unsere Toten, sind die Lebenden. Heute gibt es in Sevilla 13 verhaftete Kameraden. Als Manuel García starb, heiter und dem Feind trotzend, nahm ihn einer von diesen 13 in die Arme, damit ihn der Pöbel nicht verstümmele. Er taumelte, fiel hin, raffte sich wieder auf, konnte eine beschützte Stelle noch erreichen. Dann küßte er ihn auf die Stirn und sagte zu ihm: „Hoch lebe Spanien!“

Glaubt ihr nun angesichts solcher Tatsachen an die Fruchtbarkeit der spanischen Falange? Kürzlich liefen zwei Jungen, von Flammen erfaßt, auf die Straße und riefen: „Dies ist ein kommunistisches Attentat!" Ist das nicht wiederum ein Beispiel dafür, wie fruchtbar die Idee ist und mit welcher Liebe wir ihr dienen? Zeugt das nicht von Heldentum? Sie sorgten sich nicht um den brennenden Leib, sondern wollten nur verhindern, daß die Organisation für ein Attentat verantwortlich gemacht wird. Solche Taten geschehen Tag für Tag. Die einen fallen auf der Straße, getroffen, ermordet. Andere schmachten im Gefängnis, von wo sie uns rührende Briefe schreiben. Solche Menschen zu führen, macht Freude.

Diese Opfer und diese Leute, die uns Briefe von tiefem, heißem Empfinden schreiben, geben uns das Recht zu führen. Deshalb rufen wir Euch alle auf, die Ihr begierig darauf wartet, Spanien wieder eine sichere und dauerhafte soziale Gerechtigkeit zu geben und neuen Ruhm.

Es ist nun endlich an der Zeit, daß ein Volk, welches viele Möglichkeiten in sich birgt, aufhört, von ein paar hergelaufenen Leuten wie eine Kuh gemolken zu werden. Das Volk muß sich auch der Geldleiher und Bankiers entledigen. Sie sind Feinde der Arbeiter und der Arbeitgeber. Dafür setzen wir uns ein, dafür setzen wir alles aufs Spiel. Was wir zu opfern haben, opfern wir auch, wenn wir gegen diesen und jenen kämpfen müssen. Dies sagen wir, obgleich es, wie schon Raimundo Fernandes Cuesta ${ }^{1}$ angedeutet hat, Leute gibt, die unser Tun für unnötig halten. Wir hätten, so sagen sie, ja doch eine Regierung der Ordnung, es sei ja gar kein Grund zu Besorgnissen gegeben, die Dinge nähmen ja einen recht guten Lauf.

Nichts davon, meine Herren! Die Lage ist gar nicht gut, denn wir stehen vor einer größeren Revolution als der Oktoberrevolution. Sie ist besser organisiert, und unsere Söhne sollen sich nicht bei dem Gedanken an die Menschen schämen, die sich vom frühen Morgen bis zum späten Abend abschinden für eine erbärmliche dünne Suppe. Wieviele spanische Bürger müssen wie Schweine ihr Dasein fristen!

Mit all diesem sind wir nicht einverstanden. Wir fügen uns auch nicht dem Verlangen, auf der Straße nicht mehr zu schießen, weil doch angeblich alles gutgehe. Wenn es nötig ist, werden wir auf die Straße eilen und schießen, gerade damit die Verhältnisse nicht so bleiben, wie sie sind.

Die Parole für diesen Sommer kennt Thr schon. Es bedarf einer Mischung von Energie und Nachgiebigkeit, um die träge soziale Gleichgültigkeit, aber auch die Arbeitsunlust zu bekämpfen. Ihr sollt die Störenfriede Spaniens sein; jeder von

1 Mitglied des National-Rates der FE, zu Beginn des Bürgerkrieges auf republikanischer Seite verhaftet, später im Zuge eines Gefangenenaustausches an Franco-Spanien übergeben. Als Repräsentant der alten Falange wird er später unter Franco Minister verschiedener Ressorts. 
Euch muß wie ein Stachel sein, der allen zeigt, daß wir uns mit den jetzigen Verhältnissen nicht zufrieden geben. Dies ist unsere Aufgabe, und um ihretwillen wollen wir in der vordersten Kampflinie auf Posten stehen.

Wir Falangisten veranstalten keine Massenversammlungen auf Fußballplätzen. Wir geben auch kein Geld für Freifahren und Festessen. Man wird Euch die albernsten Geschichten von unserer Bewegung erzählen. Man wird Euch einreden, die Falange sei ein Bataillon von Kindern, das die Gewalttat verherrlicht. Das macht nichts! Die gleichen Redensarten werdet Ihr in den nächsten zehn Jahren immer wieder hören. Und genauso wie heute wird man uns weiter bekämpfen. Das macht nichts! Wir marschieren unentwegt vorwärts. Und wir werden in Málaga bei dieser Julihitze oder in den kalten Gebirgen des Nordens zusammenkommen. Überall werden wir wie bisher unsere Eindrücke austauschen, ohne uns um das Gerede der Leute zu kümmern. Wir machen uns nichts daraus! Eines Tages wird jeder einzelne im Grab seine Gebeine zittern fühlen unter dem wuchtigen, sieghaften Schritt der neuen Legionen. Hoch lebe Spanien!

O. C., a. a. O., S. $171 \mathrm{ff}$.

\section{ÜBER DIE REVOLUTION}

Die Masse eines Volkes, das eine Revolution braucht, vermag die Revolution nicht zu machen.

Die Revolution ist nicht in dem Augenblick erforderlich, in dem das Volk darniederliegt, sondern dann, wenn seine Institutionen, seine geistigen Vorstellungen und seine Wünsche unfruchtbar oder nahezu unfruchtbar geworden sind. In diesen Augenblicken tritt die geschichtliche Dekadenz zutage. Nicht der Tod durch hereinbrechendes Unglück, vielmehr das dumpfe Abgleiten in eine reiz- und hoffnungslose Existenz. Jede Haltung eines Kollektivs - ein Produkt gleichsam von Erzeugern, deren Zeugungskraft versiegt ist - trägt schon im Augenblick ihres Entstehens den Keim des Unterganges in sich. Das Leben der Gemeinschaft siecht dahin, stumpft ab, geht unter in schlechtem Geschmack und in Mittelmäßigkeit. Dem läßt sich nur durch einen Bruch mit der Vergangenheit und mit einem neuen Beginn begegnen. Die Furchen bedürfen eines neuen Samens, eines geschichtlichen Samens, da der alte seine Fruchtbarkeit verloren hat.

Doch wer soll der Sämann sein? Wer soll den neuen Samen auswählen und den Augenblick bestimmen, ihn der Erde zu übergeben? Darin liegt die Schwierigkeit. Hier stoßen wir auf den demagogischen Wortschwall von links und rechts, auf die widerlichen Lobhudeleien derer, die bei der Masse Stimmen und Beifall suchen. Sie stellen sich vor das Volk und sagen: „Volk, Du bist wunderbar, Du bist der Born der höchsten Tugenden, Deine Frauen sind die schönsten und reinsten der Welt, Deine Männer die klügsten und mutigsten, Du besitzt die verehrungswürdigsten Sitten, die reichste Kunst. Dir ist lediglich das Mißgeschick widerfahren, 
schlecht regiert zu werden. Schüttele das Joch dieser Regierung ab, befreie Dich von ihren Banden, und es wird Dir gutgehen." Das heißt mit anderen Worten: "Volk, mach Dich selbst glücklich durch einen Aufstand."

Solche Worte enthüllen entweder eine widerliche Unaufrichtigkeit, die sich nur zum eigenen Vorteil der Sprache als Köder bedient, um die Masse zu übertölpeln, oder aber einen vollkommenen Unsinn, womöglich noch verderblicher als der Betrug. Niemandem, der auch nur wenig überlegt, kann diese Wahrheit entgehen: wenn ein Volk am Ende einer unfruchtbaren Zeit die großen Triebfedern seines Handelns - durch eigenes oder fremdes Verschulden - rostig werden lie $\beta$, wie könnte es dann von sich aus die ungeheure Aufgabe einer Regeneration bewerkstelligen? Eine Revolution, die fruchtbar sein und nicht ins Leere gehen soll, fordert unabdingbar das klare Bewußtsein für eine neue Norm sowie den entschlossenen Willen, die Revolution auch durchzusetzen. Doch diese Fähigkeit, die Norm zu erkennen und durchzusetzen, ist ja gerade ein Mißgeschick. Denn sollte die Kraft gegeben sein, die Revolution durchzusetzen, so ist dies doch ein untrügliches Zeichen dafür, daß die Revolution nicht notwendig ist. Und umgekehrt erkennt man die Notwendigkeit dex Revolution daran, daß die erforderliche Klarheit und der Antrieb fehlen, sie liebend zu wollen und in die Tat umzusetzen. Mit einem Wort: das Volk als Masse ist nicht imstande, sich selbst zu retten, da die Tatsache, zur Rettung befähigt zu sein, der Beweis dafür ist, bereits gerettet zu sein. Pascal glaubte, Christus habe zu ihm gesagt: „Du würdest mich nicht suchen, hättest Du mich nicht längst gefunden." So könnte es auch der Genius der Revolutionäre den Völkern sagen.

Unter den Revolutionsführern, welche die Weltgeschichte kennengelernt hat, treffen wir verhältnismäßig häufig auf diese beiden Typen: den Anführer, der auf der Suche nach Ruhm, Macht oder Reichtum eine Masse um sich sammelt, um auf ihrem Rücken groß zu werden, und den Vergötzer des Volkes, der in seinem Glauben an die eingeborene Kraft des Volkes - Volk als Masse betrachtet - seinen eigenen Weg finden will. Der Anführer pflegt vom Gesichtspunkt der privaten Moral weniger empfehlenswert zu sein. Er hat kaum Skrupel, er raubt die Gesellschaft, die ihn trägt, aus und tyrannisiert sie. Der Vorteil liegt jedoch darin, daß er mit einem Schlag beseitigt werden kann. Mit seinem Tode endet alle Drangsal. Der andere hingegen hinterlä $\beta t$ einen bleibenden Eindruck und ist, von seiner geschichtlichen Mission her gesehen, ein größerer Verräter als der Anführer.

Jawohl, der größere Verräter. Ich benutze das Wort Verräter ohne jede melodramatische Absicht, vielmehr als einfache Bezeichnung für denjenigen, der seinen Posten in einem entscheidenden Augenblick verläßt. Gerade das pflegt der Vergötzer des Volkes zu tun, wenn ihn der Zufall auf die Kommandobrücke einer siegreichen Revolution stellt. Ist er oben, hat er in selbstgewählter Mühe die Spitze erklommen und in denen, die ihm folgen, einen Glauben entzündet, dann hat er selbstverständlich damit auch die Aufgabe übernommen, zu befehlen, zu leiten, den Weg zu weisen. Wenn er nicht so etwas wie den Ruf eines fernen Hafens in sich verspürte, hätte er nicht nach der Führung greifen dürfen. Wer Führer ist, 
siegreich bleibt und dann aber der Masse am nächsten Tag sagt: „Jetzt sollst Du befehlen; ich stehe hier, um Dir zu gehorchen!" der entzieht sich feige der Verantwortung. Der Führer darf dem Volk nicht gehorchen, er hat ihm zu dienen. Das ist etwas völlig anderes. Dem Volk dienen heißt, die Befehlsverhältnisse zum Wohle des Volkes klären und auch dann für das Wohl des Volkes sorgen, wenn es selbst seine Aufgabe nicht erkennt. Dem Volk dienen heißt, sich in Übereinstimmung mit dem geschichtlichen Schicksal des Volkes fühlen, auch wenn es im Gegensatz zu dem Fühlen und Wünschen der Masse steht.

Das gilt um so mehr in revolutionären Zeiten, wenn, wie bereits gesagt, das Volk eine Revolution benötigt, aber nicht mehr fähig ist, das Gute zu erstreben, wenn es sich sozusagen den Magen verdorben hat. Gerade von dieser Krankheit soll es geheilt werden. Das ist das Wunderbare. Und das Schwierige. Deshalb fliehen die schwächlichen Führer vor der Aufgabe und geben, um ihre Schwäche zu verbergen, vor, den Dienst am Volke, das Suchen nach einer schwierigen Harmonie zwischen der Wirklichkeit des Volkes und seiner wahrhaften Bestimmung durch Gehorsam zu ersetzen. Das aber ist, wie jede andere auch, eine besondere Form der Schmeichelei, der Korruption.

Spanien hat dies vor kurzem zum Teil erkannt: im Jahre 1931. Selten hat die Masse eine so einfache und bescheidene Haltung eingenommen wie damals. Froh hob sie diejenigen empor, welche sie für die besten hielt, froh schickte sie sich an, ihnen zu folgen.

Auf diese Weise konnten die Männer mühelos an die Spitze des Staates gelangen, die seit vielen Jahren die kritische Diagnose gestellt hatten. Es versteht sich, daß ich dabei nicht an die Demagogen denke, sondern an jene kleine erlesene Gruppe, die unter vielen Qualen - zuerst verzweifelter Widerwille, dann aber inbrünstiger Scharfblick - die Sehnsucht nach einem klareren, reineren, erfüllteren Spanien repräsentierten, nach einem Spanien, das endlich frei von soviel traditionellem Schmutz und soviel widerlicher Mittelmäßigkeit sein sollte. Den Männern dieser Gruppe war die Aufgabe gestellt, neue geschichtliche Aktivität zu entfachen, frische Triebe zu pflanzen, die die alten kraftlosen Stämme ersetzen sollten. Diese Männer waren dazu berufen, dies alles gegen jeden Widerstand durchzusetzen, auch gegen den ihrer Revolutionsgenossen, auch gegen den der Masse selbst. Die Führer einer revolutionären Bewegung haben sogar die Anschuldigung zu ertragen, Verräter zu sein. Stets glaubt die Masse, verraten zu werden. Nichts ist nutzloser als der Versuch, ihr zu schmeicheln, um dieser Anschuldigung zu entgehen. Vielleicht haben die geistigen Führer des Jahres 1931 der Masse nicht geschmeichelt, aber sie besaßen auch nicht den Mut, sich ihr entgegenzustellen, um sie Disziplin zu lehren. Mit einer verächtlichen Geste zogen sie sich wieder in ihr Schneckenhaus zurück und überließen das Feld den plumpen Demagogen wie kühnen, tatkräftigen Anführern. So wurde, wie so oft, eine Gelegenheit für Spanien vertan. Die nächste wird nicht vertan werden. Wir haben bereits gelernt, daß die Masse sich selbst nicht zu retten vermag. Und daß es für die Führer keine Entschuldigung gibt, wenn sie desertieren. Die Revolution ist die Aufgabe einer entschlossenen Minderheit, unerreichbar für 
jedwede Mutlosigkeit. Eine Minderheit, deren erste Schritte die Masse nicht verstehen wird, weil sie, Opfer einer dekadenten Periode, verlor, was das teuerste ist: ihr inneres Licht. Aber diese Minderheit wird schließlich die unfruchtbare Verwirrung unseres Gemeinschaftslebens ersetzen durch die Freude und die Klarheit einer neuen Ordnung.

„HAZ"1 Nr. 9, 12.10. 35

O. C., a. a. O., S. $547 \mathrm{ff}$.

19

\section{DIE POLITIK UND DER INTELLEKTUELLE}

\section{Lob und Tadel für Don José Ortega y Gasset}

Am 5. Dezember 1935 veröffentlicht José Antonio in dem falangistischen Studentenblatt „Haz" aus Anlaß des silbernen Professorenjubiläums von José Ortega y Gasset einen Artikel, der schon in seiner Überschrift das eigenartige, zwischen „Lob" und „Tadel“, Zustimmung und Ablehnung, Verehrung und Enttäuschung schwankende Verhältnis von jungen Falangisten zu dem wissenschaftlich wie zu Beginn der Republik auch politisch exponierten Lehrer an der Madrider Zentraluniversität erkennen läßt.

Wie in der Einleitung skizziert, zählten sich viele junge Falangisten zu den Schülern und Adepten Ortegas. Ihre politischen und gesellschaftlichen Auffassungen wie ihr politisches Vokabular waren durchsetzt von den in blendendem feuilletonistischen Stil vorgetragenen Theorien Ortegas ${ }^{2}$. Aber so wie sich die Falange in ihrer Interpretation der Geschichte, der Definition des Staates und der Nation, in ihrer Elite-Lehre wie überhaupt in der Begründung ihrer politischen Dynamik stark an Ortega anlehnte und sich auf ihn berief, so sah sie in ihm andererseits auch den Exponenten einer politisch aktiven Schicht von Intellektuellen - meist Professoren und Schriftstellern -, die als Politiker in den ersten Jahren der Republik nach Ansicht der Falange scheitern mußten, weil sie ihre politische Konzeption einer Erneuerung Spaniens nach dem Sturz der Diktatur Primo de Riveras innerhalb eines demokratischen Herrschaftssystems glaubten verwirklichen zu können ${ }^{3}$.

Ortegas Enttäuschung über den Weg der Republik, die er selbst mit vorbereitet hatte ${ }^{4}$, seiner Abwendung von der Politik durch die Auflösung der von ihm gegründeten "Gruppe im Dienst des Staates", sein berühmtes, resignierendes „esto

1 Im März 1935 erschien „HAZ“, ein falangistisches Blatt für die im Sindicato Español Universitaria vereinten Studenten, zum ersten Male. Jedoch kam es über Flugblattcharakter nicht hinaus und erschien nur sporadisch.

2 Vgl. S. 21.

3 Die Universitäten waren Kernzellen für die Vorbereitung der Republik. Radikale politische Studentengruppen gehörten ins Alltagsbild spanischer Universitätsstädte; Professoren standen in der ersten Reihe alter und neuer republikanischer Parteien. Wie Ortega gehörten viele Professoren den verfassungsgebenden Cortes an. Mit der fortschreitenden Radikalisierung des politischen Lebens ging ihr Einfluß, aber auch ihre Bereitschaft, politisch alstiv zu bleiben, zunehmend zurück. So schreibt z. B. der berühmte Rechtsgelehrte Sanchez Román: „Die Republik hat ihr Gesicht verloren" (El Imparcial v. 14. 4.33); Unamuno konstatiert "die Agonie des Regimes" (El Imparcial v. 12. 4. 33).

4 Am 15. 11. 30 veröffentlicht Ortega in „El Sol" sein berühmtes „Delenda est Monarchia“, das in dem Appell gipfelt, nun „ein wahres Spanien" zu schaffen. 
no es" - „dies ist es nicht, diese Republikaner sind nicht die Republik"1, wertet José Antonio als Bestätigung für die Richtigkeit der von der Falange propagierten Herrschaftsform und des von ihr zur Erreichung dieses Zieles eingeschlagenen Weges. „Andere Arme, die kräftiger und viel eindeutiger zuzuschlagen verstehen, nehmen die Aufgabe jetzt auf sich."

Trotz der höflichen Worte, die José Antonio in dem Jubiläumsartikel dem „fernen Meister" seiner Generation widmet, beinhaltet er die Absage der Falange an den sich gerade in Ortega personifizierenden Intellektualismus in der Politik. Der Vorwurf gegen jene kleine "erlesene Gruppe geistiger Führer", die sich, wie José Antonio in dem vorangestellten Artikel "Über die Revolution“ schrieb, „mit einer verächtlichen Geste" wieder „in ihr Schneckenhaus" zurückzogen und das Feld plumpen Demagogen und tatkräftigen Anführern überließen, wird in dem Ortega gewidmeten Artikel wieder erhoben und mit einer für alle faschistischen Bewegungen typischen Polemik gegen die zweifelnden, fragenden, ständiger Kontrolle und Revision des bezogenen Standpunktes zugetanen Intellektuellen verbunden. Sie sind für die Falangisten geradezu das Synonym für den unfruchtbaren Parlamentarismus. An die Stelle des Politikers hat der mit der Strahlungskraft eines großen Glaubens erfüllte, charismatische Führer zu treten, an die Stelle einer geistigen Argumenten offenen Diskussion der gläubig akzeptierte Appell.

Ist die Politik eine Angelegenheit der Intellektuellen? Aufdiese Frage, in allerÖffentlichkeit gestellt, würden sofort zwei verschiedene Personengruppen antworten.

Zur ersten Gruppe gehören diejenigen, die sich für unmittelbar angesprochen halten, das heißt, die sich selbst als Intellektuelle bezeichnen. Viele von ihnen reden, wie wir wissen, über jedes Thema mit affektiert-wichtigtuerischer Stimme, mit gerunzelter Stirn und in dem unwiderstehlichen Bestreben, jedes Gespräch in das Gerüst schwerverständlicher Fachausdrücke zu zwingen, ob sie nun zum Thema passen oder nicht. Andere subalterne Geister wiederum sind überaus empfindlich, so empfindlich gar, daß sie sich vor lauter Furcht, als könne nur schon ein Windhauch ihr Lebenslichtchen ausblasen, nicht auf die Straße wagen. Sie setzen sich in schummerigen Kämmerchen zusammen, wo sie sophistischen Wortspielen einen allerdings nur noch Eingeweihten ersichtlichen Hauch von Schönheit abzugewinnen suchen. Und wenn jemand fragt, was für einen Beitrag denn die einen die Affektierten - und die anderen - die Mimosen - zum menschlichen Denken geleistet haben, so wird er von der Antwort überrascht, daß, was sie hervorgebracht haben, nur aus einer einzigen Zeile besteht, vielleicht auch aus hundert Seiten nichtssagender Hybris. Wer so etwas liest, der vermag allerdings nicht zu begreifen, wie die Verfasser zu der tröstlichen Überzeugung kommen konnten, dem Rest der Sterblichen überlegen zu sein. Manche haben auch tatsächlich einige unverständliche Bände vollgeschrieben, mit denen sie den einfachen Leser einige fZeit lang überrennen und verwirren - einfach deshalb, weil dieser Leser davon ausgeht, es sei ihm ohnehin nicht gegeben, in die ihm servierte wunderbare und geheimnisvolle Rätselwelt einzudringen. Bis dann jemand mit normalem Verstand und ohne falsch verstandenen Respekt dem einfachen Leser enthüllt, daß, was er las, nichts als Schein und bar aller geheimnisvollen Tiefe war.

1 ,LUZ“, v. 16. 6. 32. 
Zur zweiten Gruppe gehören die Aristophoben [kein geeigneterer Ort für dieses Wort als diese Ortega y Gasset gewidmeten Zeilen!]. Es sind diejenigen, denen das Volk nachsagt, sie bemühten sich darum, auf alle Fragen schwierige Antworten zu finden. „Hören Sie mir auf mit den Intellektuellen! Die taugen doch überhaupt nichts. Wir brauchen ein paar ehrliche, vernünftige Männer. Wenn wir ein Dutzend anständige Politiker hätten, ginge es Spanien in ein paar Jahren wieder bedeutend besser." Auf diese Weise pflegen diese Leute im Handumdrehen die Krankheit Spaniens zu diagnostizieren und gleichzeitig ein Heilmittel dafür zu verschreiben.

Da unter uns Spaniern bei einer Diskussion nur extreme Positionen vorstellbar sind (nur bei Diskussion wohlverstanden, denn unmittelbar danach, wenn man sich wieder von Mensch zu Mensch gegenübersteht, verstehen sich schließlich alle wieder und prosten sich $\mathrm{zu}$ ), reihen sich alle, die nicht in der ersten der beiden angenommenen Gruppen streiten, aus lauter Groll in die zweite ein. Sie betrachten sich entweder selbst als "Intellektuelle“ oder sie wissen ganz genau, was ein Intellektueller ist und wozu er taugt.

Es versteht sich von selbst, daß man sich weder bei der einen noch bei der anderen Gruppe aufzuhalten braucht, wenn man der Frage einige Minuten widmen will, ob die Politik eine Angelegenheit der Intellektuellen sei.

An sich ist die Politik nicht Sache der Intellektuellen. Doch keineswegs aus den von den Aristophoben angeführten Gründen. Wenn eine Politik nicht von Grund. auf fordernd, das heißt geistig nicht streng und unnachsichtlich ist, wird sie wahrscheinlich nur schwerfällig über dem Wasserspiegel der Mittelmäßigkeit flattern können. Für das wiederholte Scheitern der Intellektuellen in der Politik müssen wir nach tieferen Gründen suchen. Vielleicht ist dies die Antwort:

Die Werte, die zu finden die Intellektuellen sich bemühen, sind zeitloser Art: Wahrheit und Schönheit, absolut gesehen, sind unabhängig von allem Äußeren. Um eine Wahrheit zu finden, bedarf es keiner besonderen Gelegenheit, und eine Wahrheit auf ihre Gültigkeit hin zu überprüfen, läßt sich nicht durch Erwägungen äußerlicher Art erzwingen. Einer der schönsten Züge wissenschaftlicher Berufung ist jene Entsagung, mit der diese Wissenschaftler sich bisweilen bemühen, eine Spur zu verfolgen, deren Ende zu erreichen aber die Begrenztheit des Lebens versagt. Unzählige unbekannte und ungenannte Wissenschaftler schreiten durch unerforschtes Gebiet auf das gelobte Land zu, das ihre Augen niemals sehen werden. Die Politik hingegen ist vor allem zeitbezogen. Die Politik ist ein Spiel mit der Zeit, in der mit keinem einzigen Zug gezaudert werden darf. In der Politik muß man zu einem bestimmten Ziel gelangen, und zwar zum genau richtigen Zeitpunkt. Die Bedeutung des binomischen Satzes von Newton wäre für die Mathematik die gleiche, auch wenn er schon ein Jahrtausend früher oder erst ein Jahrhundert später aufgestellt worden wäre. Aber die Wasser des Rubikon mußten die Hufe der Pferde Cäsars zu einem in der Geschichte genau festgelegten Zeitpunkt benetzen.

Ein zur Suche zeitloser Werte erzogener Mensch, das heißt ein Intellektueller, kann sich jeden Tag zur Politils berufen fühlen. Gelegentlich ist es nicht einmal moralisch, sich dieser Berufung zu widersetzen. Es gibt Zeiten, in denen die Welt 
oder das Vaterland so sehr erschüttert werden, daß es einer Ungeheuerlichkeit gleich käme, in den vier Wänden seiner Zelle zu verharren. Doch wenn man der Berufung zur Politik folgt, kann und darf man das nicht halb tun. So wie man mit der Wissenschaft nicht „flirten “ kann - diesen Ausdruck hat Ortega einmal verwendet -, kann man auch nicht flirten mit der Politik. Und es genügt nicht, mehr zu wollen als einen einfachen Flirt. Man muß sich darüber klar werden, daß in dem Schritt von der Wissenschaft zur Politik eine Tragödie verborgen liegt: Man nimmt eine neue Berufung auf sich und bricht mit der alten. Mit der Übernahme einer politischen Aufgabe verzichtet der Intellektuelle auf die teuerste seiner Freiheiten: ständig seine eigenen Schlußfolgerungen zu überprüfen und zu ändern und diese seine Schlußfolgerungen lediglich als vorläufige Lösung zu betrachten. Die Methode der Philosophie geht vom Zweifel aus: Solange man sich auf dem Gebiet der geistigen Spekulation bewegt, hat man nicht nur das Recht, nein, man ist sogar verpflichtet, Zweifel zu hegen und andere zu lehren, methodisch zu zweifeln. In der Politik ist dies nicht der Fall. Alle große Politik stützt sich auf die Strahlungskraft eines großen und starken Glaubens. Der Politiker schaut nach draußen, aufs Volk, auf die Geschichte; die Funktion des Politikers ist demzufolge religiös und poetisch. Die Kommunikation zwischen Führer und Volk ist nicht mehr rein geistiger, sondern poetischer und religiöser Art. Damit ein Volk sich nicht zu einer amorphen Masse auflöst, damit es nicht sein „Rückgrat verliert"1, gerade deshalb muß es seinen Führern wie Propheten folgen. Dazu bedarf es einer gegenseitigen Durchdringung von Volk und Führer; sie gelingt nur durch einen Prozeß, der dem der Liebe ähnlich ist.

Hier also liegt der Grund für den ungeheueren Ernst jenes Augenblicks, in dem man eine Führerschaft übernimmt. Mit dieser Übernahme geht man unweigerlich die ungeheuere Verpflichtung ein, dem Volk seine wahrhafte Bestimmung zu zeigen, die zu erkennen es als Masse nicht fähig ist².

Wer die erste Note in der geheimnisvollen Musik eines Satzes, das heißt einer Epoche, trifft, darf sich nicht einfach der Verpflichtung entziehen, die Melodie zu Ende zu führen. Thm ist bereits die Hoffnung eines ganzen Volkes aufgebürdet und damit die gewaltige Verpflichtung, dieser Hoffnung nach bestem Wissen und Gewissen gerecht zu werden. Wie stark muß er doch seine Verantwortung spüren, wenn er wie in dem Gedicht von Robert Browning mit seiner Flöte eine Schar von Kindern hinter sich in den Berg zieht, aus dem niemand mehr zurücklkehrt!

Ortega y Gasset, der jetzt sein 25jähriges Jubiläum als Professor feiert, hat den

1 Der Titel des von Ortega 1922 veröffentlichten Buches „España invertebrada“, in dem ex das Scheitern Spaniens in der Geschichte aufzeigt und dies vor allem zurückführt auf führungsunwillige Massen und das Fehlen einer Elite.

2 José Antonio liegt mit dieser Auffassung ganz auf der Linie Ortegas. Im „Aufstand der Massen" bescheinigt Ortega der Masse ihre politische Unbelehrbarkeit. „Politische Unbelehrbarkeit kommt aus einer tieferen, innerlichen, der geistigen und moralischen Unbelehrbarkeit ... Es ist ihr angeborener Fehler, nicht zu berücksichtigen, was außerhalb ihres Horizonts liegt, seien es Sachen, seien es Personen." Zit. n. d. span. Gesamtausgabe: José Ortega y Gasset, Obras Completas, Bd. I-VI, Madrid, 1946-47, Bd. IV, S. 184f. 
Ruf zur Politik vernommen. Wer kann ihm, wenn er gerecht sein will, in dieser Stunde wägender Rückschau kritischen Weitblick und einwandfreie moralische Haltung absprechen? Er brauchte seinen Schmerz über Spanien nicht laut hinauszuschreien (ich pflege nicht oft zu schreien, hat er einmal gesagt); wir aber, die wir nach 1898 geboren wurden, verstehen den tief in ihm nagenden Kummer sehr gut, der sich hinter der kastilischen Nüchternheit seiner Äußerungen und seiner Haltung verbirgt. Vielleicht, weil wir gelernt haben, ihn in seinen Werken wiederzufinden und näher zu betrachten. Uns aber steht es wirklich bis hier oben, diese Mittelmäßigkeit eines Spanien ohne gemeinsame Seele, diese Mittelmäßigkeit eines Spanien, das, als der Kothurn seines Imperiums zerschlissen war, sich außerstande sah, sich anders als in Pantoffeln fortzubewegen! Nein, Ortega y Gasset wollte keinen Flirt mit der Politik, aber er gab sich geschlagen. Als er entdecken mußte, daß das, was war, nicht das war, was er wollte, wandte er voller Enttäuschung der Politik den Rücken. Aber Führer haben kein Recht auf Enttäuschungen. Sie dürfen nicht kapitulieren und die Hoffnungen einer so großen Gefolgschaft mißhandeln und enttäuschen. Ortega y Gasset war hart gegen sich selbst, er legte sich eine lange Schweigezeit auf. Aber es war nicht sein Schweigen, sondern es war seine Stimme, die die Generation brauchte, die er in dem Unwetter schutzlos zurückließ. Seine prophetische, gehorsamheischende Stimme.

Ein anderer wird vielleicht $\mathrm{zu}$ behaupten wagen, in dieser Zeit des Ausflugs in die Politik sei gar nichts geschehen, und er könne deshalb zu seinen alten Aufgaben zurückkehren. Ortega y Gasset ist sich darüber im klaren, daß man etwas, was tatsächlich geschehen ist, nicht als ungeschehen hinstellen kann. Bei einer wahrhaft tragischen Haltung, wie bei diesem Sprung in die Politik, gibt es kein Zurück: entweder löst man sich und gelangt an das andere Ufer, oder man findet sich mit der täglichen Tragödie - einer wunderbaren Katharsis! - ab, sich selbst das Scheitern dessen zu bestätigen, was einmal die heißeste Hoffnung des eigenen Lebens war.

Aber nichts wirklich Entscheidendes geht damit verloren. Wenn ein großer Kopf sich ganz hingibt, um schließlich in großmütiger Frustration zu enden, ist das Opfer niemals vergeudet. Denn diejenigen, die nach ihm kommen, haben bereits ihre Lehrjahre gespart. Die Kritik der ersten Zeit hat die Bahn freigemacht. Andere Arme, die kräftiger und viel eindeutiger zuzuschlagen verstehen, nehmen die Aufgabe jetzt auf sich. Zum Schluß, möglicherweise ein Schluß, der von den Kritikern der ersten Zeit nicht vorausgesehen wurde - werden die, welche ans Ziel gelangen, mit dem Gefühl dankbarer Erinnerung an jene zurückdenken, die vielleicht nicht die ganze Wahrheit sahen oder aber zu schwach waren, der Wahrheit zum Siege zu verhelfen, dennoch aber zumindest einen großen Teil der Lügen beseitigten, die den Weg versperrten.

Eine Generation, die ihre Augen öffnete, als die Unrast Spaniens im Zeichen Ortega y Gassets sich bemerkbar machte, hat sich selbst - ebenfalls in tragischer Weise - die Verpflichtung auferlegt, Spanien wieder ein Rückgrat zu geben. Viele von denen, die diese Verpflichtung auf sich genommen haben, wären weit lieber 
ohne jede Eile und Ungestüm ihrer intellektuellen Berufung gefolgt. Doch unsere Zeit kennt kein Erbarmen. Uns ist als Schicksal der Krieg zugefallen, der Kampf, bei dem man Haut und Haare lassen muß, ob man will oder nicht. Aus Treue zu unserem Schicksal ziehen wir von Ort zu Ort und ertragen es, daß unser „Exhibitionismus" uns die Schamröte zu Kopfe treibt. Wir müssen öffentlich hinausschreien, was wir in stiller Zurückgezogenheit erarbeitet haben. Wir erdulden die Verleumdung derer, die uns verstehen, und derer, die uns nicht verstehen wollen. Wir mühen uns täglich ab, wir kämpfen aus Gewohnheit den absurden Kampf um die Eroberung der „öffentlichen Meinung“, gleichsam als könne das Volk, das der Liebe wie der Wut fähig ist, als Kollektiv eine einzige Meinung haben. Alles dies ist bitter und schwer, aber nutzlos wird es nicht sein. Und heute, am Tag des silbernen Jubiläums von Ortega y Gasset, kann man ihm als Geschenk eine Prophezeiung mit auf den Weg geben: Bevor sein Leben verlöscht - ein Leben, von dem wir alle hoffen, daß es lange währen wird und deshalb fruchtbar sein muß-, kommt der Tag, an dem er beim Triumphmarsch dieser Generation, deren ferner Meister er war, beifällig ausrufen wird: „Dies, ja, dies ist es! “

„HAZ“, Nr. 12, 5. 12. 1935. O. C., a. a. O., S. $581 \mathrm{ff}$.

WEDER LINKS NOCH RECHTS: DAS GANZE SPANIEN!

Die ersten Wahlen, an denen sich die Falange mit eigenen Kandidaten beteiligt, sind zugleich die letzten, welche die zweite Republik erlebt. Nach der Wahl vom 16. Februar 1936, die der "Volksfront" die Mehrheit bringt und damit das Pendel nach den zwei Jahren einer Koalition der Rechtsparteien wieder weit nach links ausschlagen läßt, verdichten sich konkrete Aufstandsvorbereitungen eines Teiles der Generalität wie rechtsorientierter Politiker. Fünf Monate später beginnt der Bürgerkrieg ${ }^{1}$.

Als die Parteien im Herbst 1935 mit ihren Wahlvorbereitungen beginnen, wird Spanien vom Fieber politischer Selbstzerstörung geschüttelt. Die Rechtsparteien, untereinander verfeindet, bringen keine stabilen Regierungsmehrheiten mehr zustande; es regieren Tageskabinette, welche die Auflösung der Cortes und die Ausschreibung von Neuwahlen zwingend machen. Die Zahl der Arbeitslosen erreicht die Rekordhöhe von nahezu 800000. Von Januar bis Oktober 1935 wurden 254 bewaffnete Überfälle eindeutig politischen Charakters registriert.

In der Vorbereitungszeit für Wahlkampf und Wahlen spaltet sich das politische Spanien in zwei Lager. In dem einen versammelt sich die Links-Opposition zur „Frente Popular", die von den Republikanern Azañas bis zu den Kommunisten

1 In der zeitgeschichtlichen Forschung besteht heute Klarheit darüber, daß die treibende und entscheidende Kraft für die Vorbereitung des Aufstandes das Militär war. Vgl. Estado Mayor Central del Ejército: Historia de la Guerra de Liberación 1936-1939. 2 Bd., Madrid 1945. Das gründlichste wissenschaftliche Buch über den Bürgerkrieg ist das von Hugh Thomas, a. a. O., das sich auch ausführlich mit der These auseinandersetzt, ob und inwieweit der militärische Aufstand eine präventive Maßnahme gegen einen bereits geplanten Staatsstreich oppositioneller Linksparteien und Gewerkschaften gewesen sei. Vgl. auch: Diego Sevilla Andrés: Historia Política de la Zona Roja. Madrid 1949. 
reicht und auf die Wahlhilfe der Anarchosyndikalisten rechnen kann. Diese erste Wahlhilfe des bisher jeden Wahlakt ablehnenden Anarchosyndikalismus ist das Ergebnis mühsamer Verhandlungen zwischen den von dem revolutionären Sozialisten Largo Caballero beherrschten sozialistischen Gewerkschaften und anarchosyndikalistischen Massenorganisationen. Die spanischen Kommunisten folgen mit ihrer eifrig betriebenen Einreihung in die Volksfront der Weisung des VII. Kongresses der 3. Internationale. Sie stellen jedoch noch keinen entscheidenden Faktor in der sich bildenden Volksfront dar'1. Die brutal-revolutionäre Sprache, die der die Mehrheit der Sozialisten anführende Largo Caballero anschlägt, läßt ihnen propagandistisch wenig Entfaltungsmöglichkeit. Aus der Wahl vom 16. Februar 1936 gehen die Kommunisten dann auch nur mit 16 Abgeordneten hervor.

Gegen den Zusammenschluß der erbitterten oppositionellen Kräfte bildet sich ein gegenrevolutionärer Block, die „Frente Nacional“ (nationale Front), die sich allerdings nur zu einem losen, in den Provinzen verschieden gehandhabten Wahlbündnis durchringt ${ }^{2}$.

In dieser Situation, in der sich zwei Wahllager abzuzeichnen beginnen - die Volksfront und die Nationale Front -, wird für die Falange die Frage zwingend, welche Haltung sie selbst während des Wahlkampfes einnehmen soll. Einerseits betrachtet sie sich als Feind aller Parteien und des Parlaments und erhebt aufgrund des Punktes 27 ihres Programms ${ }^{3}$ den Anspruch, als eine führende Bewegung respektiert zu werden; andererseits gibt sie sich der Hoffnung hin, durch eine parlamentarische Repräsentanz ihre durch Verbote und Konfiskationen oftmals bedrohte Existenz absichern zu können.

Eine Anlehnung an die Volksfront scheidet aus, ebenso aber wird die Falange bei dem Versuch, mit der Nationalen Front zu paktieren, sowohl durch ihr eigenes Programm gehindert, wie dadurch, daß sie selbst, noch gering an Zahl, für die Nationale Front keine wesentliche Wahlhilfe darstellt. Die Falange sieht, einerseits von den Parteien der Nationalen Front geringschätzig alleingelassen, andererseits verzweifelt bemüht, sich selbst parlamentarisch abzusichern, aus der Verstrickung keinen anderen Ausweg, als zumindest den Versuch zu unternehmen, durch einen auf wenige Provinzen konzentrierten eigenen Wahlfeldzug zumindest ihre wichtigsten Vertreter ins Parlament zu bringen.

So tritt die Falange, die Thesen ihres Parteiprogrammes verkündend und gegen die rechten wie die linken Parteien zu Felde ziehend, im Wahlkampf mit dem Anspruch auf, die „wahre Nationale Front" (Frente Nacional auténtico) zu sein. Die hier wiedergegebene Wahlrede José Antonios vom 22.12.1935 in Sevilla ist dafür repräsentativ. Freilich: Die Falange-Führung war sich darüber im klaren, daß ihr Versuch, Vertreter ins Parlament zu senden, keinerlei Aussicht auf Erfolg hatte. Und wie in der Wahlzeit des Jahres 1933, in der José Antonio in Madrid die Falange gründete und sein entschiedenes Nein gegen das parlamentarische System formulierte, gleichzeitig aber im heimatlichen Cádiz als Unabhängiger in einer Wahlgemeinschaft örtlicher Rechtsparteien kandidierte, so bemüht ex sich auch entgegen den

1 Franz Borkenau begxündet dies ausführlich. Er schreibt u. a.: „Es wirkte sich das französische Vorbild der Volksfront auf die spanischen Wahlen aus, und zwar wirkte es nicht nux auf die Kommunisten, sondern auf alle Linksparteien. Die Kommunisten behaupten, sie hätten die Initiative zu einem politischen Block der gesamten Linken ergriffen, aber im Hinblick auf ihre Bedeutungslosigkeit ist dieser Ausspruch . . . absurd. Sie wurden von den anderen Parteien zugelassen ..."; Borkenau: Der europäische Kommunismus, München 1952, S. 151.

2 Almagro, a. a. O., S. 164. Santiago Galindo Herrero: Los Partidos Monárquicos bajo la Segunda República. Madrid 1936. S. $293 \mathrm{ff}$; $302 \mathrm{ff}$.

3 Vgl. S. 117. 
von der Falange im Wahlkampf des Winters 1935/36 proklamierten Parolen aus der Erkenntnis der quantitativen Unzulänglichkeit seiner eigenen Partei heraus bis in den Januar 1936 hinein, doch noch als Kandidat der Nationalen Front wieder in Cádiz zugelassen zu werden. Das Wahlkomitee der Rechtsparteien in Cádiz, denen er sein Mandat des Jahres 1933 zu verdanken hatte, lehnt jedoch ab und verbaut damit diese letzte erhoffte Möglichkeit. Die Falange findet bis zum Februar 1936 in der Öffentlichkeit so wenig Zuspruch, daß es ihr trotz der staatlich gebilligten Kandidatenliste nicht gelingt, auch nur einen Kandidaten durchzubringen ${ }^{1}$.

Mit diesem Wahlkampf endet die legale Etappe der Falange während der Zweiten Republik. Nach dem Wahlsieg der Volksfront wird bereits am 27. Februar 1936 die Schließung aller ihrer Zentren verfügt; am 14. März wird sie verboten; die Zeit der Illegalität beginnt.

$\mathrm{Zu}$ dieser gleichen Stunde werden in Spanien Hunderte von Versammlungen abgehalten. Das Thema ist überall gleich: die Wahlen. Vielleicht sind einige von Euch aus Neugierde hierhergekommen, weil sie sich im stillen gefragt haben: „Was werden uns denn die Falangisten zur Wahl sagen?" Nun, wir Falangisten haben immer noch nichts zu den Wahlen zu sagen, denn für uns steht über dem Tagesthema des Sonntags die eine brennende, unablässig beängstigende Tatsache, die uns schon mehr als ein Jahrhundert auf der Seele liegt: wir haben kein Spanien mehr!

Wir haben kein Spanien mehr. Das ist die wichtigste Tatsache am Vorabend der Wahl. Ihr wißt ja schon, was wir unter dem Begriff Spanien verstehen. Spanien ist nicht nur dieser Boden, der doch für die meisten eine Stätte jahrhundertelangen Hungers ist. Spanien ist auch nicht unser Blut, denn Spaniens Schicksal wurde es, zu dem gleichen Ruhm viele verschiedene Blutströme zu vereinen. Spanien ist nicht einmal diese Zeit oder die Zeit unserer Ahnen oder unserer Kinder. Spanien ist eine Schicksalsgemeinschaft im Weltgeschehen. Das ist das Wichtigste. Dies vereint uns alle, dies vereinte unsere Vorfahren, dies wird auch unsere Nachkommen vereinen, damit sie ein großes Geschick in der Geschichte erfüllen. Solange Spanien sich nicht der verlorenen Einheit bewußt ist und solange es nicht die Kraft verspürt, ungestüm wieder zu ihr hinzudrängen, solange wird Spanien nichts bedeuten.

Die anderen, die politischen Parteien, denken an Wahlen, an nicht ganz saubere Abmachungen und Zugeständnisse und an die Eintragung in die amtlichen Wählerlisten. Das Innenministerium gräbt die ältesten Vorschriften aus, um eine Mehrheit nach dem Wunsche der Regierung zustande zu bekommen. So etwas tun die Parteien. Wir aber ziehen inzwischen durch die Lande und fahren in unbequemen Zügen. Bei den Regengüssen versinken wir auf dem Marsch bis an die Knie im Schlamm, und wir rufen: Gebt uns unser Spanien zurück!

Wir stehen ganz allein mit diesem Ruf. Wendet den Blick von uns ab, und Thr seht die Parteien in zwei Fronten aufmarschieren: Die Linken ohne Verbindung mit der Vergangenheit, die Rechten ohne Fühlung mit der Gegenwart. Die Linken überlassen alles dem Zufall der Wahlurnen, dem Los, obwohl daraus doch nur

\footnotetext{
1 Payne, a. a. O., S. 94. Nellessen, a. a. O., S. $94 \mathrm{ff}$., dort auch Literatur.
} 
Zerstückelungen und Gotteslästerungen resultieren können. Die Linken sagen: „Mag die Wählerschaft sein wie sie will“ - als wären wir, die wir jetzt wählen sollen, die Schöpfer Spaniens. Die Linken tun gerade so, als könnten wir mit dem, was so viele Geschlechterfolgen in mühseliger Arbeit überliefert haben, das machen, was uns am Sonntag gerade in den Sinn kommt. Als ob uns allen nicht der Wille Isabellas der Katholischen mehr gelten müßte als der Wille der gesamten Wählerschaft! Und die Rechtsparteien? Ja, sie berufen sich auf das Vaterland, auf die Tradition, aber sie fühlen sich nicht mitverantwortlich für den Hunger des Volkes, für das traurige Los dieser Bauern, die hier in Andalusien, in Estramadura und in León noch immer ein Leben führen, wie es nach dem Ausspruch von Julio Ruíz de Alda schon vor 5000 Jahren üblich war. Ich wiederhole: sie leben, wie seit der Erschaffung der Welt einige Tiere leben. So darf das nicht bleiben. Man kann das Vaterland nicht rühmen und gleichzeitig von seinen Opfern und Nöten keine Notiz nehmen. Man kann nicht von einem Volk begeisterte Vaterlandsliebe verlangen, wenn das Vaterland nichts anderes bedeutet als dem Boden dienstbar zu sein, auf dem seit Jahrhunderten gelitten wird. Jetzt rufen sie das Vaterland an und klagen, wo die Lage schwierig wird: „Das Vaterland geht unter! Wir verlieren unsere kostbarsten geistigen Güter! " Haben uns denn nicht erst diese Leute in die drohende Gefahr dadurch gestürzt, daß sie gegen eine Erhöhung der Steuern für die Banken und die großen Vermögen votierten? Man kann nicht beides zugleich tun.

Mit keiner dieser beiden Hälften erklären wir uns einverstanden. Gegen die ersten zwei Jahre waren unserer Meinung nach die folgenden beiden Jahre kein Heilmittel. Wir glauben nicht, daß nach den grausamen ersten zwei Jahren die dummen zwei Jahre, die wir jetzt begraben, irgendeinen Vorteil gebracht haben. Wenn man zwei Jahre lang auf dem rechten Auge geschielt hat, wird es um nichts besser, wenn dann auf dem linken Auge geschielt wird. Wir wollen ein ganzes und harmonisches, ein starkes und verwurzeltes, ein freies Spanien sehen; frei als ein Vaterland, das keine Einmischung von außen duldet und sich nicht wie eine Wirtschaftskolonie behandeln läßt, ein Vaterland, das keine unbeschützten Grenzen und Küsten kennt, das jedem seiner Bewohner offensteht. Man ist doch nicht frei, wenn man nur die Freiheit hat, vor Hunger zu sterben, vor den Toren einer Fabrik oder der Tür eines Wahllokals Schlange zu stehen. Frei ist man erst dann, wenn die vollständige Freiheit wieder hergestellt ist: der einzelne respektiert als Träger einer Seele und als Besitzer eines Vermögens. Die Familie respektiert als Zelle des Gemeinschaftslebens, die Gemeinde respektiert als Lebenseinheit, wiederaufgebaut in all ihrem Reichtum für die Allgemeinheit und mit all ihrer Tradition. Die Syndikate respektiert als Einheiten des Berufslebens und als Treuhänder wirtschaftlicher Autorität, die für jeden einzelnen der Produktionszweige notwendig ist. Stellt Euch das nur einmal vor: wir werden uns wieder zusammenschließen zu einem Staat, der der Bestimmung des Vaterlandes dient; unsere Familien, unsere Gemeinden, unsere Syndikate und wir selber werden nicht mehr bloß statistische Einheiten bilden, sondern vollständige, vom Leben erfüllte Wesen. Wenn es soweit ist, dann brauchen wir nicht mehr Schlange zu stehen vor den Türen der Wahl- 
lokale, um Zettel in die Urnen zu werfen, die den Wucherern oder Arbeitgebern gerade genehm sind. Dann werden wir mit Recht sagen können: Wir sind freie Menschen!

Wegen dieser Forderungen stehen wir allein, und unsere Aufgabe wird von Tag zu Tag schwerer. Niemand liebt uns. Uns liebt nicht die jetzige Regierung, die von uns mit ebensoviel Argwohn betrachtet wurde, wie sie von den katalanischen Separatisten jubelnd begrüßt worden ist. Die jetzige Regierung wird von einem fuchsigen Manne geleitet, und ihr werdet sehen, daß sie es zu keinem offenen $\mathrm{Zu}$ sammenstoß mit uns kommen läßt. Aber Ihr werdet auch erleben, wie sie uns mit Polizeimaßnahmen schikaniert. So verbietet sie uns, unsere Hemden offen zu zeigen. Ihr Vertreter verschiedener J.O.N.S. werdet es bald merken: in wenigen Tagen oder Wochen wird die Polizei beginnen, in Eure Parteilokale einzudringen und bei Euch ein paar Pistolen an Stellen finden, wo Ihr sie am wenigsten vermutet hättet. Und der Fund dieser Pistolen wird dann als Vorwand dienen, die Räume zu schließen und Euch einzusperren. Zwar werden sie wohl innerhalb kurzer Zeit die Vorzensur aufheben, die sie über uns verhängt haben, aber stets wird ein Staatsanwalt da sein, der unsere Zeitung im Augenblick des Erscheinens denunziert, damit die Polizei sie in der Druckerei beschlagnahmen kann. Ihr werdet sehen, wie wir bei jedem unserer Schritte über Schwierigkeiten stolpern werden. Und um die Verfolgungen ganz zu rechtfertigen, wird die Regierung nicht müde werden zu behaupten, sie behandele uns nicht anders als die Sozialisten. Wenn daran auch nur ein Schimmer von Wahrheit wäre, so wäre es schon deshalb eine haarsträubende Ungeheuerlichkeit, weil sich die Sozialisten vor einem Jahr gegen die Einheit Spaniens, gegen den Geist und die Tradition Spaniens empörten. Von unseren Leuten dagegen mußten vier verbluten, das Gesicht der Sonne Spaniens zugewandt, weil sie seine Traditionen und seine Einheit verteidigten.

Auch revolutionäre Parteien stehen gegen uns. Wißt Ihr weshalb? Nicht etwa, weil wir reaktionär seien - das wissen sie sehr wohl -, sondern gerade aus dem entgegengesetzten Grund. Sie wissen es ganz genau: wir sind nicht revolutionär wie diese Männer, die als Revolutionäre beginnen, sich dann aber mit Hilfe und auf Kosten ihrer Kameraden über sie erheben und nach dem Sieg in Staatskarossen zu 20000 Duros spazierenfahren. Viele der unsrigen werden an dem Tage, an dem unsere Revolution siegen wird, vieles, vielleicht sogar alles verlieren. Aber trotzdem sehnen wir sie herbei, denn wir wissen, es nützt ja nichts, nur ein paar Jahre länger Privilegien zu genießen, wenn dabei Spanien zugrunde geht. Und weil wir das wissen und bekennen, aufrichtig und offen - das sieht man einem Menschen am Gesicht an -, deshalb wollen die kleinen revolutionären Parteifunktionäre nicht, daß wir zu den Arbeitern vordringen. Nur deshalb halten sie uns von den Arbeitern mit einer Reihe von Verdächtigungen und Verleumdungen fern. Aber wir werden schon einen Weg zu den Arbeitern finden, wir beginnen ja schon damit. Sie sind einstweilen die besten spanischen Volksschichten. Wir sind mit ihnen in Fühlung gekommen, mit diesen Schichten, die treu die unauslöschliche Ader jenes persönlichen Heldenmutes bewahrt haben, der einst Amerika eroberte. Allerdings haben 
wir zunächst Schüsse miteinander gewechselt. Das macht nichts. Das ist auch eine Art, sich näherzukommen. Am Ende werden wir uns doch mit diesen Männern verstehen, mit denen wir uns jetzt noch durch Schüsse unterhalten. Bedauern würden wir nur, wenn sich in unsere Kämpfe die ganzen morschen Bräuche der alten Politik einschleichen würden, oder wenn sich dieser zum Untergang geweihte Staat einmischen wollte. Wir haben auf den Straßen geschossen, und wir werden das wahrscheinlich auch weiterhin tun. Wir werden selbst fallen und auch andere opfern müssen. Wir wünschen aber nicht, daß sich dieser morsche liberale Staat in unsere Angelegenheiten einmischt. Wir sind niemals vor einem offenen Kampf zurückgewichen. Ihr Kameraden aus Sevilla wißt es, und wir scheuen uns nicht, an diesem Morgen als die ersten Jerónimo Misas Begnadung zu fordern ${ }^{\mathbf{1}}$.

Es werden gegen uns die Männer der Rechten kämpfen. Nachdem sie die Wahlen gewonnen hatten, was sie auf der ganzen Halbinsel lauthals verkündeten, erklärten wir am 7. Dezember 1933, ihr Sieg sei ein „Sieg ohne Flügel“. Nichts Gutes könne daraus werden. Dieser Sieg sei vergeudet. Jawohl, wir störten den Frieden, aber wir waren damals hellseherische Störenfriede. Heute, nachdem seit dieser Prophezeiung zwei Jahre vergangen sind, können wir wie damals den Artikel hervorholen, den wir in der ersten Nummer der „Falange Española " geschrieben hatten ${ }^{2}$. Und jetzt können wir ihnen sagen : „Seht Thr nun, daß Euer Sieg ein unnützer Sieg war?“

Vor der letzten Entscheidung riefen wir am 17. Dezember vor einer Zuhörerschaft von 15000 Menschen zur „Nationalen Front" auf, um den von den russischen, asiatischen, kommunistischen und materialistischen Weltanschauungen drohenden Gefahren entgegenzutreten. Wir taten dies $^{3}$. Und dann genügten denen von der Rechten ein paar Wochen, um sich dieser „Nationalen Front" zu bemächtigen, ohne auch nur unseren Narnen zu erwähnen. Aber sie wollten ja nicht den Gedanken übernehmen oder unseren Namen nennen - wir würden es mit Freuden begrüßen, denn wir sind nicht so eitel, unbedingt als Initiator dieses Gedankens genannt werden zu müssen. Nein, unter dem Deckmantel der nationalen Front soll sich noch einmal jene Vereinigung der Rechtsparteien zusammenfinden, die es im November 1933 verstanden hatte, einen Sieg ohne Flügel zu erringen.

Sei's drum. Wir haben unser Lager unter diesen Fahnen aufgeschlagen. Wir haben alle aufgerufen, in diesem tragischen, entscheidenden Kampf um Spanien die Ersten oder die Letzten zu sein. Auf den Zeitpunkt kommt es nicht an. Ob mit anderen oder allein: wir werden auf unserem Posten ausharren. An Zahl werden wir bald mehr oder weniger sein. Wir werden den ganzen zugelaufenen Haufen von Neugierigen, von Feiglingen, von Sensationslüsternen, von Leuten abschütteln, die bloß kamen, weil es nun einmal Mode war, vom korporativen Staat zu reden oder ein einfarbiges Hemd anzuziehen. Diesen Verlust können wir verschmerzen.

1 Ein Falangist, der als Anführer einer gewalttätigen Auseinandersetzung in Sevilla, bei der ein Todesopfer zu beklagen war, zu einer langjährigen Gefängnisstrafe verurteilt worden war.

2 "FE" Nr. 1, vom 7. 12.1933.

3 Rede José Antonios zum Abschluß des zweiten Nationalkongresses der Falange; O.C., a. a. O., S. $85 \mathrm{ff}$. 
Wir, die Unentbehrlichen, die Begeisterten, wir werden bleiben. Heutzutage wittert die kapitalistische Presse jede lächerliche Versammlung, in der 400 Personen das Pech haben, eine Stunde lang einen Haufen von Ungereimtheiten anzuhören. Unsere Versammlungen aber, in die Tausende von tatenfrohen Kämpfern kommen, verschweigt die Presse. Aber die Zeiten, in denen so etwas möglich ist, werden vorübergehen. Wir nehmen das auch nicht wichtig. Wir werden auf unserem Posten ausharren. Alles wird zu Boden stürzen, weil es morsch ist, aber wir werden auch weiterhin die Saat einer künftigen Zeit hegen. Heute verbergen wir noch die Hemden unter der Jacke vor der wachsamen staatlichen Polizei. Doch eines Tages werden wir sie stolz im Sonnenschein zeigen. Und Ihr, Kameraden aus Sevilla, die ihr die meisten Blutopfer gebracht habt, habt ja gesehen, wie sich die Reihen durch den Tod so vieler Märtyrer lichten. Thr werdet den Ehrenplatz erhalten, wenn unsere Scharen am frohen Morgen Spaniens paradieren werden.

O. C., a. a. O., S. $181 \mathrm{ff}$.

21

\section{LETZTE BEKANNTMACHUNG JOSÉ ANTONIOS}

Das letzte Schreiben José Antonios an seine Falangisten datiert vom 17. Juli 1936, an dem der Aufstand beginnt. José Antonio verfaßte es im Gefängnis von Alicante, wohin er, um ihn von den mitinhaftierten Freunden abzusondern, aus dem Madrider Gefängnis überführt worden war. Die Führung der in der Illegalität kämpfenden Falange ${ }^{1}$ war ihm kaum möglich. Sein aus dem Gefängnis herausgeschmugge]tes Schreiben konstatiert lediglich, was die nicht mehr zentral gelenkten Falangeeinheiten meist auf eigene Faust zu vollziehen bereits im Begriffe sind: die Beteiligung am Aufstand auf seiten der Militärs. Diese Beteiligung macht aus ihnen zwangsläufig zum Gehorsam verpflichtete Gehilfen einer stärkeren Potenz und läßt ihr Ziel zunichte werden, die politische Führung eines „neuen Staates" allein bestimmen zu können.

Eine Gruppe von Spaniern, manche Soldaten, manche Zivilisten, weigert sich, der vollständigen Auflösung des Vaterlandes tatenlos zuzuschauen. Sie erhebt sich heute gegen die verräterische, unfähige, grausame, ungerechte Regierung, die Spanien ins Verderben stürzt.

Fünf Monate der Schmach haben wir ertragen müssen. Eine Art von Meuter-

1 Durch Parteiverbot und Verhaftung der gesamten Führung ist der Zusammenhalt der Falange nicht mehr gewährleistet. Die lokalen Gruppen sind auf sich gestellt. Korrespondierend zu der fiebrigen Atmosphäre des Landes in jenen letzten Monaten vor Ausbruch des Bürgerkrieges steigert auch die Falange ihre aus der Illegalität geführten direkten Aktionen. Bis zum Mai 1936 beläuft sich die Zahl der toten Falangisten auf 40. Das grausamste Beispiel für die Art der Auseinandersetzungen, wie sie in jenen Monaten praktiziert werden, ist der $\mathrm{Zu}$ sammensto $B$ in Carrión. Dort wurde der Lokalchef der Falange in einen Hinterhalt gelockt und erschossen. In der folgenden Nacht hängten Falangisten den Vorsteher des sozialistischen Volkshauses und zwei andere Sozialisten an Bäumen der Hauptstraße „als Vergeltung für das Verbrechen" auf. (Bravo, a. a. O., S. 191.) Kurz vorher waren auch in Madrid 4 Falangisten auf offener Straße erschossen worden. Almagro, a. a. O., S. 172. 
bande hat sich der Herrschaft bemächtigt. Seit diesem Augenblick gibt es keine ruhige Stunde mehr, ist keine Wohnung, kein Arbeitsplatz, kein Leben mehr sicher. Während ein Haufen Besessener, zur Arbeit ohnehin untauglich, im Parlament herumschreit, dringt die Polizei in die Häuser ein (sofern der Mob sie nicht einfach anzündet), werden die Kirchen geplündert und anständige Leute nach Belieben auf unbestimmte Zeit eingesperrt ${ }^{\mathbf{1}}$. Justitias Waage wiegt mit zweierlei Gewicht: Das eine ist für die Volksfront, das andere für diejenigen, die ihr nicht angehören. Heer, Marine und Polizei werden von Agenten Moskaus, eingeschworenen Feinden der spanischen Kultur, unterwandert. Eine niederträchtige Presse vergiftet das Gewissen des Volkes und schürt die wildesten Leidenschaften, vom Haß bis zur Schamlosigkeit. Es gibt kein Dorf, kein Haus mehr, das nicht zu einem Inferno der Rachsucht wird; separatistische Bewegungen werden geschürt, der Hunger nimmt zu. Und damit das finstere Schauspiel vollständig wird, haben ein paar Handlanger der Regierung in Madrid einen angesehenen Spanier ermordet ${ }^{2}$, der von allen, die ihn kannten, als überaus aufrichtig, ehrenhaft und verantwortungsbewußt geschätzt wurde. Die verbrecherische Roheit dieser letzten Untat findet im modernen Europa nicht ihresgleichen; sie läßt sich höchstens mit den schwärzesten Kapiteln der russischen Tscheka vergleichen.

Dieses Schauspiel bietet unser Vaterland gerade zu jener Stunde, in der es durch die Weltsituation dazu aufgerufen ist, erneut einer großen Bestimmung gerecht zu werden. Die fundamentalen Werte der spanischen Kultur erlangen nach Jahrhunderten des Niedergangs ihre alte Autorität zurück, während andere Völker, die ihre Hoffnung auf einen fiktiven materiellen Fortschritt gesetzt hatten, ihren Stern von Minute zu Minute sinken sehen. Unserem alten, sendungsbewußten, soldatischen Spanien, unserem Spanien der Bauern und Seefahrer, eröffnen sich herrliche Wege. An uns, am spanischen Volk liegt es, ob wir sie gehen, ob wir in Einigkeit und Frieden leben werden, mit Herz und Hand tatkräftig mitarbeiten im gemeinschaftlichen Bestreben, das Vaterland groß zu machen. Ein großes Vaterland für alle, nicht für eine Gruppe Bevorrechtigter. Ein Vaterland, groß, einig, frei, angesehen und reich. Im Kampf um dieses Spanien brechen wir heute offen mit den das Land knebelnden antispanischen Kräften. Unsere Erhebung ist ein Dienst an der Sache Spaniens.

Wenn es uns darum ginge, nur eine Partei durch die andere, nur eine Diktatur durch die nächste zu ersetzen, würde uns der Mut - Zeichen der reinen Seelen fehlen, dieses Wagnis der letzten Entscheidung auf uns zu nehmen. Dann gäbe es

1 Allein in der Zeit vom 16. 2. bis zum 2. 4. 36 wurden von 100 in Brand gesetzten Kirchen 50 völlig vernichtet. Raub und Überfälle forderten im gleichen Zeitraum 345 Verwundete und 74. Tote. Parlamentsdebatte vom 15. und 16. April (Diario de Sesiones. Madariaga, a. a. O., S. 294-296. Almagro, a. a. O., S. 170-175).

2 Calvo Sotelo, der Führer der monarchistischen Opposition in den Cortes, wurde am 13. Juli meuchlings ermordet. Sein Tod ließ die Rebellen den Stichtag für den Beginn des Aufstandes endgültig auf den 17. Juli für Afrika festsetzen, von wo er dann, dem Plan gemäß, bis zum 19. Juli auf das Mutterland übergriff. 
auch in unseren Reihen keine Männer in der Uniform des Heeres, der Marine und der Luftwaffe, der "Guardia Civil“. Sie alle wissen, daß sie ihre Waffen nicht zugunsten einer einzelnen Partei gebrauchen dürfen, sondern nur im Dienst für das ewige Fortbestehen jenes Spaniens, das jetzt unterzugehen droht. Unser Sieg wird kein Sieg der Reaktion sein, und er wird dem Volk nicht den Verlust irgendeines Vorteils bringen. Ganz im Gegenteil: unser Werk wird eine nationale Tat sein, es wird die Lebensbedingungen des Volkes, die jetzt in manchen Landesteilen wahrhaft furchtbar sind, verbessern, und das gesamte Volk wird dann teilhaben am Stolz über den Wiedergewinn einer großen Bestimmung.

Arbeiter! Bauern! Intellektuelle! Soldaten! Seeleute! Wächter unseres Vaterlandes! Schüttelt angesichts des Unterganges Spaniens die Resignation ab und kämpft mit uns für ein einiges, freies und großes Vaterland!

Gott helfe uns! Hoch lebe Spanien!

O. C., a. a. O., S. $773 \mathrm{ff}$.

DAS PROGRAMM DER FALANGE DE LAS J.O.N.S.1

Nation - Einheit - Imperium

1

Wir glauben an die hohe Wesenheit Spaniens. Seine Stärke, Größe und Macht zu mehren ist die vordringliche Gemeinschaftsaufgabe aller Spanier. Dieser Aufgabe haben sich unerbittlich Einzel-, Gruppen- und Klasseninteressen unterzuordnen.

2

Spanien stellt im Weltgeschehen eine Schicksalsgemeinschaft dar. Jeder Anschlag auf diese Gemeinschaft ist verwerflich. Separatismus ist ein unverzeihliches Verbrechen.

Die geltende Verfassung richtet sich, da sie zur Zersplitterung aufhetzt, gegen die schicksalhafte Einheit Spaniens. Wir verlangen daher ihre völlige Abschaffung.

3

Wir haben den Willen zum Imperium. Wir bekunden, daß die geschichtliche

1 Der der Übersetzung zugrunde liegende Text ist den 1942 erschienenen „Obras Completas" von José Antonio entnommen. A. a. O., S. 589-597. In dieser Fassung, wie in nahezu allen Fassungen, die nach der Schaffung der Staatspartei durch Franco (19. 4. 1937) erschienen, ist jedoch der 27. Punkt des Programms nicht mehr enthalten. Für diesen Punkt wurde auf eine Fassung des Programms aus dem Jahre 1934 zurückgegriffen, die als hektografiertes Schreiben an die Provinz- und Lokal-Gruppen versandt worden war. Abgesehen von dem durch Franco gestrichenen 27. Punkt ist der Wortlaut des FE-Programms nicht verändert worden, jedoch hat er für die Staatspartei unter Franco keinerlei bindende Vexpflichtung mehr. Das Programm, für die alte Falange ein Dogma, erscheint fortan unter dem wesentlich einschränkenden Titel: „Normas Programmáticas“. Vgl. dazu: „Revolución Nacional“, Puntos de Falange. Textos de José Antonio, seleccionados y ordenados por Agustín del Rio. Madrid 1959. Nellessen, a. a. O., S. 154. 
Erfüllung Spaniens das Imperium ist. Wir fordern für Spanien einen hervorragenden Platz in Europa. Wir dulden keine internationale Isolierung. Ausländische Einmischungen sind uns unerträglich.

Hinsichtlich der Beziehungen zu den hispanoamerikanischen Ländern erstreben wir eine einheitliche Ausrichtung der Kultur, der wirtschaftlichen und machtpolitischen Interessen. Spanien ist die geistige Achse der hispanischen Welt; dies begründet unseren Anspruch auf Teilnahme am internationalen Geschehen an hervorragender Stelle.

4

Unsere Streitkräfte - zu Lande, zu Wasser und in der Luft - sollen die Wirksamkeit und den Umfang haben, die zur dauernden Sicherung der vollen Unabhängigkeit und der Spanien zukommenden Stellung in der Welt notwendig sind. Wir werden den Streitkräften zu Lande, zu Wasser und in der Luft die öffentliche Würde wiedergeben, die ihnen gebührt. Wir werden dafür sorgen, daß nach ihrem Bilde ein soldatischer Geist das gesamte spanische Leben beseelt.

5

Spanien wird, wie einst, Ruhm und Wohlstand wieder auf dem Meere suchen. Spanien soll eine große Seemacht werden, um Gefahren abzuwenden und den Handel schützen zu können.

Ebenso fordern wir für das Vaterland eine starke Luftflotte und den Ausbau des Luftverkehrsnetzes.

Staat - Individuum - Freiheit

Unser Staat soll ein allesumfassendes Werkzeug im Dienste der Unversehrtheit des Vaterlandes sein. Am Staat sollen alle Spanier durch Familie, Gemeinde und Berufsstand teilhaben. Niemand kann über politische Parteien am Staate teilhaben. Rücksichtslos wird das System der politischen Parteien mit allen seinen Folgen wie dem unnatürlichen Wahlrecht, der Vertretung durch sich bekämpfende Gruppen und der bekannten Form des Parlaments abgeschafft.

7

Würde, Unverletzlichkeit und Freiheit des Menschen sind ewig und unantastbare Werte.

Wahrhaft frei ist jedoch nur, wer zu einer starken und freien Nation gehört.

Niemandem wird erlaubt sein, seine eigene Freiheit zum Schaden der Einheit, der Stärke und der Freiheit des Vaterlandes zu gebrauchen. Eine strenge Disziplin wird jeden Versuch der Vergiftung, Entzweiung oder der Aufhetzung der Spanier zu einem Handeln gegen die Berufung des Vaterlandes verhindern.

8

Der Nationalsyndikalistische Staat wird jede private Initiative zulassen, die mit den Interessen der Gesamtheit vereinbar ist. Er wird sie sogar fördern und anregen, wenn es von Nutzen ist. 
Wirtschaftlich verstehen wir Spanien als einen gewaltigen Berufsstand von Erzeugern. Wir werden die spanische Gesellschaft korporativ in einem System vertikaler Syndikate nach Produktionszweigen ordnen. Es hat der volkswirtschaftlichen Gesamtheit zu dienen.

Wir verwerfen das kapitalistische System. Es verkennt die Nöte des Volkes, es entmenschlicht das Privateigentum, es drängt die Arbeiter in unförmige Massen zusammen, die für Elend und Verzweiflung anfällig sind. Unsere geistige Einstellung und unser nationales Bewußtsein verwerfen auch den Marxismus. Wir werden den Schwung der arbeitenden Klassen, die heute durch den Marxismus irregeführt sind, in rechte Bahnen lenken, indem wir auf ihre unmittelbare Teilnahme am großen Werk des nationalen Staates dringen.

11

Der nationalsyndikalistische Staat wird sich nicht grausam dem wirtschaftlichen Kampf der Menschen versagen. Er wird auch nicht müßig der Unterdrückung der schwächeren durch die stärkere Klasse zusehen. Unsere Ordnung wird den Klassenkampf radikal beenden, da alle, die im Produktionsprozeß stehen, in ihr eine organische Einheit bilden.

Wir verwerfen und verhindern in Zukunft mit allen Mitteln den Mißbrauch von Sonderinteressen zum Schaden anderer und die Anarchie in der Arbeitsordnung.

Reichtum ist in erster Linie dazu bestimmt - und diesen Grundsatz wird unser Staat verwirklichen -, die Lebensbedingungen aller Glieder eines Volkes zu bessern. Es ist untragbar, daß ungeheure Massen im Elend leben, während eine kleine Schicht allen erdenklichen Luxus hat.

13

Der Staat wird das Privateigentum als rechtmäßiges Mittel zur Erfüllung der Zwecke des einzelnen, der Familie und der Gemeinschaft anerkennen. Er wird es vor Übergriffen des Großkapitalismus, der Spekulation und der Geldverleiher schützen.

14

Wir sind dafür, das Bankwesen und, mittels der Korporationen, die für die Gemeinschaft wichtigen Betriebe zu verstaatlichen.

15

Alle Spanier haben ein Recht auf Arbeit. Die öffentlichen Körperschaften sind verpflichtet, alle zu unterstützen, die ohne Verschulden arbeitslos sind.

Bis zur Vollendung der neuen Gesamtordnung halten wir alle Vorteile aufrecht und bauen sie weiter aus, die die geltenden Gesetze dem Arbeiter bieten. 
Alle arbeitsfähigen Spanier sind zur Arbeit verpflichtet. Der nationalsyndikalistische Staat wird keine Rücksichtnahme denjenigen gegenüber kennen, die keiner Tätigkeit nachgehen und auf Kosten der anderen leben wollen.

\section{Grund und Boden}

17

Unter allen Umständen sind die Lebensbedingungen auf dem Lande zu verbessern. Das Land ist die bleibende Lebensgrundlage Spaniens. Wir werden daher rücksichtslos die wirtschaftliche und soziale Reform in der Landwirtschaft durchführen.

Wir werden die landwirtschaftliche Erzeugung (Wirtschaftsreform) mit folgenden Mitteln steigern:

Für alle landwirtschaftlichen Erzeugnisse wird ein lohnender Mindestpreis sichergestellt.

Wir verlangen, daß ein großer Teil des Vermögens, das heute die Stadt für kulturelle und wirtschaftliche Zwecke verschlingt, dem Land wieder zugeführt wird, damit es über ausreichende Mittel verfügt.

Wir werden ein wahrhaft nationales, landwirtschaftliches Kreditsystem schaffen, das dem Bauern zu niedrigem Zinssatz Geld leiht, ihm dabei sein Vermögen und seine Ernten garantiert und ihn vor Wucher und Ausbeutung schützt.

Die fachliche Schulung in Ackerbau und Viehzucht soll gefördert werden. Die Ausnutzung des Bodens soll seinen natürlichen Bedingungen und den Absatzmöglichkeiten der Erzeugnisse angepaßt werden.

Die Zollpolitik soll so gehandhabt werden, daß sie Ackerbau und Viehzucht schützt.

Wasserbauten sollen beschleunigt durchgeführt werden.

Die landwirtschaftlichen Betriebe sind zu rationalisieren. Dadurch sollen sowohl die verschwenderischen und vernachlässigten Latifundien als auch die wegen ihres geringen Ertrages unwirtschaftlichen Zwergbetriebe beseitigt werden.

\section{9}

In sozialer Hinsicht werden wir die Landwirtschaft durch folgende Mittel ordnen:

Wir werden kultivierbares Land neu verteilen, um Familienbesitz zu schaffen und den berufsständischen Zusammenschlu $\beta$ der Bauern energisch zu fördern.

Die Volksmassen, die heute ihre Arbeitskraft in der mühseligen Bebauung unfruchtbaren Bodens erschöpfen, sollen aus ihrer elenden Lage befreit und auf neues, kultivierbares Land umgesiedelt werden.

Wir werden einen unermüdlichen Feldzug für die Aufstockung des Viehbestandes und die Aufforstung führen. Wir werden diejenigen mit schweren Strafen belegen, die dies zu stören versuchen. Wir werden sogar zeitweilig die gesamte spanische 
Jugend zwangsweise für diese historische Aufgabe der Wiederherstellung des Reichtums des Vaterlandes heranziehen.

Der Staat kann ohne Entschädigung unrechtmäßig erworbenen oder genutzten Boden enteignen.

22

Die Wiederherstellung des Gemeindebesitzes wird ein besonders wichtiges Vorhaben des nationalsyndikalistischen Staates sein.

\section{Nationale Erziehung - Religion}

Es ist eine wesentliche Aufgabe des Staates, durch eine straffe Disziplin in der Erziehung ein starkes und einheitliches Nationalbewußtsein zu schaffen und in die Herzen der kommenden Generationen die Freude und den Stolz auf das Vaterland zu pflanzen.

Die männliche Jugend wird eine vormilitärische Erziehung erhalten, die sie auf den ehrenvollen Dienst im Volksheer Spaniens vorbereitet.

\section{4}

Das Bildungswesen wird so gestaltet, daß kein Talent wegen fehlender wirtschaftlicher Mittel scheitert. Alle, die es verdienen, sollen leichten Zugang selbst zum Hochschulstudium haben.

Unsere Bewegung legt das katholische Bewußtsein - das in Spanien eine glorreiche Tradition hat und vorherrschend ist - der nationalen Erneuerung zugrunde.

Kirche und Staat werden ihre Rechte durch ein Konkordat regeln. Eine Einmischung wird ebensowenig geduldet wie irgendeine Tätigkeit, welche die Würde des Staates mindern oder die nationale Einheit schädigen könnte.

\section{Nationale Revolution}

26

Die Falange Española de las J.O.N.S. erstrebt eine neue Ordnung nach diesen Prinzipien. Um sie durchzusetzen im Kampf gegen die bestehende Ordnung, trachtet sie nach der nationalen Revolution.

Als ihren Stil wird sie ein unmittelbares, leidenschaftliches und kämpferisches Handeln vorziehen. Das Leben ist Soldatentum; es muß vollzogen werden in untadeliger Dienstauffassung und glühendem Opfersinn.

Es ist unser heißes Bemühen, den Kampf nur mit den unserer Disziplin unterworfenen Kräften siegreich zu bestehen. Wir werden sehr wenig paktieren; nur in der Schlußphase zur Eroberung des Staates wird die Führung für eine notwendige Zusammenarbeit eintreten. Dabei muß jedoch stets unser Führungsanspruch gesichert sein. 